Portland State University

PDXScholar

Summer 1-1-2012

\title{
Differential Susceptibility to Social Network Influences on School Motivation in a Cohort of Sixth Graders
}

Justin William Vollet

Portland State University

Follow this and additional works at: https://pdxscholar.library.pdx.edu/open_access_etds

Part of the Curriculum and Social Inquiry Commons, Educational Psychology Commons, and the Social and Philosophical Foundations of Education Commons Let us know how access to this document benefits you.

\section{Recommended Citation}

Vollet, Justin William, "Differential Susceptibility to Social Network Influences on School Motivation in a Cohort of Sixth Graders" (2012). Dissertations and Theses. Paper 79.

https://doi.org/10.15760/etd.79

This Thesis is brought to you for free and open access. It has been accepted for inclusion in Dissertations and Theses by an authorized administrator of PDXScholar. Please contact us if we can make this document more accessible: pdxscholar@pdx.edu. 
Differential Susceptibility to Social Network Influences on School Motivation in a Cohort of Sixth Graders

by

Justin William Vollet

A thesis submitted in partial fulfillment of the requirements for the degree of

\author{
Master of Science \\ in \\ Psychology
}

Thesis Committee:

Thomas A. Kindermann, Chair

Ellen A. Skinner

Robert W. Roeser

Portland State University

(C)2012 


\begin{abstract}
Students' classroom engagement is a strong predictor of positive educational outcomes including academic achievement, GPA, and standardized test scores. Most existing research has focused on the role of quality parenting and teaching in the development of student engagement. However, some research has shown small, yet significant effects of influences from students' peer groups on the development of their engagement. The goal of this study was to explore whether some children are more susceptible to the effects of their peer groups, and to examine a series of possible factors that might amplify the influence of a target students peer group on the development of that students' own engagement over the course of an academic year. In a re-analysis of an existing data set (Kindermann, 2007), peer group profiles of student engagement were examined as predictors of changes in individual engagement from fall to spring. It was expected that peer groups' levels of engagement would vary in their predictive power for changes in students' own engagement over the school year, depending upon individual levels of peer relatedness, the number of peers with whom the student affiliates with, student perceptions of parental involvement, as well as person-to-group differences in engagement. Gender differences were expected to be non-significant. As expected, results from two sets of analysis indicate no significant gender differences in susceptibility to peer influence. Furthermore, results suggest that susceptibility to peer influence on school engagement may depend upon the number of peers with whom a student affiliates with, parental involvement, as well as person-to-group differences in engagement. However, contrary to expectations, results suggest that a student's
\end{abstract}


susceptibility to peer influence may not depend upon self-reported peer relatedness.

Details of the analyses, results, strengths, limitations, and implications for future research are discussed. 


\section{Acknowledgments}

I would like to formally thank the many special individuals who, over the past few years, provided me with professional and personal resources that made it possible for me to complete this project and make it to this point in my professional journey.

First, I would like to thank the members of my committee, Dr. Thomas Kindermann, Dr. Ellen Skinner, and Dr. Robert Roeser. I appreciate the time and energy that all of you sacrificed to help me learn and develop as a researcher. Words cannot accurately capture how grateful I am for your guidance, or how honored I am to have developed under your wings.

Second, I would like to thank my peers who helped me throughout the long process of creating this document. In particular, I would like to thank the members of my peer research group, Shawn Mehess, Price Johnson, Hyuny Clark--Shim, and Rita Yelverton for the hours of stimulating conversation that have been a crucial source of inspiration for me. I would have made no progress without all of you. I would also like to thank Jen Pitzer, for helping me throughout the process of preparing this document, both practically and emotionally. Your help and encouragement will be forever appreciated.

Finally, I would like to thank my beautiful wife Carly, for being there for me during the highs and lows of this project. You have been and always will be an inspiration to me, and I truly believe that I have become who I am because of you. I hope you know how much you mean to me. Thank you all. 


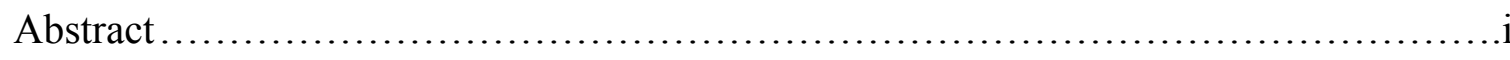

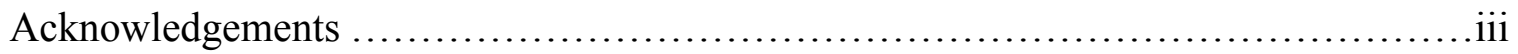

List of Tables ..............................................................................

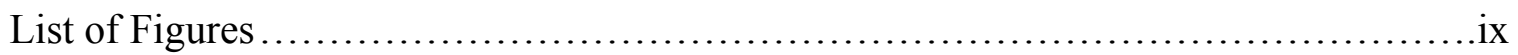

Chapter 1: Problem Statement ...................................................

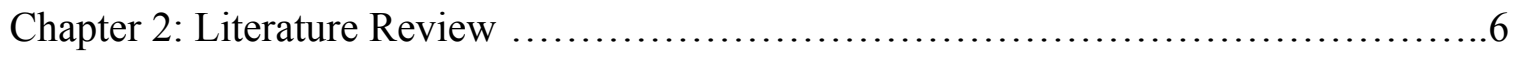



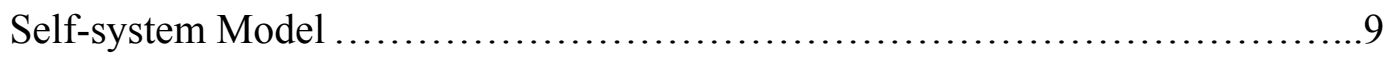

Peer Influences on Children's Developing School Motivation ...................11

The Study of Network Influence......................................12

Types of Social Ties Represented in SNA Research .............13

Theory Guiding Influence Research ..........................14

Network Influences on Academic behavior ..........................15

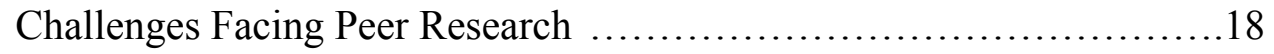

Social Crowds .................................................19

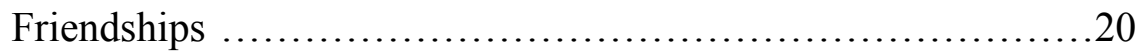

Peer Groups...............................................22

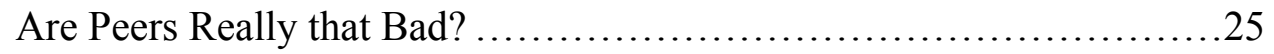

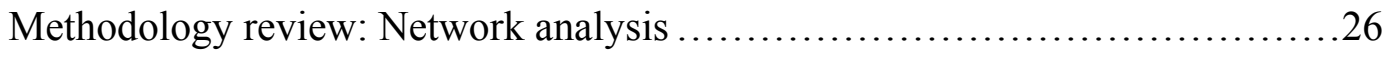

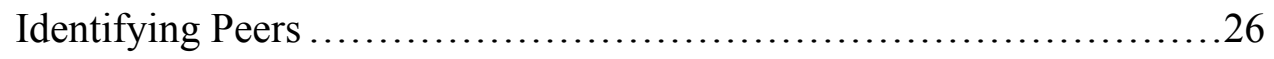

Self-reports \& Identifying Networks .........................26 
Table of Contents: Differential Susceptibility $\quad \mathrm{v}$

SCM \& Identifying Networks or Individuals ..................28

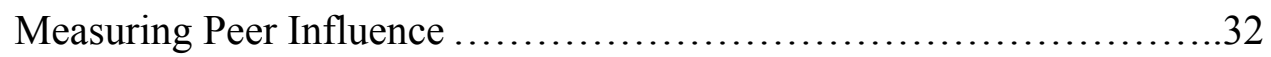

Capturing Network Characteristics.................................32

Capturing Peer Influence While Controlling for Peer Selection............33

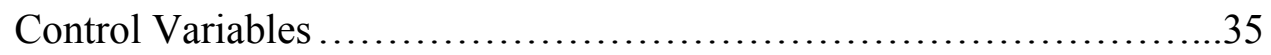

Differential Susceptibility to Peer Influence .................................36

Gender Differences ................................................. 37

Person-to-Group Differences ........................................ 37

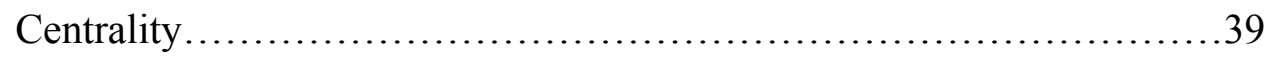

Peer Relatedness ................................................... 42

Parental Involvement ...............................................43

Chapter 3: Purpose of the Study and Research Questions .............................45

Chapter 4: Methods .............................................................. 49

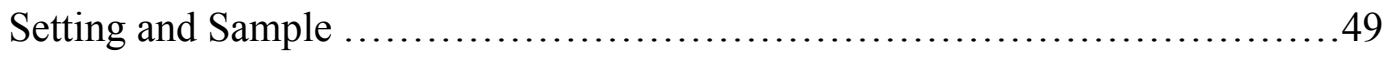



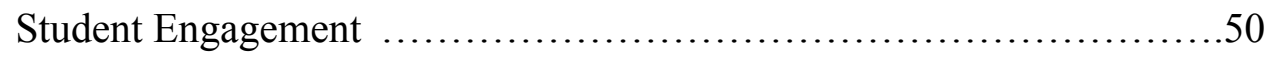

Naturally Occurring Peer Groups ...................................51

Peer Engagement Profiles .........................................52

Person to Group Differences ........................................52

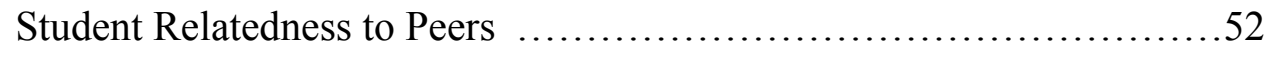

Student's Network Centrality ......................................52

Student's Perception of Parent Involvement ...........................53 


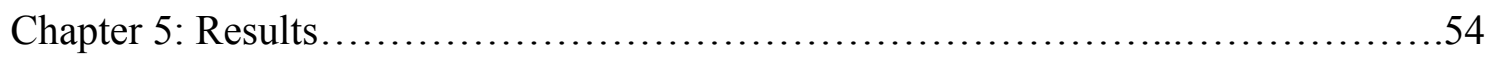



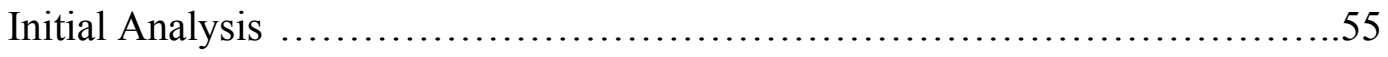

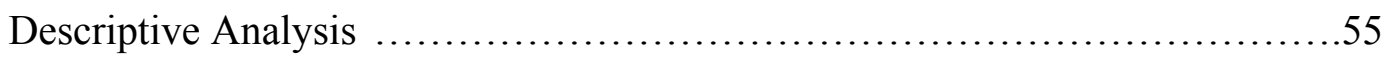

Methods Used to Explore the Research Questions ............................58

Research Question 1: Are boys more susceptible to peer influence than girls? ...63

Research Question 2: Are students who are highly related to their peers more susceptible to peer influence than students who a less related to their peers? .....67

Research Question 3: Are students who hang out with many peer affiliates more susceptible to peer influence than students who hang out with few peer affiliates?

Research Question 4: Are students whose parents are highly involved in their academic lives less susceptible to peer influence than students whose parents are uninvolved?

Research Question 5: Are students whose engagement in school is different than their peers more susceptible to peer influence than students whose school engagement is similar to their peers' engagement? ..........................82

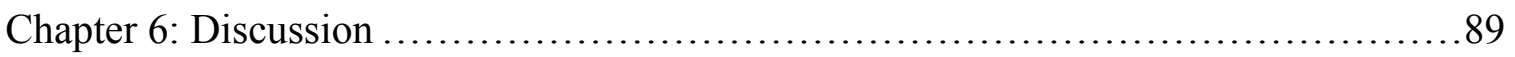

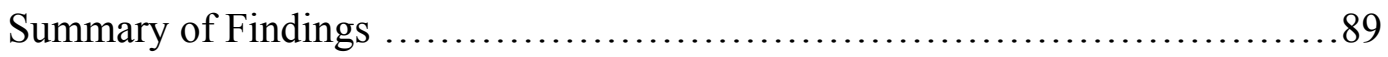

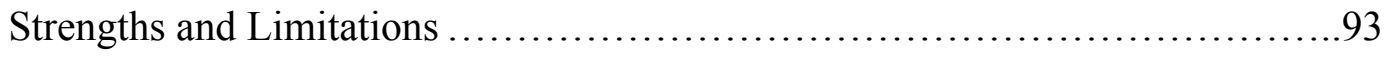

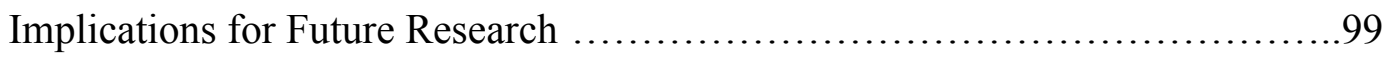

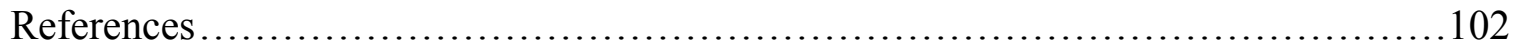


Table of Contents: Differential Susceptibility vii

Appendix A. Teacher-reported School Engagement Items ...........................116

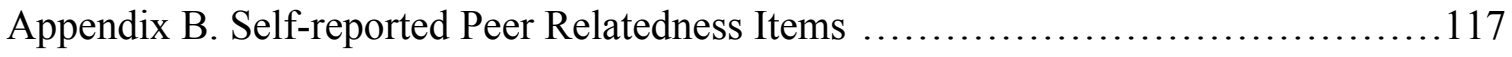

Appendix C. Parental Involvement Items ...................................... 118 


\section{List of Tables}

Table 2.1: Subset of a Cooccurance matrix of girls in $6^{\text {th }}$ grade.........................30

Table 5.1: Summary of Descriptive Statistics.....................................56

Table 5.2: Summary of Intercorrelations Among Variables of Interest .................56

Table 5.3: Moderated Path Analysis: Group Engagement X Sex........................66

Table 5.4: Moderated Path Analysis: Group Engagement Spring X Peer Relatedness ...71

Table 5.5: Moderated Path Analysis: Group Engagement Spring X Degree...............76

Table 5.6: Moderated Path Analysis: Group Engagement Spring X Parental

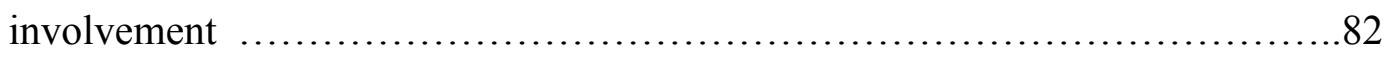

Table 5.7: Moderated Path Analysis: Group Engagement Spring X Person-to-Group

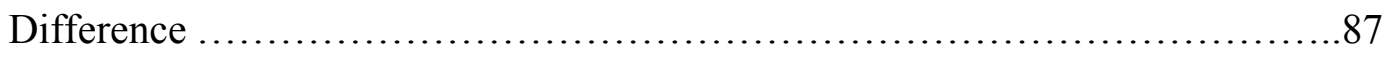


Figure 3.1. Theory of differential susceptibility to peer influence .....................45



Figure 5.2. Moderated SEM Model …...........................................62

Figure 5.3. Multigroup SEM configural model. Gender differences in peer influence.



Figure 5.4. Multigroup SEM measurement model. Gender differences in peer influence.

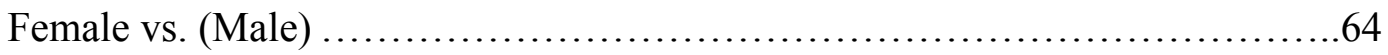

Figure 5.5. Multigroup SEM path invariance model. Gender differences in peer influence. Female vs. (Male) …..........................................65

Figure 5.6. Moderated path model: Peer group engagement X sex ....................66

Figure 5.7. Multigroup SEM configural model. Group differences in peer influence.

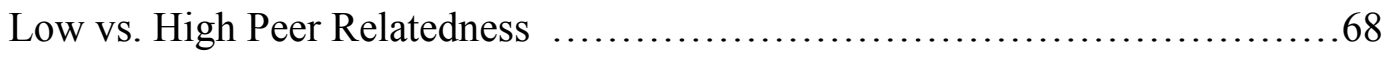

Figure 5.8. Multigroup SEM measurement model. Group differences in peer influence.

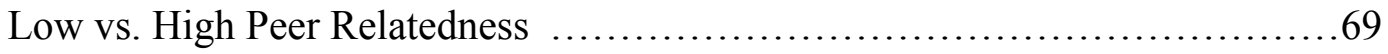

Figure 5.9. Multigroup SEM path invariance model. Group differences in peer influence. Low vs. High Peer Relatedness ................................. 70

Figure 5.10. Moderated path model: Peer group engagement X peer relatedness ........71

Figure 5.11. Multigroup SEM configural model. Group differences in peer influence.



Figure 5.12. Multigroup SEM measurement model. Group differences in peer influence. 
Figure 5.13. Multigroup SEM path invariance model. Group differences in peer

influence. Low vs. high centrality ........................................ 75

Figure 5.14. Moderated path model: Peer group engagement X degree centrality........76

Figure 5.15. Group engagement $X$ degree interaction plot............................77

Figure 5.16. Multigroup SEM configural model. Group differences in peer influence.



Figure 5.17. Multigroup SEM measurement model. Group differences in peer influence.

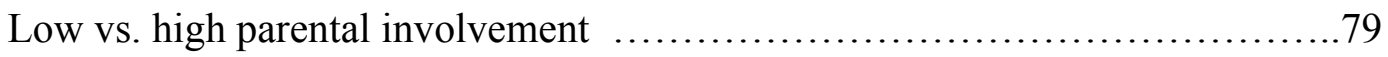

Figure 5.18. Multigroup SEM path invariance model. Group differences in peer influence. Low vs. high parental involvement ............................... 80

Figure 5.19. Moderated path model: Peer group engagement X parental involvement ...81

Figure 5.20. Group engagement $X$ parental involvement interaction plot ..............82

Figure 5.21. Multigroup SEM Configural Model. Group differences in peer influence.

Low vs. High Person-to-group difference in engagement.....................83

Figure 5.22. Multigroup SEM Measurement Model. Group differences in peer

influence. Low vs. High Person-to-group difference in engagement .............88

Figure 5.23. Multigroup SEM Path Invariance Model. Group differences in peer influence. Low vs. High Person-to-group difference in engagement ..............85

Figure 5.24. Moderated Path Model: Peer Group Engagement X Person-to-group

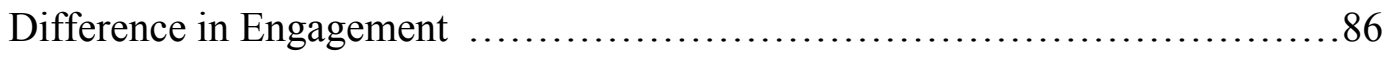

Figure 5.25. Group engagement $X$ person-to-group difference interaction plot ..........88 
Table of Contents: Differential Susceptibility xi

Figure 6.1: Theory of differential susceptibility to peer influence on student engagement

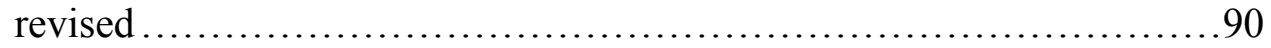




\section{Chapter 1: Problem Statement}

Education is a crucial component of an individual's development. The experiences children have in academic contexts influence how they approach academic challenges later in their student careers and can have far reaching effects on the quality of their lives. Unfortunately, despite slight improvement over the past three decades, dropout and educational attainment rates in the U.S. remain at alarming levels (Aud, Hussar, Planty, Snyder, Bianco, Fox, Frohlich, Kemp, \& Drake, 2010): In 2009, only an estimated 89 percent of 25 - to 29 -year-olds had obtained a high school diploma or it's equivalent, and the completion rate for Blacks and Hispanics remained significantly lower, $89 \%$ and $69 \%$ respectively, compared to the completion rate of Whites, $95 \%$. The percentage of individuals 25- to 29-years-old who had completed a 4-year college degree was only 29 percent. Of the high school graduates who went on to higher education approximately $56 \%$ complete a four-year degree within 6 years. With the current economic climate, it is becoming increasingly important that we adequately prepare our young students for their future and that we help them to develop a variety of skills, both academic and social, that they will need to succeed and become productive members of tomorrow's workforce. It is vitally important that children establish an early pattern of achievement in school and maintain this pattern over time.

Unfortunately, in today's schools many students are falling behind and are failing to meet national achievement standards. According to the most recent Condition of Education report, which is conducted by the National Center for Education Statistics, only about a third of eighth grade students tested at or above a proficient level in math 
and reading in 2009. Futhermore, more than a quarter of eighth grade students demonstrated below basic understanding in both math and reading that same year $(27 \%$ and 25\%, respectively; Aud, et al., 2010). While surprisingly these statistics indicate a slight improvement in academic achievement over the past decade, they also imply that still more needs to be done to ensure that all students meet achievement standards, and more importantly that they are learning skills that will help them become healthy productive adults.

Children's active participation in the classroom is a necessary precondition of their learning and achievement in the classroom. Children who are not actively engaged with classroom material have no chance of learning or applying the material being taught. Findings from existing research support this intuitive assumption, suggesting that academic engagement is a robust predictor of students' long-term academic achievement (Skinner et al., 1998) and later school completion (Connell, Spencer, \& Aber, 1994).

With accumulating findings supporting the notion that engagement is a requirement for school success, researchers have explored many factors that are believed to foster children's engagement in the classroom, including qualities of the school and classroom (Teven \& McCroskey, 1997; Qin, Johnson, \& Johnson, 1995; Anderman \& Maehr, 1994).

Others have examined the role children's social relationships play in the development of their motivation in the classroom. Cumulative findings from extant research suggest three major sources of social influence of the development of young people's school motivation: parents, teachers, and peers (Skinner \& Pitzer, in press). 
Most of the existing work in this area has concentrated on the influence parents and teachers have on young students' academic engagement. Studies have provided consistent evidence that students who have supportively involved parents and teachers are more likely to be actively engaged in classroom activities than students whose parents and teachers are coercively involved or uninvolved (Skinner, Kindermann, Connell, \& Wellborn, 2009).

In contrast, relatively little research has explored how the day-to-day exposure to and interactions with peers affects the development of a young person's academic engagement. Although many people would agree, at least on an intuitive level, that peers are an important factor which influences the development of young people's academic motivation and that the importance of these relationships likely increases as development unfolds, little research has attempted to quantitatively explore this influence process. However, the relative neglect of research in this area is not for lack of interest. For methodological reasons that will be discussed in sections that follow, peers are particularly difficult contexts to study.

Despite these difficulties, peer researchers have published findings with wide range of conclusions made about the contribution peers make to development. Some have argued that peers are one among many important environmental sources of influence for the development of young peoples school engagement and motivation (Kindermann, 2007). Others have made claims that the peers contribute the most, influentially, to the psychological development of children and adolescents (more so than parents; Harris, 1998). While this may be an overstatement, research does suggest that peers become 
increasingly important for young people's development as they move through development toward adulthood (Berndt, 1979). These findings represent an important advancement in the ways in which psychological researchers understand the complete set of contextual influences driving the development of academic engagement.

However, many of these findings speak only to the "average" individual. While it is a step in the right direction to establish whether or not and to what degree peers influence student engagement, it remains largely unexplored whether there are some individuals in some peer groups for whom the process of peer influence is stronger or weaker. The purpose of this project was to further explore the specifics of the nature of peer influence on academic engagement. This research project sought to test a basic assumption: that individuals differ in their susceptibility to peer group influences. This project sought to test a theory that there are four underlying principles (amount of contact with peers, diversity amoung peer contacts, closeness to peer contacts, the availability of other social contacts) that determine the extent to which an individual is susceptible to peer group influence. Specifically, the goal of this study was to examine whether differences in the extent to which middle school students are influenced by their peer groups in terms of the development of their own academic motivation are based on (a) gender, (b) differential levels of interpersonal closeness that these students experience with their peers, (c) differential levels of network embeddedness, or the extent to which they are centrally located within the social fabric at school (i.e. degree centrality), (d) the degree to which students experience their parents as being involved in their academic 
Problem Statement: Differential Susceptibility $\quad 5$

endeavors, and (e) the degree to which students' academic motivation differs from that of the peers with whom they spend the most time with. 


\section{Chapter 2: Literature Review}

\section{School Motivation and Engagement}

As has been widely reported, school motivation tends to decline significantly across the developmental timeline (Eccles, Midgley, \& Adler, 1984; Fredricks \& Eccles, 2002). By the time students reach high school, many appear to have become accustomed to doing just enough to get by, and attend class primarily because they "have to." Most students are able to "successfully" complete their journey through the primary and secondary school systems, despite their personal apathy and lack of interest in learning. For some though, a lack of engagement in school, when combined with other risk factors, often leads to sharp increases in disaffection over time and eventual school dropout. Aware of the seriousness of this issue, more and more developmental researchers have begun to examine the ameliorative effect school engagement has on student alienation.

Academic engagement, which has been broadly conceptualized as a students' active, energized, and sustained involvement in learning activities (Skinner, Kindermann, Connell, \& Wellborn, 2009), has received a large amount of attention from researchers who are concerned with understanding possible motivational antecedents of school achievement (Fredricks, Blumenfeld, \& Paris, 2004). Typically considered a metaconstruct, academic engagement has been described as consisting of two distinguishable components: behavioral and emotional engagement (Wellborn, 1991; a third component, cognitive engagement, has been described by some authors, despite the empirical overlap often observed with the behavioral component; see Fredricks, et. al, 2004). 
Behavioral engagement is conceptualized as a student's effort, attention, involvement and participation during classroom activities. For example, a student who attentively listens to a teacher's lecture, frequently raises his or her hand to add to the discussion, and is always an active member while doing group work in class is an exemplar of a behaviorally engaged student. On the other hand, a student whose attention seems to wander toward the window during lecture, frequently has off-topic conversations with other students during class, and seldom participates during group activities is a model of a behaviorally disaffected student.

Emotional engagement is often described as the affective reactions that students display in response to material and activities presented in the classroom. An emotionally engaged student appears enthusiastic about learning and is visibly excited about topics they are learning. Teachers may experience emotional engagement as their students' faces lighting up with excitement while learning about an interesting topic. On the other hand, emotionally disaffected students seem disinterested and exude a spirit of boredom while in class.

Existing research provides supportive evidence that increased engagement in the classroom is associated with subsequent increases in school achievement and decreases in the likelihood of school dropout and participation in delinquent behaviors and activities (Jimerson et al., 2003). This relationship may not be particularly surprising. It may seem intuitive that students who are interested and involved in the material and activities they experience in the classroom should do well academically. The process through which this relationship operates may be less intuitive. Skinner and Belmont (1993) suggest a process 
underlying the effect of engagement on achievement may involve a self-reinforcing process by which a student's engagement elicits favorable teacher responses (e.g., personal attention, teacher warmth, and enthusiasm). Students who receive increased personal attention and warmth from their teachers likely do better in school and maintain relatively higher levels of engagement throughout their academic career. Similarly, Roeser, Eccles, and Sameroff (2000) describe how adolescents' perceptions of opportunities (or lack thereof) provided to them by teachers and staff are related to the development of their academic functioning.

It may be possible that similar reciprocal processes occur between students and their peers. For example, students who are visibly engaged and energized in the classroom may elicit positive relational responses from other students who are similarly engaged. Over time, through increasingly frequent student-student interactions, an academically engaged student may become increasingly engaged and successful due to increases in his or her sense of school belongingness and school identification. Furthermore, relationships with highly engaged peers may afford a student more avenues through which he or she may receive instrumental help (e.g., study groups with academically engaged friends).

Findings from programs of research focusing on academic engagement as a lever for changing student achievement may be particularly important for interventions. Unlike many other predictors of achievement commonly explored in psychological and educational research (personality, cognitive ability, race, gender and socio-economic status), engagement is a malleable factor (Fredricks et al., 2004). The ultimate goal of 
these programs of research is to identify manipulable factors that promote engagement such that through careful manipulation of these factors student achievement may be positively affected, via the student's engagement.

\section{Self-system Model and Academic Engagement}

Humans are born with an innate interest and curiosity about the world around them. Healthy children, from birth, eagerly explore their new environments. They soak up information about the nature of things, not because they have to, but because they want to. Although we all are born intrinsically motivated by this natural curiosity, in order for this motivation to be sustained over the course of development it has been proposed that a set of intrinsic needs must be met. Deci and Ryan's self determination theory (SDT; 1985) is a theory of motivation that postulates that an individual's innate motivational force is either supported or undermined depending on the extent to which a set of psychological needs are supported by the individual's social context. Underlying this theory is the assumption that humans are naturally oriented toward positive growth, but that healthy development is dependent upon the quality of the environmental inputs. Just like a flower needs water, sunlight, and nutrient soil, SDT argues that a developing person has needs for autonomy, relatedness, and competence. When these motivational needs are met by an individual's environment, the individual shows positive growth. When some or all of these needs are undernourished, motivation is impeded.

Autonomy refers to the extent to which an individual feels like an agent of his or her own decisions, actions or behaviors. An individual who feels highly autonomous feels free to engage in tasks and pursue goals which he or she is intrinsically interested in, 
rather than feeling forced to perform a task that he or she is naturally uninterested in. Individuals are more likely to feel autonomous when interactions with their parents, teachers, and peers are perceived as being supportive of their agency. Consider a scenario in which a parent is trying to improve their struggling child's study skills. A coercive parent, in effort to motivate an increase in time spent studying, might resort to the "because I'm the parent, and I say so" argument. According to SDT, this type of parentchild interaction undermines motivation because it is not supportive of the child's need to feel authorship of his or her reason to act. Alternatively, an autonomy-supportive parent might explain why doing well in school is generally important, help them identify their goals and interests, and explain how doing well in school will help them meet their goals and explore their interests in the future. By providing a rationale for why studying is important, the autonomy-supportive parent in this example is able to help their child cultivate their own motivation by nuturing their sense of autonomy.

Competence refers to a person's belief that through his or her intentional actions, he or she should be able to produce the desired effects. An individual who feels competent feels as though he or she possesses the requisite knowledge or skills needed to produce change in or control the environment. Individuals are more likely to feel compitent when developmentally appropriate goals and challenges are presented to children in structured and supportive environments that allow for the satisfaction derived from successfully meeting goals and overcoming challenges. For example, a child's need to feel competent may be supported by teachers through the careful selection of developmentally appropriate yet challenging classroom tasks. 
Relatedness refers to a person's belief that he or she belongs and is generally cared for and accepted by others occupying the same social setting. An individual who feels highly related to those around him or her feels a sense of connectedness, an enhanced sense of wellbeing and worthiness. Individuals are more likely to feel a sense of relatedness when there are people (e.g. peers, parents, and teachers) who are actively and warmly involved in their lives. For example, a child who has a group of peers who are consistently there to confide in and are emotionally supportive will most likely possess a strong sense of relatedness to those peers. Similarly, a child whose teacher is warm, caring and empathetic will likely possess a strong sense of relatedness with that teacher.

\section{Peer Influences on Children's Developing School Motivation}

An abundance of research has provided evidence that the quality of a young student's engagement (motivation) in the classroom is determined by the extent to which his or her school social environment (which comprises an individual's peers, teachers, and other school staff) supports the three fundamental needs outlined by SDT. A majority of extant research in this area has focused on and demonstrated positive effects of both quality of parenting and teaching on student motivation and engagement (Grolnick et al., 1994; Marsh et al., 2008), competence and goals (Roeser, Midgley, \& Urdan, 1996) and on children's academic achievement (Englund et al., 2004; Roeser et al., 2000).

Relatively fewer studies have focused on how peers contribute to the development of school motivation. The following sections review research that explores the impact peers have on children's developing academic engagement. The first section focuses 
broadly on the types of social ties represented using network analysis methods, as well as the theories and concepts that guide the social network research on influence processes. The second section focuses more on research that has specifically explored the extent to which networks of peers, or peer groups, influence the development of a child's motivation in school.

\section{The Study of Network Influences}

Modern social network analysis (SNA) methods were developed largely out of the pioneering ideas of Jacob Moreno. Although his educational background was in medicine and psychiatry, he became fascinated by social structures while developing an actingbased form of psychotherapy. As he put it:

Sociometric measurement started with things like this: how much "time" does an actor A spend with another actor B? He may spend half as much time with another actor $C$ and three times as much time with another actor D. Or, what is the "spatial distance," near or far, in inches, feet or meters, between actors $A, B, C$ and $D$ in the course of the same situation and what effect have nearness or distance upon behavior and acting? Or, how frequently do two actors appear simultaneously in a scene and how frequently do they exit together? (Moreno, 1953)

With the statistical help of Helen Jennings, Moreno would later use his Sociometry to show that the network of social ties that connected a cohort of young girls could be used to explain an outbreak of runaways among girls at a boarding school. Since then a variety of methods for objectively capturing the structure of social networks have been 
developed and reported on in the literature.

Although there now is an accumulating body of psychological research which has examined the influence groups can have on the way individuals think feel and behave, only relatively recently have researchers interested in psychological phenomena begun to utilize network analysis methodologies. The use of these methods has seen exponential growth and has recently been utilized by researchers focusing on issues related to social and developmental psychology, psychiatry, and medicine. SNA methodologies have been used to study the influence social contexts have on the development of a myriad of psychological phenomena including prosocial and antisocial behavior (Gest, GrahamBermann, \& Hartup, 2001; Farmer \& Rodkin, 1996), participation in risky behaviors including tobacco use (Christakis \& Fowler, 2008), and the social transmission of happiness (Fowler \& Christakis, 2008) and depression (Rosenquist, Fowler, \& Christakis, 2010).

Types of social ties represented in SNA

Many different types of social ties may be represented in a social network graph. Borgatti (2009) provides a typology of four different ties commonly examined by researchers who use social network analysis methodologies. The four different types of ties include similarities, social relationships, interactions, and flows. Similarities occur when individuals occupy the same spatial or social space, belong to similar organizations (e.g., church, school), or are homogenous in a socially salient attribute (e.g., race). Social relationships may include kinships — such as being the child or sibling of another individual, or other relationships - such as being the friend or student of another 
individual. Social relationships may be characterized as having emotional and/or cognitive qualities. For example an individual may be asked to indicate whom he or she like or hates (emotional) or be asked to indicate whom he or she knows (cognitive). Interactions are discrete, observable events that may occur between two or more individuals either once or repeatedly over the course of a period of time-for example an individual may "help" or "hang out with" another individual. Flows describe the way things, either tangible or intangible, move through a network. For example SNA may be used to model the way a rumor spreads through a school network.

There is likely a relationship between these four types of ties. For example, if two middle school students share similar space, attributes, or crowd membership there may be an increased probability that a social relationship may occur between them (Urberg, Değirmencioğlu, Tolson, \& Halliday-Scher, 2000). Through a social relationship, social interactions should occur; through these interactions, information or resources should flow from one individual to the other. This likely relationship may have important implications. Researchers who capture and study social crowds also likely capture and study peer groups and friends.

\section{Theory guiding influence research}

At the heart of much of the work being done in network influence research is the idea that frequent interaction with proximal others is a necessary requirement for influence. The first proposition of Bronfenbrenner's (1998) bioecological model suggests that human development occurs primarily through ongoing interactions with the people, objects, and symbols that make up an individual's environment. For the most significant 
effect, the interactions, or proximal processes, must occur on a fairly regular basis. For example, a middle school student's motivational development would be assumed to be affected most dramatically by the teachers, family members, and peers with whom he or she spends the most time and interacts with socially. Similarly, Marsden's concept of social proximity (1993) suggests that two individuals must be socially "near" each other, in some way, in order for one to influence the other's thoughts, attitudes, behaviors, or social and personal preferences. He describes the concept of structural cohesion, in which two individuals are considered more or less proximate depending on the number, length and strength of social ties connecting them. Under the most restrictive form, two individuals would be considered socially proximate if and only if they were directly tied in a network (e.g., mutual friendship, hang out together frequently, etc.).

\section{Network Influences on Academic Behavior}

Although a wealth of research has examined the effect of parenting and teaching on student motivation, research examining the influence peers often have on student motivation is relatively scarce. However, the lack of research on peers' effects on developing school engagement is not because peers are considered to be unimportant contexts for developing youth. On the contrary, peers are very influential on a child's development in multiple domains for a variety of reasons (Harris, 1995; Piaget, 1959; Vygotsky, 1962).

One reason the peer context is an important area of study is that unlike teachers, or parents, children are relatively free to choose their peers. In most cases parents are biologically assigned and are a social context to which individuals remain relationally 
tied for most of the duration of their lives. Similarly, in most cases children are not afforded the opportunity to select their teachers. In most cases children are assigned, randomly or non-randomly (e.g., tracking), to the schools they will attend and the instructors they will be taught by. On the other hand, peer groups and friends are often selected (within geographical or institutional constraints) by children based upon similarities that exist between themselves and others on demographic factors such as age, sex, or race as well as according to common interests and behaviors (Hartup, 1983). This process has been referred to as "assortative pairing" or "assortiveness" (Kandel, 1978; Kindermann, 2007). Because of this unique property of peers as social context - that the agents of influence are not imposed upon but rather selected by the targets of influenceit is vitally important that research explore more deeply the intricacies of peer influence. Another unique feature of peers is that unlike other social contexts, particularly parents and teachers, children's peer context changes rapidly in three ways. First, children's peers change and develop at roughly the same rate they do (Kindermann, 1995). Second, the specific peers with whom an individual spends time changes over relatively short periods of time, as old group members leave and new group members are acquired. Finally, the nature and composition of the groups change as well. As individuals develop, their peer groups evolve and usually become more complex. Dunphy (1963) suggests five stages of peer group development. In childhood, during the first stage, individuals interact mainly in same-sex groups. At stage two, cross-sex interaction begins to occur but mainly at the group level, interactions at an individual level between boys and girls are rare. At stage 3, high-status boys and high-status girls initiate 
heterosexual interactions that lead to the formation of social crowds that subsume male, female groups. At stage 4, the intersecting same-sex and cross-sex groups re-form to comprise separate mixed-sex groups that associate in a crowd. In the last stage, the social crowds dissolve into loosely associated groups of couples. Empirical research seems to support this theory showing that individuals go from being "socially blind" to their peers at birth (Buhler, 1930; Vincze, 1971) to preferring dyadic interaction as preschool-aged children (Bronson, 1975), to belonging to larger groups during early and late adolescence (Brown, 1993). In sum, the nature and quality of the peer groups with whom individuals spend their time change in multiple ways.

Finally, peers become increasingly important socially as children develop and seek to gain independence from their parents as they proceed into and through adolescence. In one study, researchers found that only ten percent of the social interactions of toddlers occurred with other toddlers. However, by the time these children reached the age of 11 the percentage of their peer interactions increased to approximately fifty percent (Barker \& Wright, 1955). Interestingly, the increases in the frequency of peer-child interactions during the period of development that occurs from childhood to adolescence are accompanied by a decrease in the frequency of parent-child interactions (Hartup, 1983). This dynamic shift in orientation toward peers should not be interpreted as meaning that parents become less influential with development; rather, it should reinforce the idea that peers become progressively more important and highlight the importance of studying their effect on children's development. 


\section{Challenges Facing Peer Research}

While it is generally agreed that the peer group is an important factor to consider while examining the development of academic engagement, exploring the influence peer groups have in a natural context presents more challenges than research focusing on the effects of parents or teachers. For research that focuses on parental and teacher influences on children's development identification of the parent or teacher is relatively easy. However, peer researchers are faced with the additional step of accurately identifying the social context exerting influence. Accurate identification of peer groups is challenging for several reasons. First, peer groups have no concrete delineating features so it is often hard to identify the boundaries and structure of a group. Second, children frequently belong to many, sometimes overlapping, peer groups. For example, a child may affiliate with one group of peers while at school, but a completely different group while not at school. Additionally, children often keep certain affiliations from being publically known. For example, an eight-year-old boy might have a secret friendship with a neighborhood girl, but intentionally hide the relationship by acting in an unfriendly manner when others are around in order to avoid embarrassment or ostracism. Finally, peer group members constantly move in and out of the peer group. It is very common, especially at younger ages, for peer groups and friendships to change multiple times during a school year. Because of the transient nature of child peer groups, it is exceedingly difficult to measure their influence on a child's development.

Despite these difficulties, previous research has explored the effects of different types of peer contexts on academic motivation. The peer context has been conceptualized 
in a many different ways, but most often in terms of social crowds (Urberg et al., 2000), friends (e.g., Berndt, Hawkins, \& Jiao, 1999; or friendship groups: Urberg et al., 2000), or peer groups (e.g., Cairns, Perrin \& Cairns, 1985; Kindermann, 1996). What follows is a brief overview of key studies in each of these three areas.

\section{Social Crowds}

Social crowds are large groups of individuals who share some common feature or features (Eckert, 1989; Brown, 1993; Urberg et al., 2000). A social phenomenon that is more common during adolescence, they are distinct from friendships because there is not a relational component to this type of "relationship." They are distinct from groups because members of particular crowds do not necessarily spend time with all other members of that crowd. Additionally, individuals typically do not actively seek membership in a social crowd. Rather, membership in a social crowd may be imposed upon an individual by the collective consensus of their age mates based upon a host of observable characteristics of the individual including the quality of clothing worn, the types of music preferred, and the places one prefers to hang out (Eckert, 1989). For example, if an adolescent enjoys and participates in school-sponsored athletic activities, is clean cut in dress and appearance, and spends a lot of extracurricular time at school, he may be labeled as a "Jock" by his peers and be grouped with others who, because of their appearance and observable behavior, are labeled in a similar way. This would occur even if he didn't actually interact with other "jocks". Despite the possibility that members of social crowds might not ever actually interact, some research suggests that social crowds may influence an individual's development (for review, see Brown \& Dietz, 2009). 


\section{Friendships}

A focus on friendships is arguably the single most frequent route taken by social networks researchers (for review, see Bukowski, Metzow, \& Meyer, 2009). Research examining the effect friendship has on children's development focuses on the dyadic, reciprocal, and emotionally bonding relationships that form between children. Using an experimental method Berndt, Laychack and Park (1990) examined the influence friends have on individual's achievement motivation. Participants included 118 eighth-graders and one of their closest friends. First, each participant (and their friend) was independently presented with six school-related dilemmas (e.g. "stay home and study for a test" vs. "go to a rock concert") and instructed to choose between two available actions: one reflecting high achievement orientation, the other low achievement orientation. Next, each friendship dyad was randomly assigned to one of two groups; an experimental group or a control group. Dyads assigned to the experimental group were instructed to discuss their response to the dilemmas they were previously presented with independently. Dyads assigned to the control group discussed topics unrelated to academics, such as what they wanted to do over summer break. Finally, each participant/friend dyad was presented with dilemmas similar to the ones they encountered at the beginning of the experiment in order to see if their decisions became more similar. Results of this experiment suggest that friends who had conversations about how they each would respond to the dilemmas became more similar in how they later responded to academic dilemmas similar to the dilemmas they encountered in the first stage of the experiment. Based upon the result, Berndt and his colleagues concluded that children's achievement 
motivation is susceptible to influence by friends. Furthermore, they concluded that conversation occurring during face-to-face interaction is one pathway through which this influence travels.

More recently Altermatt and Pomerantz (2005) explored the differential consequences of establishing close relationships with high-achieving versus lowachieving classmates on an individual's self-evaluative beliefs (self-perceptions of competence, self-esteem, and attributional style), preference for challenge, academic performance (GPA), and the importance placed on being academically competent. This research was particularly interested in investigating whether being friends with highachieving friends is universally advantageous, and conversely whether being friends with low-achieving friends is universally disadvantageous. Motivated by Festinger's social comparison theory (1954), the authors anticipated that upward comparisons associated with being friends with others who are higher-achieving might have a negative impact on an individual's self-evaluation. The results of their study indicate that having friends who do well in school is not always beneficial, broadly speaking, for an individual. Specifically, results from this study indicate that for low achieving children, having friends who do well in school has specific costs and benefits. Presumably due to social comparison, these children suffered losses in self-esteem and evaluated themselves less positively. However, these children did show improvements in achievement and performed better in school than low-achieving children who had low-achieving friends. 


\section{Peer Groups}

Research focusing on peer groups examines the larger groups of peer affiliations in which friendships sometimes are embedded. Peer groups are often defined as containing more than two members who spend a lot of time together, and are usually thought to be less intimate in nature compared to friendships. Cairns, Cairns, and Neckerman (1989) examined multiple factors (including peer group affiliations) which they hypothesized would have some predictive relation to early school drop out. By analyzing data using multiple statistical methods (including contingency analysis, logistic regression, and cluster analysis), they found that students who were rated as high on aggression and low on academic achievement in the seventh grade were subsequently more likely to drop out than students who were clustered into other groups (e.g., students who were rated low on aggression and high on academic achievement.)

In addition, using a procedure known as social cognitive mapping (SCM; Cairns, Perrin, \& Cairns, 1985; Cairns, Gariépy, Kindermann, 1990), a method that allows for the identification of the peer groups within which individuals are embedded, they found that students who dropped out between ninth and eleventh grade tended to affiliate with peers in the seventh grade who also later dropped out prior to graduation.

Cairns and colleagues' study offers two important findings. First, the results suggest that there may be a relationship between both social aggression and academic success and school completion. Second, the results suggest that students who later drop out of school tend to spend a lot of time with other students who also later drop out of school. One possible interpretation of the combination of these results may be that the 
regular presence of certain types of peers may influence aggressive and academically disaffected behaviors, which may in turn increase the likelihood of future dropout.

While this study provides interesting findings highlighting how the influence of peers in childhood may sometimes be detrimental to a minority of individuals, it overlooks the many beneficial contributions peer relationships afford the majority of youth. It is important to point out that peers often influence individuals in positive ways. For example, peers are often providers of valuable resources (e.g., help with homework) and can be reliable sources of emotional support. Furthermore, having relationships with others in the school setting may foster development of a young person's school identification.

More recently, Kindermann (2007) explored the extent to which peer group members influence the development of academic engagement over and above the effects of parental and teacher influence. With the participation of 340 sixth-grade students recruited from the only school in a rural town in upstate New York $(93 \%$ of the entire cohort), teacher- and student-report methods were used to measure student engagement, student achievement, parental involvement, teacher involvement, and demographic information. In addition, students were asked to recall and report on whom they frequently observed "hanging out together." Using this method, the frequency that two individuals were reported as being members of the same group was entered into a cooccurrence matrix, and peer groups were identified using conditional probability analyses. Data from all of these measures were collected in fall and again in the spring of the same school year. 
Fall peer group engagement scores were created for each participant by aggregating the fall engagement scores of all the members of an individual's peer group. A theoretical advantage of this method is that it considers the nature of a peer group from the subjective position of the individual being affected by it.

Data were analyzed using structural equation modeling. Results indicate that a model in which fall peer group engagement profiles predict individual spring engagement (controlling for fall individual engagement, parent/teacher involvement, math achievement, and peer group size) showed good fit $\left(\chi^{2}(23)=22.660, p<.481\right.$, $\mathrm{CMIN} / \mathrm{DF}=.985, \mathrm{CFI}=1.00, \mathrm{RMSEA}=.000,90 \% \mathrm{CI}=.000$ to .042$).$ Furthermore, the results suggest that peer groups may have a significant impact on the development of a young student's engagement in school, over and above the influential effect of his or her parents and teachers.

Although a distinction between friendships, groups, and crowds has been made in the literature (Kindermann \& Gest, 2009), and these three types of peer contexts are the focus of three somewhat distinct areas of research, there is likely substantial overlap among them. For example, three individuals who are categorized as belonging to the same crowd may gravitate toward each other. Over time, after becoming aware of their superficial similarities (e.g., physical adornment, interests), they may spend an increasing amount of time together. Through consistent interactions experiences within these peer groups, the three individuals may begin to develop more intimate friendships. Empirical research supports this, suggesting that social crowds often function to funnel adolescents 
into social groups (Urberg et al., 2000) and that friendships often develop within the context of these social groups (Cairns, Leung, Buchanan, \& Cairns, 1995).

Are Peers Really that Bad?

Although there seems to be a burgeoning interest in examining peer influence and its mechanisms, the majority of existing peer influence research focuses on the "dark side" of peer influence. The overwhelming majority of peer influence studies focus on a variety of issues, such as substance abuse (Ennett \& Bauman, 1993; Bauman \& Ennett, 1994) and bullying (Espelage \& Swearer, 2003) and antipathies (Laursen, Bukowski, Nurmi, Marion, Salmela-Aro, \& Kiuru, 2010), that lead to the conclusion that peer influence functions almost exclusively in a negative direction. Prinstein, Brechwald, and Cohen (2011) examined children's differential susceptibility to peer influence on deviant behavior, finding that individuals who are most susceptible to influence by high-status peers showed the most powerful, longest-lasting effects. Although understanding the ill effects of peer influence is certainly important, particularly for intervention work that seeks to mitigate negative outcomes of peer interaction, more work exploring the circumstances under which peer influence has positive effects needs to be done. One of the goals of the current study is to explore not only circumstances in which individuals are negatively influenced by their peers (academic disaffection), but also how they may be influenced in the often overlooked positive ways (e.g., academic engagement). 
Methodology review: Social Network Analysis and Peer Influence

There are two major issues for researchers exploring the role peers play in affecting child and adolescent development. The first concerns how to accurately identify friends or peer groups. The second concerns how to accurately disentangle peer influence effects from peer selection effects when observing individual/group similarities. The following sections will review methods that have been developed to overcome these difficulties.

Identifying Peers. Accurate identification of friends and peer group members can be difficult. Unlike with parents and teachers, who are in normal situations easily identifiable, accurate identification of which individuals make up a student's group of peers can be troublesome because (a) individuals affiliate with friends and peers in a variety of different contexts (e.g., the mall, school, club sports), (b) the boundaries of peer groups are not often clearly defined, and (c) peer groups and friendships change frequently over a relatively short time period. Considering the difficulties associated with identifying peers, it should not be surprising that over the past few decades a handful of different methods have been developed to overcome some of these challenges. What follows is a brief description of two broad categories of methods used to identify friends and peers: self-report methods \& peer-report methods.

Self-reports and identifying networks. As previously stated, self-report methods remain the most commonly employed methods in social network research. Self-report social network methods have been utilized to examine peer influence and selection in a variety of different research areas including aggression (Espelage, Holt, \& Henkel, 2003), 
spread of obesity (Christakis \& Fowler, 2007), food and media preferences (Rozin, Riklis, \& Margolis, 2004), and student engagement and achievement (Ryan, 2001; Wentzel \& Caldwell, 1997).

In research that utilizes self-report methods of identifying networks or groups, participants are asked to identify other individuals (e.g., peers, friends, co-workers) with whom which they have some type of social or relational connection. For example, social network researchers who are interested in networks of peers may ask their participants, "Who are the people who you enjoy hanging out with?" Participants usually respond by providing a list of people whom they recollect as being their social partners. Unfortunately, especially in late childhood and adolescence, participants sometimes provide inaccurate accounts of their social contexts, sometimes reporting on others they wish to affiliate with. This phenomenon is called "self-enhancement bias" (Leung, 1996). This type of response bias can create problems; specifically, popular and admired students typically are reported as being connected with more individuals in the network than they actually are connected with. To deal with this problem, most researchers only consider nominations that are reciprocated as relational ties.

Unfortunately, sometimes the solutions to problems create new problems. By considering only reciprocated nominations as relational ties, many actual ties are lost in cases where one of the individuals fails to reciprocate. Failure to reciprocate a nomination could occur for a variety of reasons, including lack of parental consent to participate, absence during the data collection, or not being captured in the sample (e.g., goes to a different school). When an unreciprocated nomination occurs, researchers using this 
method have to assume that disagreement about the relationship exists between the two informants, despite not actually having sufficient evidence to support this claim. It is possible that the other informant simply forgot to indicate a connection, or that he or she was unable to due to a barrier to participation. This problem leads to actual ties not being reflected in a network, and as a result a researcher's model of a network can be inaccurate (an individual may be represented as being isolated in a network model, despite actually having many friends, because these did not participate or were friends outside of school).

In order to avoid misrepresenting actual social networks, researchers using selfreport methods must obtain network information from all individuals in the networks being studied. As is the case with all research using human subjects, achieving a 100\% sample rate is very difficult and in some cases, particularly in research using children and adolescents as participants where parental consent is mandatory, is likely impossible.

SCM Methods to Identify Networks and Individual Members. Social Cognitive Mapping ( $\mathrm{SCM}$ ) is a method by which participants are used as "expert observers", being asked to identify individuals (e.g., peers, friends, co-workers) whom they frequently observe having some type of social or relational connection. For example, researchers who use this method to explore networks of peers may ask their participants, "Are there people who you see hanging out with each other a lot?" Participants typically respond by providing a list of people whom they observe as being frequent interaction partners. More often than not, these lists also include groups to which they themselves belong. In order to identify valid peer groups, nominations are entered into a cooccurrence matrix. Peer affiliations are identified using either correlation-based methods 
(Cairns \& Cairns, 1994; Cairns, Gariepy \& Kindermann, 1990) or conditional probability methods (Kindermann, 1993; 1996; 2007). Cairns' method is the most frequently used method, and is implemented in the traditional SCM analysis program (Leung, 1998). With this method, two individuals are assumed to have a tie if their network connection patterns are significantly correlated with a correlation above .40 . If for two participants, the individuals with whom they affiliate and the individuals they do not affiliate with are similar, then it is assumed that they belong to the same peer group. Researchers who use this method also frequently utilize a method of quantifying an individual's social status within the network. This method is discussed later (see pg. 40).

An alternative is Kindermann's $(1993,1996)$ method, which is based on probability assumptions. Using this method the frequency by which individuals are conominated with all other members of the network is entered into a cooccurrence matrix. Binomial Z-tests are used to determine whether an individual is more likely to be nominated as being in a group with another individual than is be expected by chance. Consider an example (see Table 2.1) using two students, KER and RYB. Of the 36 times KER was nominated as belonging to a group, RYB was nominated as belonging to the same group 28 times. Furthermore, RYB received 32 total group membership nominations herself out of 694 total group nominations network-wide. The conditional probability of observing RYB as a member of a group, given that KER was a member of a group $(28 / 36=.78)$ is compared to the unconditional probability that RYB belonged to any group (32/694=.05) using a binomial z-test. The significant z-score resulting from this comparison $(Z=21.47)$ indicates that the two belong to a group. To avoid problems 
Literature Review: Differential Susceptibility 30

Table 2.1 Subset of a Cooccurance matrix of girls in $6^{\text {th }}$ grade (Kindermann, 2007)

\begin{tabular}{|c|c|c|c|c|c|c|c|c|c|c|c|c|c|}
\hline & KER & RYB & DAL & $\mathrm{COD}$ & SUO & $\mathrm{ROM}$ & STQ & CHR & KAA & KAW & ELT & JEP & Nominations \\
\hline KER & - & 28 & 23 & 12 & 10 & 3 & 3 & 0 & 0 & 0 & 0 & 0 & 36 \\
\hline RYB & 28 & - & 20 & 11 & 12 & 3 & 4 & 0 & 0 & 0 & 0 & 0 & 32 \\
\hline DAL & 23 & 20 & - & 10 & 9 & 4 & 2 & 0 & 0 & 0 & 0 & 0 & 28 \\
\hline COD & 12 & 11 & 10 & - & 19 & 8 & 13 & 0 & 0 & 0 & 0 & 0 & 29 \\
\hline SUO & 10 & 12 & 9 & 19 & - & 9 & 10 & 0 & 0 & 0 & 0 & 0 & 29 \\
\hline ROM & 3 & 3 & 4 & 8 & 9 & - & 4 & 0 & 0 & 0 & 0 & 0 & 11 \\
\hline STQ & 3 & 4 & 2 & 13 & 10 & 4 & - & 0 & 0 & 0 & 0 & 0 & 17 \\
\hline CHR & 0 & 0 & 0 & 0 & 0 & 0 & 0 & - & 10 & 10 & 9 & 10 & 14 \\
\hline KAA & 0 & 0 & 0 & 0 & 0 & 0 & 0 & 10 & - & 13 & 13 & 12 & 16 \\
\hline KAW & 0 & 0 & 0 & 0 & 0 & 0 & 0 & 10 & 13 & - & 13 & 10 & 17 \\
\hline ELT & 0 & 0 & 0 & 0 & 0 & 0 & 0 & 9 & 13 & 13 & - & 10 & 18 \\
\hline JEP & 0 & 0 & 0 & 0 & 0 & 0 & 0 & 10 & 12 & 10 & 10 & - & 13 \\
\hline LIP & 0 & 0 & 0 & 0 & 0 & 0 & 0 & 0 & 0 & 0 & 0 & 0 & 24 \\
\hline $\begin{array}{l}\text { No. of } \\
\text { informants }\end{array}$ & & & & & & & & & & & & & 260 \\
\hline $\begin{array}{l}\text { Total } \\
\text { Nominations }\end{array}$ & & & & & & & & & & & & & 3,047 \\
\hline $\begin{array}{l}\text { Groups } \\
\text { Generated }\end{array}$ & & & & & & & & & & & & & 694 \\
\hline
\end{tabular}

associated with the fact that for many individuals expected cell frequencies are low, Fisher's exact test (Sterling's approximation; von Eye, 1990) is used in conjunction with the binomial z-test. Only network connections that are significant at the .01 level using both tests were retained (see Kindermann, 2007).

Regardless of the method used to identify ties, the SCM method offers researchers solutions to some of the problems plaguing network researchers who rely on self-report methods. First, informants are not able to have an impact on a rendered network's accuracy by reporting on relationships that don't exist (e.g., when an individual falsely reports hanging out with the most popular child in school as a form of impression management). When SCM methods are employed, a consensus is used to validate a 
relational tie and an individual's false reports usually don't fit with the consensus and are disregarded. Second, with SCM methods researchers do not have to obtain network information from all members of a network. It has been suggested that accurate depictions of naturally occurring networks can be obtained when only half of the network is reporting on it, provided that the sample is fairly representative (e.g., matches a classroom's distribution of boys and girls; Cairns \& Cairns, 1994; Kindermann, 2007). Finally, SCM and other peer-report methods may be less stressful for some participants than self-report methods. Being asked to produce a list of their friends may be distressing for participants who have few social ties. For some participants, this self-reflective exercise may raise into awareness the fact that they have few close relationships. This awareness is likely distressing. Peer-report methods avoid this problem by asking essentially the same question, but in a way that is not self-oriented. Reporting on the relationships or interactions that occur between others may be less likely to raise distressing awareness in a participant who has few social connections.

Unfortunately, there are some limitations to the use of SCM methods. First, since networks are constructed using participants as expert observers, only networks in which the relational ties represent an observable phenomenon can be identified. For example, relying on other-reports of friendships, which are commonly thought of as being relationships based upon mutual liking between individuals, may be problematic because of difficulties of accurately observing mutual liking between two others. However, for research where the focus is on frequent interactions that occur between individuals, utilizing peer-reports may be the best methodological option available. After all, who is 
better suited to report on peer group membership than the individuals who observe them every day?

\section{Measuring Peer Influence}

In order to accurately capture the process of peer influence, a researcher needs to (1) obtain an accurate measurement of a group-level construct (e.g., peer engagement), and (2) sufficiently disentangle selection effects from influence effects in explaining individual/group similarities. The following sections discuss these issues.

Capturing network characteristics. Regardless of the method used, once peer groups have been identified a new problem arises: How to accurately capture characteristics of the peer network. One commonly used method to estimate peer network characteristics involves the aggregation (arithmetic average) of an individual's peer affiliate scores (Kindermann, 1993; Kurdek \& Sinclair, 2000). Using this method, group characteristics are relatively easy to compute. Unfortunately, it has been noted that this method is not without its flaws (Kindermann, 1996; Kindermann, 2007). First, the theoretical validity of this method breaks down when applied to relatively small groups. For example, the average engagement score of a group of three individuals may be a poorer representation of "group engagement" compared to the average engagement score of a group consisting of twelve individuals. Peer groups frequently consist of smaller numbers of individuals, raising valid concern for the use of simple aggregation in estimating group characteristics. Second, by estimating group characteristics through aggregation, the researcher assumes that the individuals who make up the group are equal in how they exert influence. Group members likely differ in the strength of influence they 
have on an individual (Kindermann, 1996). By aggregating group member scores, this potential differential influence is averaged away.

Despite these potential flaws, this method has been used to estimate peer group characteristics along a variety of different dimensions including school engagement (Kindermann, 1996; 2007; Ryan, 2001), academic achievement (Kurdek \& Sinclair, 2000; Ryan, 2001), and aggression (Espelage, Holt, \& Henkel, 2003).

Capturing peer influence while controlling for peer selection. Social influence can be conceptualized as the degree to which an individual's thoughts, beliefs, feelings, preferences or behaviors are affected (either changed or maintained) by other individuals or groups of individuals. Influence is most frequently viewed as being the extent to which an individual becomes similar on a given variable to individuals who make up his or her group. For example, researchers exploring the phenomenon of peer pressure and conformity have examined the extent to which certain individuals are similar to their peers in their alcohol consumption (Urberg, Degirmencioglu, \& Pilgrim, 1997), tobacco use (Urberg, Degirmencioglu, \& Pilgrim 1997), and other delinquent behaviors (Espelage, Holt, \& Henkel, 2003). However, it is important to keep in mind that peer influence that occurs through interactions with peer group members may often make individuals of a peer group different than each other. For example research has provided evidence that individuals who belong to bullying groups often take on a distinct role that serves the needs of the group (e.g. the "lookout", or the "muscle")

While individual/group similarities may be an expected and likely outcome of the influence processes, similarity by itself is not sufficient to imply influence (Kandel, 
1978). Peer groups do not form at random. On the contrary, individuals often choose which peers they spend time with based upon existing similarities, including academic orientation (Kindermann, 2008). Therefore, observed similarity between an individual and the peers he or she affiliates with may result either from peer selection, peer influence, or other variables. Individuals may be similar in their marijuana use partly because they actively select others who are similar to themselves in their drug use habits or other associated behaviors or values ("assortative pairing"; Kandel, 1978) and partly because over time they are influenced by their peers, presumably through a collection of processes (imitation, reinforcement, etc.). Likewise, individuals may be similarly engaged in school compared to those they hang out with partly because they selected those peers for this quality and partly because their peers influenced them.

Some researchers have attempted to demonstrate peer influence in their work using cross-sectional designs. As has been discussed, cross-sectional "influence" research is inherently flawed because by using concurrent measures of individual/group similarity, researchers are not able to tease apart the distinct contributions selection and influence make toward producing the similarity that often develops between friends and individuals who spend time together. Because influence is a process, a model that accounts for how an individual's thoughts, beliefs, feelings, preferences or behavior change over a period of time in the presence of peers, controlling for peer selection based upon initial similarity must be used.

A methodological model that examines the degree to which social group characteristics predict change in an individual's characteristic has been used in a variety 
of areas of research to explore the nature of social influence (Kindermann, 1996; Christakis et al., 2007). With this method, individual scores are obtained at two time points and a group score is obtained or created (group aggregate) for the first time point. A model is constructed in which the individual score at the second time point is regressed on the individual score at time 1 (stability) and group score at time 1 (influence), while the group score at time 1 and the individual score at time 1 are allowed to correlate (selection). This model allows a researcher to examine a process of influence with the effects of selection controlled for. Stated in a slightly different way, this model estimates the effect of peer group engagement on changes in individual engagement over time, controlling for prior individual engagement.

Control variables. In addition to controlling for the individual's prior engagement, it is vital that a researcher control for other variables when attempting to capture the unique effect peer influence has on children's and adolescents' developing school engagement (see Kindermann, 2006). Third variables that are correlated with both the independent variable (peer group engagement) and the dependent variable (change in students' engagement) create an uncertainty in conclusions of a causal link. Among the variables that should be controlled for are characteristic of the individual such as gender and achievement. Past research indicates that girls tend to be more highly motivated in school and demonstrate higher achievement rates (e.g., Eccles, Wigfield, \& Schiefele, 1998). Similarly, students who do well and achieve good marks in school may be expected to subsequently be more motivated. Therefore, in order capture the unique 
Literature Review: Differential Susceptibility 36

contribution peer influence has on developing school motivation, the effects gender and achievement have on the development of engagement must be controlled.

In addition to controlling for characteristics of the individual, characteristics of the group must also be considered and statistically controlled. Kindermann (2008) points out that the selective assortment process often produces peer groups that are homogeneous not only in terms of their individual characteristics (e.g., gender, race, and achievement) but also in terms of its members' social experiences. When highly engaged children select affiliates who are also highly engaged, they also likely end up forming groups that are homogenous in terms of parental and teacher involvement, which can also be responsible for shaping changes in students' engagement. Because it is likely that members of a group are similar in the influence they experience from outside the group, it is important to control for these other potential sources of influence.

\section{Differential Susceptibility}

While previous research provides evidence that indicates that children's susceptibility to peer influence increases as they begin their emergence into adolescence (Berndt, 1979), it remains likely that there is some inter-individual variability in susceptibility to influence and that some young people are more susceptible while others may be less susceptible to peer influence than the average. What makes some individuals more susceptible to the influence of peers? What makes others less susceptible to the influence of peers? In this section, relevant research pertaining to how certain qualities of the individual and the social context in which they are embedded (including gender, person-to-group differences, network centrality, network diversity, relatedness to peers, 
and adult involvement) might affect an individual's susceptibility to peer influence is explored.

Gender Differences. Urberg and her colleagues (1995) provide evidence suggesting that girls tend to be better connected to their school social network (i.e., greater number of best-friend nominations; more likely to be a member of a clique). Furthermore, results from their research, which analyzed data provided by $90 \%$ of the student populations of three schools, suggests that the friendship groups of boys tend to be more diverse in the types of social crowds the members belong to. For example, “preps" may predominate a female friendship group, whereas a male friendship group may consist of members from a variety of different social crowds such as "Jocks" "Preps" and "Stoners". By being members of more socially diverse peer groups, the exposure to ideals and values that are different than their own may also be greater for boys as compared to girls. Taking these results into consideration, it seems possible that boys, who are more often connected to diverse sets of others in their school networks, may be more susceptible to the influence of their peer group members' diverse values and behaviors as a way to build social relationships and gain acceptance from their age mates. On the other hand, it is also possible that girls, who tend to be better connected within the social network of their schools, may be more susceptible to the influence of their peer group members.

Person-to-Group Differences. Influence may be a function of both the individual and the group. According to the person group similarity model (Wright, Giammarino, \& 
Parad, 1986; Stormshak \& Bierman, 1999) groups evaluatively process an individual group member's behaviors and compare these behaviors to the behavior norms of the group. When an individual's behaviors are consistent with the norms of the group, the individual is more likely to be accepted by and have high peer status within the group. When an individual's behavior is inconsistent with the norms of the group, he or she is more likely to have low peer status. For example, Wright and colleagues (1986) found that aggressive individuals were more likely to have low peer status when they belonged to groups in which aggressive behavior was not normative and infrequent. However, similarly aggressive individuals were more likely to have high peer status when they belonged to groups in which aggressive behavior was more typical.

The person-group similarity model suggests that a person whose behaviors are inconsistent with the norms of his or her peer group should experience a decrease in acceptance from and status within the group. Since having a feeling of belongingness and acceptance by others is a primary human need, it should be expected that an individual would act in particular ways to gain peer acceptance. Two options are available to such an individual that could increase the acceptance received from his or her proximal age mates. The individual could either find a new peer group (e.g., an academically engaged child exits a predominantly disaffected group to join another, similarly engaged group), or adjust his or her behavior to be in alignment with the behavior norms of the group (e.g., an academically engaged child adjusts behavior to more closely match the engagement profile of the group). In some cases, the former may be a more difficult option, particularly for individuals who through a publicly known association with a 
particular peer group or social crowd have developed an offensive reputation. For example, a child who is associated with a group that consists predominantly of academically disaffected individuals may find it difficult to gain acceptance into other, more academically oriented groups. Moving one's own behavior into alignment with the normative behavior of their group, on the other hand, may be an easier option, particularly for emerging adolescents who are, at that stage in development, likely still exploring their developing identities and therefore may be somewhat flexible behaviorally and in how they define themselves.

Because behavior change (as opposed to group change) may represent a "path of least resistance", it seems possible that individuals for whom there is a large difference between their own and their group's behaviors should be more likely to adjust their own behavior (be influenced) to be in alignment with the group norm. Therefore, it is expected that individuals for whom the difference between their own engagement and their group's engagement is great should be more influenced than individuals for whom the difference is slight.

Centrality. Recent research examining peer group influence on individual's behavior has provided compelling evidence suggesting that the extent to which a individual is susceptible to influence emanating from their peer group may depend upon the status or centrality of their group within the network. Ellis and Zarbatany (2007) found that peer group influence effects on children's own developing behavior may depend upon how prominent or central a child's peer group is within the network. Specifically, results from their research suggest that the socialization of relational 
aggression, deviant behavior, and prosocial behavior is strongest for individuals who belong to highly central groups. Furthermore, they found that peer group-level deviancy predicts changes in individual-level deviancy, but most strongly for individuals who belong to peer groups composed by members who are generally disliked. Although the focus of this research was to explore how the network position of an individual's group may explain differential susceptibility to peer influence of deviant and prosocial behaviors, similar differences may exist between individuals of differing social network position regarding their susceptibility to peer influence of their behavior, including their academic engagement. It is one goal of this project to explore differences that may exist between highly central students and less central students in their susceptibility to peer influence of the development of their school engagement.

Centrality is a term used by researchers who use social network analysis techniques to describe an individual's (actor) structural or social position in a social group or network. Coined by Bavelas in 1948, the concept of centrality was originally applied to research that explored individual differences in the influence of group processes in small communications networks (Bavelas, 1948; 1950). Since then, many ways in which centrality is conceptualized and measured have emerged.

Having their origins in a branch of mathematics known as graph theory, the indices of centrality originally used by Bavelas and many others since are very structural in nature. Most notable among the indices of structural centrality are the concepts of degree, betweenness, and closeness (Freeman, 1978). 
Degree is generally defined as the sum of graphical connections a given point has to all other points in the network. A point is said to be maximally central, by this criteria, if its degree is equal to one less than all the points in the network. For example, if a student has relational ties with everyone in his or her class, then this student would be maximally central by degree (within the class) because the number of ties would equal the number of students in the class minus him or herself. Within the context of the proposed study, a student's degree would represent the number of peers with whom he or she is observed to hang out with frequently.

Betweenness is generally defined as the sum of geodesic distances a point is positioned between. A geodesic distance is defined as the shortest path between two points in a network. This measure of centrality is most useful when examining the flow of things through a network (e.g., money, information, illness). A point that is highly central by this criterion should be thought of as being integral and necessary for the spread of things through the network. Within the context of this study, the concept of betweenness makes little theoretical sense and therefore will not be used.

Closeness centrality is generally defined as the inverse of the average distance a point has to all other points in the graph. Closeness is traditionally conceptualized as meaning the degree to which a node (or individual) can control the communication access it has to the entire network; in other words, it is the extent that it can avoid the control potential of other nodes. For example, if a node's geodesic distance from all other points in the network is one, it is maximally close and does not need to send information through any other nodes to pass information to any node in the network. As is the case 
with the measure of betweenness, the concept of closeness makes little theoretical sense and therefore will also not be used.

Relatedness to Peers. A cumulative body of research provides support for the hypothesis that having a feeling of connectedness and belonging to peers at school is crucial for engagement and success in an academic environment (Hymel et al., 1996; Sage \& Kindermann, 1999; Wentzel, 1999). Urberg and colleagues (2003) found that individuals who experienced a high degree of peer-acceptance and friendship quality were more likely to be influenced by the behaviors of those peers. Although this research looked specifically at the acquisition of substance abuse behaviors, it does not seem unreasonable that young people who feel accepted and have high quality relationships with prosocial and academically engaged peers would be similarly more susceptible to their positive influence. Furrer \& Skinner (2003) found that students' sense of belonging to a group of peers was predictive of engagement behaviors, controlling for their sense of relatedness to their parents and teachers.

There may be two possible explanations for why individuals may be more influenced by peers to whom they feel related. First, individuals may be more influenced by others who they feel close to because of the credibility the person has as being a person who cares for and is concerned about their well being. For example, an student may take the advise of a friend (e.g., "you better study for that exam!") because he or she perceive the friend as being genuinely concerned. Second, individuals may be more influenced by those with whom they are close out of fear of losing those relationships. 
For example, a student may work harder in school because he or she is afraid that his or her friends may not want to be friends with a "failure".

Parent involvement. When faced with the common and inevitable stresses of life, emerging adolescents need others whom they feel they can turn to, to confide in and seek counsel from. Generally speaking, children have three main sources of support: parents, teachers, and peers. Results from a body of research indicates that students who experience their parents as being supportive and involved are more engaged in school and with classroom activities (Furrer et al. 2003, Mo \& Singh, 2008) and subsequent academic achievement (Kurdek, et al., 2000). Although there seem to be age-graded declines in the amount of time individuals spend with their parents (Downs, 2001; Johnston, 1998), for many young people parents remain a main source of emotional and instrumental support throughout their development. While there is an abundance of research examining the role parents play in influencing their children's academic success, little research explores the extent to which parents' involvement effects the degree to which children turn to and are influenced by their peers.

Some parents are able to adapt to the changing needs of their children as they mature. By adapting their supportive role to match the developmental needs of the child, they are able to continue to be important sources of support and guidance that are ageappropriate for and appreciated by their children. Unfortunately, some parents are not successful in adapting their roles to meet the needs of their child, and in some of these cases a child may react by orienting away from them to search for others from whom they may get their needs met. For example, Fuligni \& Eccles (1993) showed that the children 
of parents who asserted their power to a high degree and who did not relax their restrictiveness or allow their child's input in decision making processes showed more extreme forms of peer-orientation. Furthermore, even when some parents are able to attune their role to meet the needs of their children, they are not as able to remain a supportive resource for their child for a variety of different reasons. For example, competing demands from work may make it difficult for some parents to be aware of or able to help their children with the difficulties and challenges they face on a day-to-day basis. With the wide variability in parents' abilities and capacities to be involved and offer parental support, it seems likely that there should be a high degree of variability in children's perceptions of parental support. Some young people may experience a lot of support from their parents, while others may experience relatively little. To whom do children who perceive a lack of involvement or support from their parents turn to? Research indicates that children who experience little support or involvement from their parents often turn toward their peers (Fuligni et al., 1993). Depending on the specific peers they turn to, an individual's degree of peer orientation can have different effects on their academic success (Fuligni et al., 2001). 


\section{Chapter 3: Purpose of the Study and Research Questions}

This study aims to explore how children's susceptibility to peer influence on the development of their own academic engagement may depend upon a variety of individual and contextual factors. Four principles are theorized to underlie children's susceptibility to peer influence (See Figure 3.1).

First, students' susceptibility to peer influence on their engagement was expected to be affected by the amount of contact or interaction that occurs between the individual and his or her peers. To explore this issue, this study examined one indicator

Figure 3.1. Theory of differential susceptibility to peer influence on student engagement.

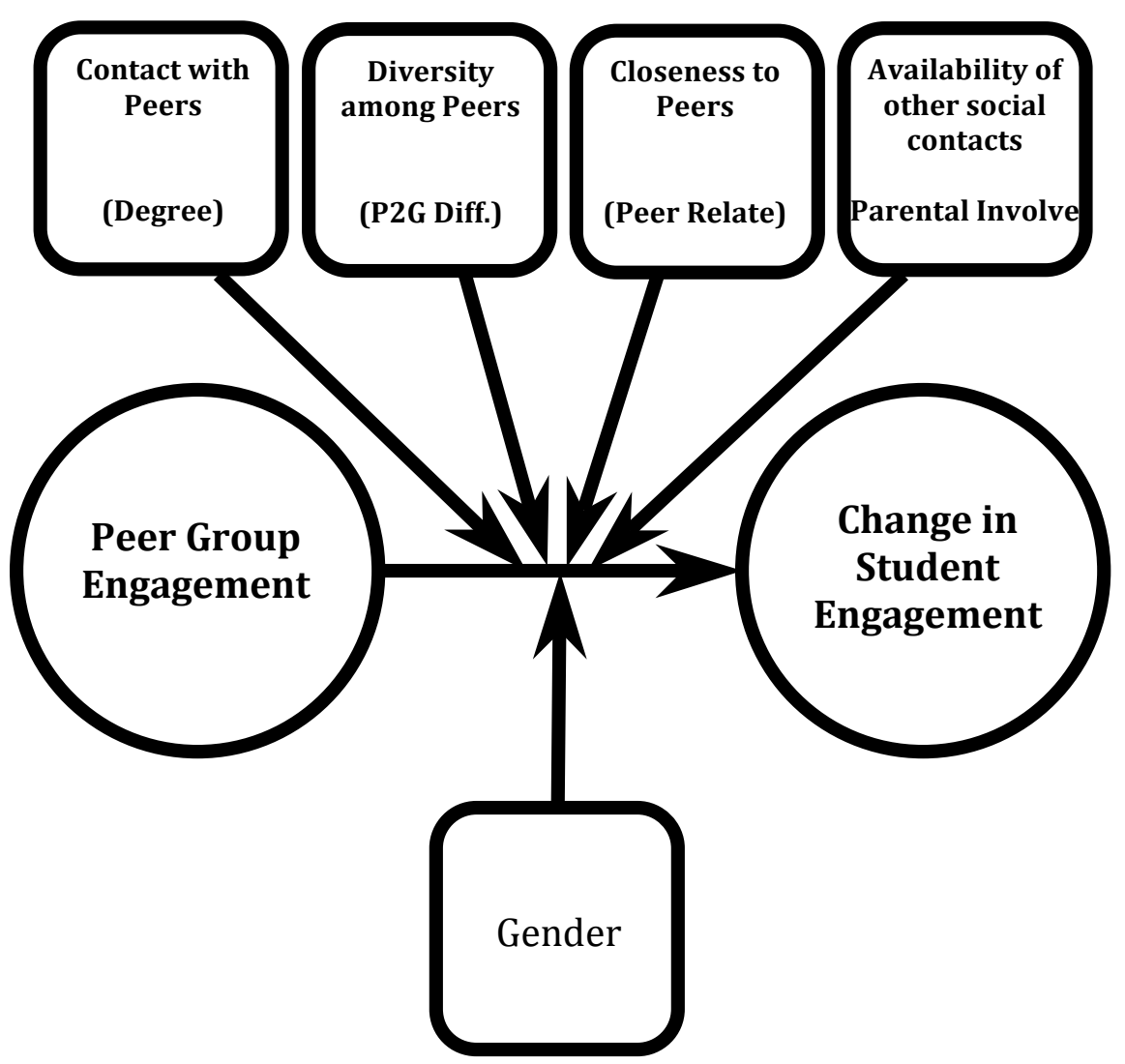


of children's centrality within their peer network (Degree). Specifically, this study explored how children's susceptibility to peer influence on the development of their motivation in school may depend on the centrality of their network location. The main question is whether the number of peers with whom a student interacts makes a difference in predictions of peer group influences on the development of their classroom engagement.

In the literature on Social Network Analysis, far-reaching claims have been made about the extent to which specific people in a network may be identified as having higher status or more power than others. Specifically, attention will be paid to degree centrality (Freeman, 1978), which is the number of connections to other people in a network an individual possesses.

Second, students' susceptibility to peer influence on their engagement was expected to be affected by the degree to which an individual's values and behavior diverge from that of his or her peers. To explore this issue, the current study examined the possibility that children's susceptibility to peer group influence on their school motivation may vary depending upon person-to-group differences in school motivation. Based upon prior research using the person-group similarity model (Wright et al., 1986; Stormshak et al., 1999), it was expected that peer influence would be greatest among students for whom the difference between their own classroom engagement and the classroom engagement of their peer affiliates was great.

Third, students' susceptibility to peer influence on their engagement was expected to be affected by the individual's sense of feeling relationally close to his or her peers. To 
explore this issue, the current study examined how children's susceptibility to peer influence on the development of their motivation in school may depend on the extent to which they feel like they belong and are accepted by their peers. Existing research indicates that children's sense of relatedness to their peers may be important predictor of school success (Furrer et al, 2003); therefore, it was expected that students who were more highly related to their peers would be more susceptible to influence because of their more intimate and emotionally closer connections.

Fourth, students' susceptibility to peer influence on their engagement was expected to be affected by the availability of other social contacts. To explore this possibility, the current study explored whether children's susceptibility to influence by their peers varied depending upon their perceptions of parental involvement. Based upon prior findings (Fuligni et al., 2001), it was expected that students who perceived their parents as being uninvolved would be more susceptible to peer influence on their academic engagement.

Finally, gender differences in susceptibility to peer influence were also explored. Based upon prior research findings which suggest that boys tend to affiliate with peers who are more diverse in their crowd affiliation (Urberg et al., 1995) and girls tend to be better connected within the social network of their schools, it was expected that susceptibility to peer influence would not differ by gender.

The gender, centrality, social status, relatedness, parental involvement, and individual-to-group difference indices were used in two types of analyses. First, they were used for extreme group comparisons, each in comparison to Kindermann's (2007) 
analyses that did not pay attention to such potential differences. Thus, questions were explored about the extent to which smaller (or larger) peer group influences were found for girls (or boys), high (or low) central students, highly (or minimally) peer-related students, students whom experience high (or low) parental involvement, and students who are more (or less) similar to their peers in academic engagement. Secondly, the indices were used as moderators in path analyses of peer group influences on engagement over time, with the expectation that the extent to which peer group engagement predicts changes in students' own engagement depends upon these indices. 
Chapter 4: Methods

\section{Setting and Sample}

Data from an existing longitudinal dataset were used for the present study (see Kindermann, 2007). Participants included all sixth grade students of the only middle school in a rural/suburban town in upstate New York. Data was collected in the 1990/1991 academic year. The study had the approval from the University of Rochester and the support of the Principal and the teachers. Additionally, the project has the ongoing approval form the Portland State University Human subjects Review Boards.

Parents were notified prior to data collection, and passive consent procedures were employed for each participant. Of the 366 sixth-graders enrolled at the school, 340 (93\%) participated. Although information on ethnic background was not obtained for each participant, the town in which the school was located was predominately Caucasian ( $>90 \%$ European American decent) and largely lower middle to middle-class $(87 \%$ of the adult population had at least a high school degree). The number of male and female participants was roughly equivalent (48\% female).

The school from which participants were recruited was the only middle school in the town, which was inhabited by approximately 8,000 residents. In the middle school from which participants were recruited, student's classes were organized around homerooms; these were daily classes in which the students met at least once each day. In total, there were thirteen homerooms and each student had one "homeroom" teacher. Homeroom teachers were primarily responsible for and therefore very familiar with the 
children they taught; they saw them on each school day. All 13 homeroom teachers participated in the study.

Design \& Measures

For the current study self-reports (Relatedness, Parental Involvement), teacherreports (Student Engagement), and peer reports (Peer Groups) were used.

Student engagement was assessed using a 14-item Likert-type scale that was designed to measure teacher perception of student academic engagement (Wellborn, 1991). The scale assesses two dimensions of engagement: behavioral engagement (e.g., "This student works as hard as he/she can") and emotional engagement (e.g., "In my class, this student appears happy"). Prior research has indicated that the two components are significantly intercorrelated $(\mathrm{r}=.31, \mathrm{n}=144$; Wellborn, 1991; $\mathrm{r}=.72, n=1,018$; Skinner, Kindermann, \& Furrer, 2008) and that they form an internally consistent indicator of engagement ( $\alpha=.95, n=144$; Wellborn, 1991; $\alpha=.90, n=1,018$; Skinner et. al, 2008). These teacher reports of engagement have been shown to be stable over time (r=.73, $p<.001, n=144$; Wellborn, 1991; $\mathrm{r}=.78, p<.001, n=1,018$; Skinner et al., 2008) and moderately correlated with academic achievement in the expected direction $(\mathrm{r}=.40$ with math achievement, $\mathrm{r}=.58$ with reading achievement; Skinner \& Belmont, 1993; Skinner et al., 1990). See Appendix A for a complete list of items.

Teacher perceptions of student engagement were obtained at two time points during the school year, first in October and then again in May. At the first time point, homeroom teachers reported on 318 students (93\% of the consenting students; $87 \%$ of the total population). At the second time point, homeroom teachers reported on 322 students 
(the sample size differs at the two time points due to a combination of student attrition and new students entering the sample). Three hundred students had teacher reports at both time points.

Naturally occurring peer groups were assessed using SCM (Social Cognitive Mapping; Cairns et al., 1985). Using this method, participants serve as "expert observers," reporting on whom they frequently see "hanging around" together while at or away from school. For this study, student participants were provided with a form containing space for up to twenty groups, each group having space for up to twenty members. No student participant exhausted the space provided on the form. Students were encouraged to list as many groups as they could from free recall, to include dyadic groups, as well as groups in which they were themselves included. The method allows for children to be placed into more than one group at the same time (e.g., Student A may belong to the choir club and the sports club).

At the first time point, 280 participants (77\% of the sample; $56 \%$ female) completed the peer group questionnaire. At the second time point, 219 students $(60 \%$ of the sample) provided peer group information.

Peer networks were identified using results from the peer group questionnaire. In order to identify valid peer groups, the frequency by which individuals were conominated with all other members of the network was entered into a cooccurrence matrix. Binomial z-tests were used to determine whether an individual was more likely to be nominated as being in a group with another individual than would be expected by chance. 
(Refer to pg. 27 for a more detailed description of the analysis procedure; see Kindermann, 2007).

Peer engagement profiles were estimated by taking an arithmetic average of the engagement scores of all of the affiliates of a student (the individual student not included). For example, if student $\mathrm{A}$ is shown to have valid affiliations with students $\mathrm{B}$, C, D, and E (with individual engagement scores 1, 5, 2, and 4), student A would have a peer engagement score of 3 . It is important to note that the peripheral students from whom the focal student's peer engagement score is calculated are themselves not always necessarily affiliated with each other.

Person-to-group differences in engagement were calculated by subtracting student's peer engagement profile from their own engagement. Students who are more engaged than their peer group will receive a positive score on person-to-group difference in engagement. Students who are less engaged than their peer group will receive a negative score on person-to-group difference in engagement.

Student Relatedness to peers was assessed using an 8-item self-report questionnaire (Wellborn, 1991). Four of the eight items assess a participant's relatedness to their classmates while the other four items assess their relatedness to their friends. Participants were asked to rate from one to four (i.e. "not at all true" to "very true") how well each statement described how they felt. For example one-question states, "When I'm with my classmates, I feel accepted.” See Appendix B for a complete list of the items.

Student's network centrality in the school network was obtained by analyzing peer nominations with the social network analysis software package UCINET. Valid 
social ties identified using the conditional probability techniques described above will be entered into a square dichotomized matrix representing cooccurrence between individuals. Using this dichotomized cooccurrence matrix constructed to represent affiliations between individuals ( $1=$ valid affiliation, $0=$ no or invalid affiliation), degree centrality will be calculated for each student. In this context, degree centrality is the sum of the number of direct relational ties a student has to other students in the network.

Student's perceived parental involvement was assessed using an 18-item selfreport questionnaire (Wellborn, 1991). Four of the items assess a student's perception of their parents' knowledge and consist of items such as "my parents know a lot about what's important to me in school." Two of the items assess a student's perception of their parents' time spent and consist of items such as "my parents spend time with me on schoolwork" Four of the items assess a student's perception of their parents' affection and consist of items such as "my parents enjoy hearing about my school day." Four of the items assess a student's perception of their parents' availability and consist of items such as "when I want to talk about school my parents take the time." Four of the items assess a student's perception of their parents' dependability and consist of items such as 'I can count on my parents when I have problems in school.” Students were asked to rate from one to four (i.e. "not at all true" to "very true") how accurately each statement described how they felt. See Appendix C for a complete list of the items. 


\section{Chapter 5: Results}

\section{Prior Research Summary}

Previous research investigated the extent to which change in children's own academic motivation from fall to spring can be predicted by the academic motivation of their peer affiliates in fall (Kindermann, 2007). To explore this question, data were analyzed using structural equation modeling (SEM; AMOS 5; Arbuckle, 2003). The extent to which the average engagement of a student's peer affiliates in the fall can predict changes in student's engagement from Fall to Spring was estimated controlling for peer group size, student sex, adult involvement, academic achievement, percentage of group that comprised same-sex peers, person-to-group differences in engagement, and the stability group membership. Results from a fully-latent structural regression model suggested that the academic engagement of peer group members in the fall significantly and positively predicted student's own academic engagement in the fall, accounting for control variables including their own academic engagement in the fall $(\beta=.128, p<.05)$.

These results suggest that children who affiliate with highly engaged peers may experience relative increases in school motivation over the school year, while students who affiliate with disaffected peers may experience relative decreases in school motivation across the school year, regardless of gender, prior achievement, size or demographic composition of the group, or adult involvement. Nevertheless, the amount of peer influence that was found was small (peer engagement in fall accounted for $2 \%$ of the variance in children's engagement in spring, over and above the controls). The goal of the present study was to further examine the relationship between individuals' developing 
Results: Differential Susceptibility 55

academic motivation and the academic motivation of the peers they spend much of their time with, and to explore and better understand factors which make individuals more or less susceptible to the process of peer influence.

\section{Initial Analyses}

Before proceeding with the main analyses of this study initial analyses were conducted. Thorough examination for violations of assumptions underlying the methods of analysis was undertaken and completed. Examination of the data revealed no dramatic violations of these assumptions. For all the analyses, which are discussed below, missing data was estimated using Full Information Maximum Likelihood (FIML).

Descriptive Analyses

Mean levels were computed for all variables of interest (See table 5.1). Congruent with findings from prior research that used this sample (Kindermann, 2007), the mean level of children's own school engagement was fairly high in both fall and spring ( $M=3.09$ and 3.08 on a 4-point scale). On average, students also perceived their parents as being fairly involved ( $M=3.22$ on a 4-point scale). Peer group size, which is mathematically equivalent to degree centrality, was found to be 4.8 students on average and ranged from zero to 17. On average, student's relatedness to their peers was found to be relatively high and distributionally skewed ( $M=3.35$, on a 4-point scale; skewness $=-.79)$. Finally, perhaps because children tend to select peer affiliates to whom they are similar, the mean level of person-to-group difference in academic engagement was found to be low $(M=.00 ; \min =-1.57, \max =1.27)$. 
Results: Differential Susceptibility 56

Table 5.1.

Summary of Descriptive Statistics

\begin{tabular}{lccccc}
\hline & $n$ & $M(S D)$ & Min & Max & Skewness \\
\hline Std. Eng. Fall & 366 & $3.09(.57)$ & 1.65 & 4.00 & -0.19 \\
Std. Eng. Spring & 366 & $3.08(.62)$ & 1.35 & 4.00 & -0.34 \\
Grp Eng. Fall & 290 & $3.14(.38)$ & 1.69 & 4.00 & -0.37 \\
Sex & 366 & $1.47(.50)$ & 1.00 & 2.00 & 0.11 \\
Peer Relatedness & 366 & $3.35(.55)$ & 1.50 & 4.00 & -0.79 \\
Degree & 366 & $4.81(3.99)$ & .00 & 17.00 & 0.52 \\
Person/Grp Diff & 260 & $.00(.56)$ & -1.57 & 1.27 & -0.31 \\
Parental Involvement & 366 & $3.22(.50)$ & 1.20 & 4.00 & -0.69 \\
\hline
\end{tabular}

Note. Student and group engagement, peer relatedness and parental involvement items were on 4-point scales.

Table 5.2.

Summary of Intercorrelations Among Variables of Interest

\begin{tabular}{|c|c|c|c|c|c|c|c|c|c|}
\hline Measure & 1 & 2 & 3 & 4 & 5 & 6 & 7 & 8 & 9 \\
\hline $\begin{array}{l}\text { Student } \\
\text { Eng. Fall }\end{array}$ & $\begin{array}{c}1 \\
\sigma^{2}=0.3 \\
3\end{array}$ & 0.28 & 0.09 & 0.05 & 0.08 & 0.45 & 0.25 & 0.08 & 0.03 \\
\hline $\begin{array}{l}\text { Student } \\
\text { Eng. Spring }\end{array}$ & $\begin{array}{l}.78^{* *} \\
n=366\end{array}$ & $\begin{array}{c}1 \\
\sigma^{2}=0.3 \\
9\end{array}$ & 0.09 & 0.07 & 0.07 & 0.24 & 0.20 & 0.09 & 0.03 \\
\hline $\begin{array}{l}\text { Grp Eng. } \\
\text { Fall }\end{array}$ & $\begin{array}{c}.42 * * \\
n=290\end{array}$ & $\begin{array}{c}.39 * * \\
n=290\end{array}$ & $\begin{array}{c}1 \\
\sigma^{2}=0.1 \\
5\end{array}$ & 0.03 & 0.03 & 0.21 & -0.06 & 0.04 & 0.01 \\
\hline Sex & $\begin{array}{c}.18^{*} \\
n=366\end{array}$ & $\begin{array}{c}.22 * * \\
n=366\end{array}$ & $\begin{array}{c}.17 * * \\
n=290\end{array}$ & $\begin{array}{c}1 \\
\sigma^{2}=0.2 \\
5\end{array}$ & 0.01 & 0.55 & 0.00 & 0.02 & 0.03 \\
\hline $\begin{array}{l}\text { Peer } \\
\text { Relatedness }\end{array}$ & $\begin{array}{c}.24 * * \\
n=366\end{array}$ & $\begin{array}{c}.20 * * \\
n=366\end{array}$ & $\begin{array}{c}.13^{*} \\
n=290\end{array}$ & $\begin{array}{c}.05 \\
n=366\end{array}$ & $\begin{array}{c}1 \\
\sigma^{2}=0.3 \\
0\end{array}$ & 0.30 & 0.06 & 0.13 & 0.04 \\
\hline Degree & $\begin{array}{l}.20^{* *} \\
n=366\end{array}$ & $\begin{array}{c}0.10 \\
n=366\end{array}$ & $\begin{array}{c}.16^{* *} \\
n=290\end{array}$ & $\begin{array}{l}.27 * * \\
n=293\end{array}$ & $\begin{array}{c}.14^{*} \\
n=293\end{array}$ & $\begin{array}{c}1 \\
\sigma^{2}=2.0 \\
8\end{array}$ & 0.06 & 0.08 & 0.12 \\
\hline $\begin{array}{l}\text { Person/Grp } \\
\text { Difference }\end{array}$ & $\begin{array}{l}.77 * * \\
n=260\end{array}$ & $\begin{array}{c}.55^{* *} \\
n=260\end{array}$ & $\begin{array}{c}.27 * * \\
n=260\end{array}$ & $\begin{array}{c}.00 \\
n=260\end{array}$ & $\begin{array}{c}.20 * * \\
n=260\end{array}$ & $\begin{array}{c}.03 \\
n=260\end{array}$ & $\begin{array}{c}1 \\
\sigma^{2}=0.3 \\
1\end{array}$ & 0.06 & 0.02 \\
\hline $\begin{array}{l}\text { Parental } \\
\text { Involvemen } \\
t\end{array}$ & $\begin{array}{c}.27 * * \\
n=366\end{array}$ & $\begin{array}{c}.27 * * \\
n=366\end{array}$ & $\begin{array}{c}.19 * * \\
n=290\end{array}$ & $\begin{array}{c}.07 \\
n=366\end{array}$ & $\begin{array}{c}.45 * * \\
n=366\end{array}$ & $\begin{array}{c}.04 \\
n=366\end{array}$ & $\begin{array}{c}.19 * * \\
n=260\end{array}$ & $\begin{array}{c}1 \\
\sigma^{2}=0.2 \\
5\end{array}$ & 0.03 \\
\hline $\begin{array}{l}\text { Group } \\
\text { Stability }\end{array}$ & $\begin{array}{c}.14^{*} \\
n=293\end{array}$ & $\begin{array}{c}.14^{*} \\
n=293\end{array}$ & $\begin{array}{c}.05 \\
n=289\end{array}$ & $\begin{array}{c}.17 * * \\
n=293\end{array}$ & $\begin{array}{c}.22 * * \\
n=293\end{array}$ & $\begin{array}{c}.09 \\
n=293\end{array}$ & $\begin{array}{c}.10 \\
n=259\end{array}$ & $\begin{array}{c}.16^{* *} \\
n=293\end{array}$ & $\begin{array}{c}1 \\
\sigma^{2}=0.1 \\
4\end{array}$ \\
\hline
\end{tabular}


In addition to examining means, correlations were examined between all the variables using SPSS 17 (See table 5.2). In congruence with Kindermann (2007), student engagement in fall and student engagement in spring showed a high degree of covariation $(r=.78, p<.001)$, indicating high stability in student engagement across the school year. Similarly, the correlation between student engagement in fall and peer engagement in fall was positive and significant $(r=.42, p<.001)$, indicating that students tend to select peer affiliates who are similar to themselves in academic engagement. It was also found that student perception of parental involvement in fall was significantly correlated with teacher-rated student engagement in both fall and spring $(r=.27, p<.01$ and $r=.27, p<.01$, respectively).

Correlations not reported by Kindermann (2007) were also examined. As expected, the correlations between peer relatedness and engagement in fall and spring were positive and significant $(r=.24, p<.01$ and $r=.20, p<.01$, respectively), indicating that feeling close to and accepted by other students is associated with high academic engagement. Also in alignment with expectations, the association between parental involvement and peer relatedness was found to be positive and significant $(r=.45, p<.01)$, suggesting that students who perceive their parents as being involved tend to feel relationally connected their classmates. Because students tend to affiliate with and form friendships with others to whom they are similar, the correlation between person-to-group differences and peer relatedness was expected to be negative and significant. This hypothesis was not supported; specifically, results indicated no significant relationship between these two variables. The relationship between degree centrality and engagement 
in fall was found, as expected, to be positive and significant $(r=.20, p<.01)$, suggesting that individuals who hang out with many peers from school tend to be highly engaged in school. A slight, yet significant, positive correlation between degree centrality and peer relatedness was also found $(r=.14, p<.05)$.

Gender differences in some of the variables were also explored. Consistent with prior findings (Kindermann, 2007), results from an ANOVA suggest that in fall girls were, on average, significantly more engaged in school $(M=3.20, S D=.57)$ than boys $(M=2.99, S D=.59 ; F(1,364)=12.29, p<.001)$. Similarly, in spring girls were, on average, significantly more engaged in school $(M=3.20, S D=.57)$ than boys $(M=2.99, S D=.59$; $F(1,364)=19.34, p<.001)$. Although gender differences in peer relatedness were also expected to be significant, results from an ANOVA indicate no significant differences between boys and girls in their feelings of relatedness toward their peers. As expected, no significant differences between boys and girls were found in perception of parental involvement. Finally, as was expected, mean differences between boys and girls in degree centrality were significant $(F(1,364)=29.62, p<.001)$. Inline with prior findings, results suggest that girls tended to affiliate with a larger number of peers $(M=5.97$, $S D=4.17)$ than did boys $(M=3.51, S D=3.51)$.

\section{Methods Used to Explore the Research Questions}

Multi-group SEM. The set of research questions this study aims to address deal with investigating the extent to which an individual's susceptibility to peer influence may depend on gender, person-to-group differences in engagement, network size or centrality, peer relatedness, and parental involvement. One statistical technique employed in effort 
to explore these questions was multiple-groups structural equation modeling (Kline, 2011; Tabachnick \& Fidell, 2007) with AMOS 17. First, for this analysis, two groups were formed for each moderating variable (male vs. female, high person-to-group difference vs. low person-to-group difference, high vs. low centrality, high vs. low peer relatedness, and high vs. low parental involvement).

In order to determine the extent to which the relationship between peer engagement and student's own engagement may depend upon where a student falls on each of these five variables, model invariance between the two different groups for each variable was explored, with the expectation that the model parameter representing peer influence on change of student's engagement would be different between the two groups (e.g., high vs. low parental involvement).

Using multiple-groups SEM, invariance testing of the model proceeded in three steps for each moderating variable (See figure 5.1). The first step tested the Configural model, and is the least restrictive model. At this step, the same model was tested for the two extreme groups, simultaneously, without any cross-group equality constraints imposed; in other words, both measurement and structural model parameters were allowed to be free to vary between groups. Model fit (particularly $\chi^{2}$ ) was estimated and noted.

In the second step, cross-group equality constraints were imposed upon all factor loadings in the model. Again model fit was estimated, and the $\chi^{2}$ value for this model was compared to the $\chi^{2}$ value of the configural model. Imposing any constraints on a model invariably leads to decease in model-data fit. However, it is important to determine 
whether the addition of model constraints leads to significant reductions in model-data fit. To help in this determination, a chi-square difference test was used. This revealed whether the fit of the constrained model was significantly worse than the unconstrained model. It was hoped that $\Delta \chi^{2}$ would be non-significant. This would indicate that the fit of the constrained model was not significantly worse and that the factor loadings were similar across the two groups, suggesting that the items used in the model measure the same thing in both groups. However, in cases where this expectation was not met, invariance testing of the structural parts of the model proceeded by releasing constraints on some of the factor loadings. In cases where the release of these constraints lead to a non-significant $\Delta \chi^{2}$, then partial measurement equivalence was assumed and the analysis proceeded to the next step (see, Tabachnick \& Fidell, 2007).

In the last step, structural model parameters of interest were constrained to be equal across the groups. Specific to this study, the path from peer engagement in fall to student engagement in spring was constrained to be equal across groups, for each variable. Again, a chi-square difference test was used to determine whether the fit of this more constrained model is significantly worse than the model in which the factor loadings were constrained to be equal across groups. Where significant differences exist between groups (e.g., male vs. female or central vs. peripheral) in their susceptibility to peer influence, the constrained model was expected to fit significantly worse, as indicated by a significant chi-square difference test. Differences between groups in the strength of influence, as indicated by the path coefficient from peer group engagement in fall to engagement in spring, were also expected to be apparent. 
Results: Differential Susceptibility

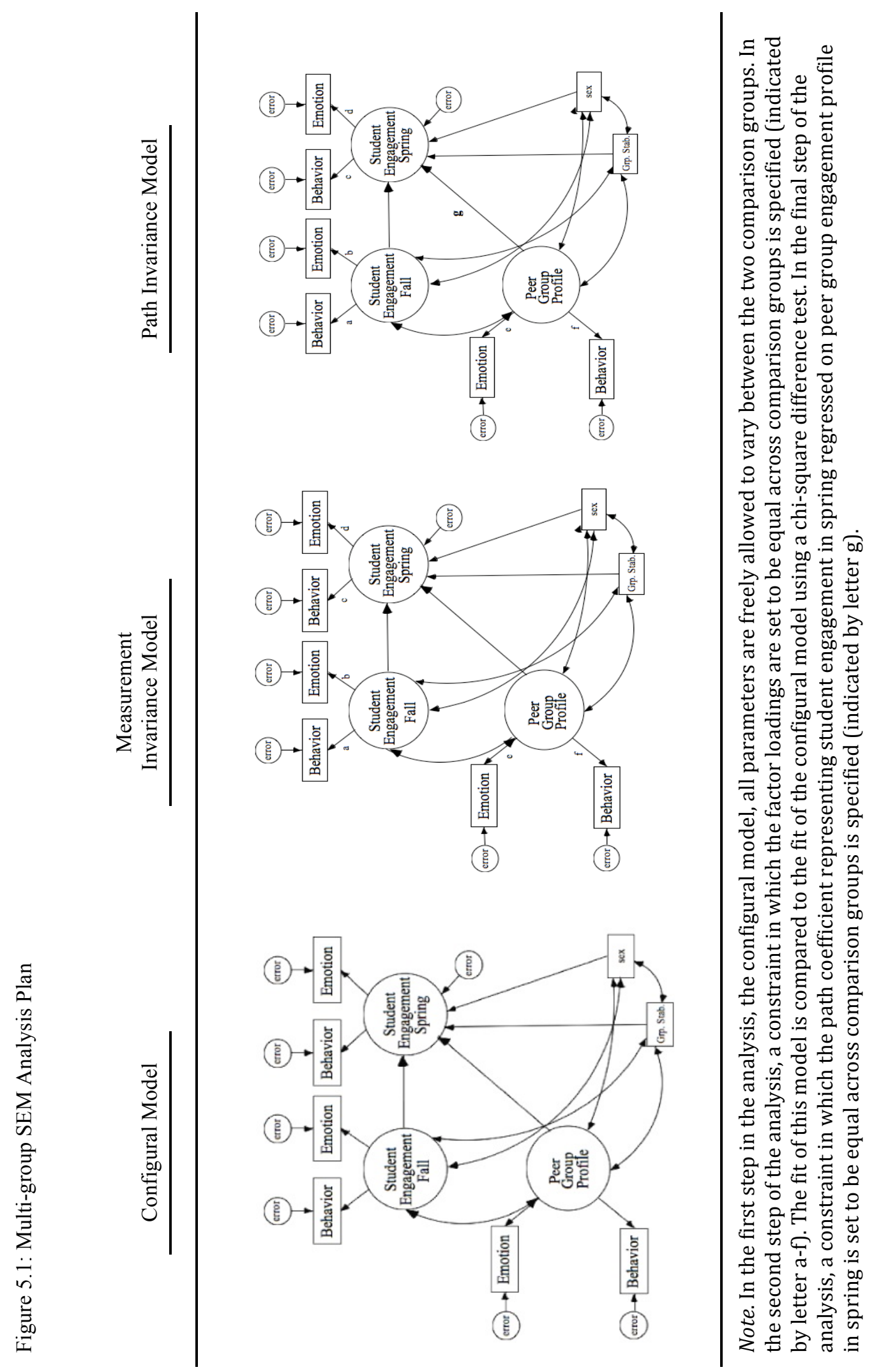


Moderated Path Analysis. To follow up the multiple-groups SEM analyses, gender, degree centrality, status, peer relatedness, parental involvement, and person-togroup differences were each tested as moderating variables in separate Path Analysis models (See Figure 5.2). When interaction terms were found to be significant, the simple regression equations for two levels of the moderating variable (one standard deviation above the mean, one standard deviation below the mean) were plotted together to graphically aid interpretation.

Figure 5.2

Moderated Path Model

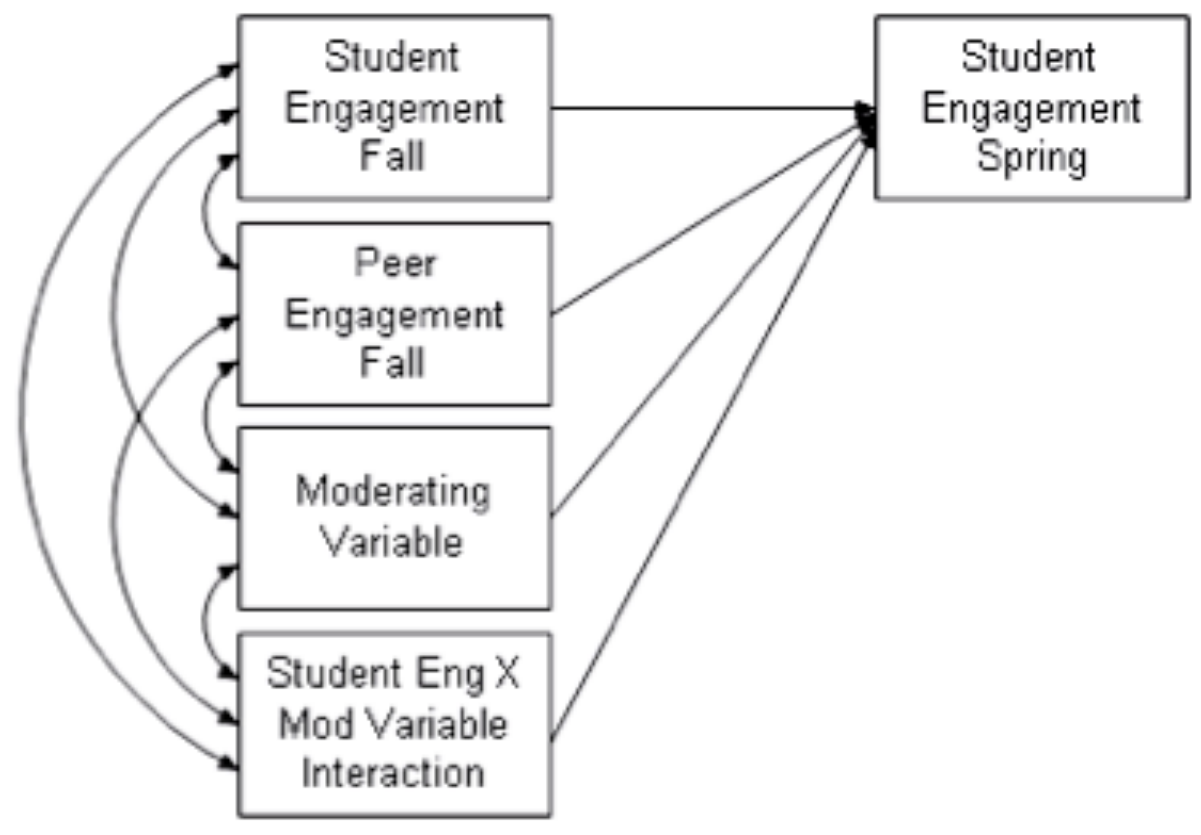

Note. To avoid problem associated with multicollinearity in moderated path models, the interaction terms were computed as the product of mean centered terms. 
Research question 1: Are boys more susceptible to peer influence than girls? A non-significant difference between boys and girls in their susceptibility to peer influence was expected. Specifically, it was expected that boys would be more influenced than girls but that the difference would be non-significant. As expected, results from both sets of analysis suggest a marginal but non-significant difference between boys and girls in their susceptibility to peer influence. However, contrary to expectations, results suggest that, while the difference is slight, female students are more susceptible to influence from their peers compared to male students.

As illustrated by figure 5.3, the configural model of the multiple-groups SEM showed good fit to the data $\left(\chi^{2}(20)=24.04, p>.05, \mathrm{CFI}=1.00, \mathrm{RMSEA}=.02, \mathrm{C} . \mathrm{I} .=.00-\right.$ .05) and highlights interesting model differences between girls and boys. Controlling for both prior engagement and peer group stability, peer group engagement in fall

Figure 5.3

Multigroup SEM Configural Model. Gender differences in peer influence. Female vs. (Male).

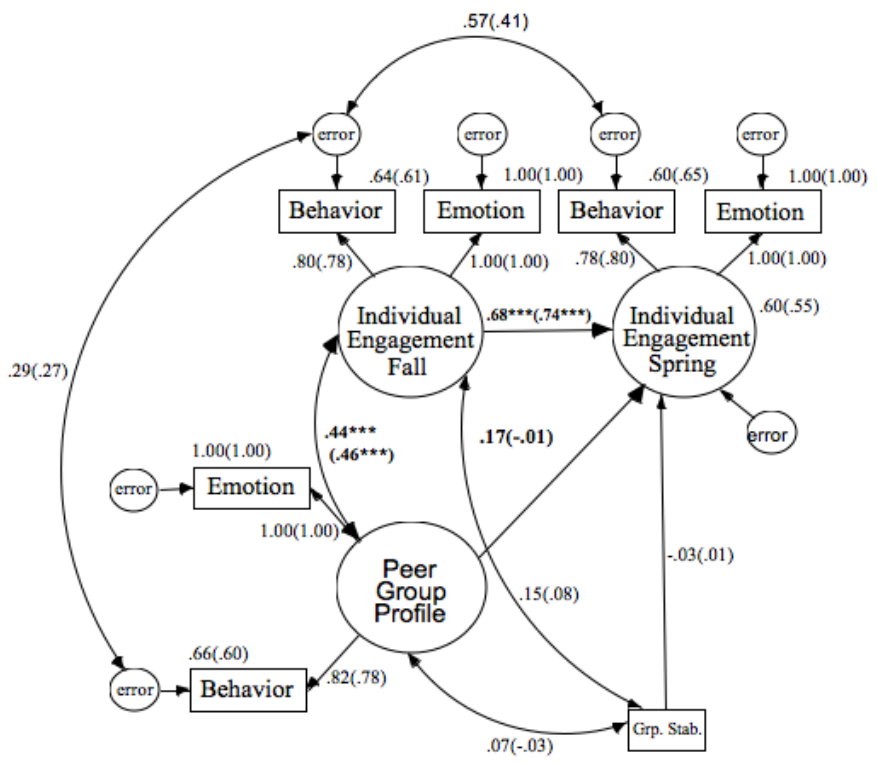

Note. $X^{2}(20)=24.04, p=.24 ; \mathrm{CMIN} / \mathrm{DF}=1.20 ; \mathrm{CFI}=1.00 ; \mathrm{RMSEA}=.02 ; 90 \%$ C.I. $=.00-.05$. $N=366 . * * \mathrm{p}<.001 * * \mathrm{p}<.01 * \mathrm{p}<.05$. Values for male students appear in parentheses. 
significantly predicted student engagement in spring for girls $(r=.17, p<.01)$ but not for boys $(r=-.01, p>.05)$. Whether differences between the two groups were significant was explored in two additional steps.

In the second step (figure 5.4), invariance testing at the measurement-level of the model revealed differences between boys and girls for some of the factor loadings. Specifically, gender differences were found in how the behavioral engagement items loaded onto the peer group engagement factor. In order to proceed with the analysis, this constraint was released and the factor loading was allowed to vary between the groups (see Tabachnick et. al, 2007) and the fit of the resulting model was not found to be significantly worse than the configural model $\left(\Delta \chi^{2}(2)=5.49, p>.05\right)$, suggesting measurement equivalence between boys and girls for the constrained items.

Figure 5.4

Multigroup SEM Measurement Model. Gender differences in peer influence. Female vs. (Male).

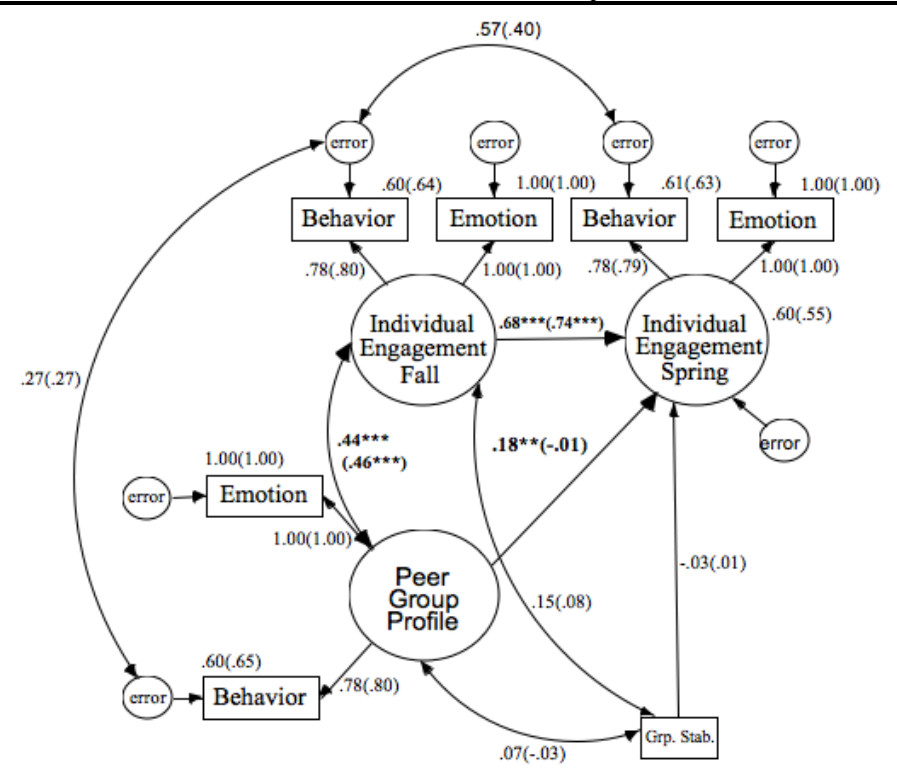

Note. $X^{2}(22)=29.53, p=.13 ; \mathrm{CMIN} / \mathrm{DF}=1.34 ; \mathrm{CFI}=.99 ; \mathrm{RMSEA}=.03 ; 90 \%$ C.I. $=.00-.06$. $\Delta X^{2}(2)=5.49, p>.05 . N=366 .{ }^{* * *} \mathrm{p}<.001 * * \mathrm{p}<.01 * \mathrm{p}<.05$. Values for male students appear in parentheses. 
Figure 5.5

Multigroup SEM Path Invariance Model. Gender differences in peer influence. Female vs. (Male).

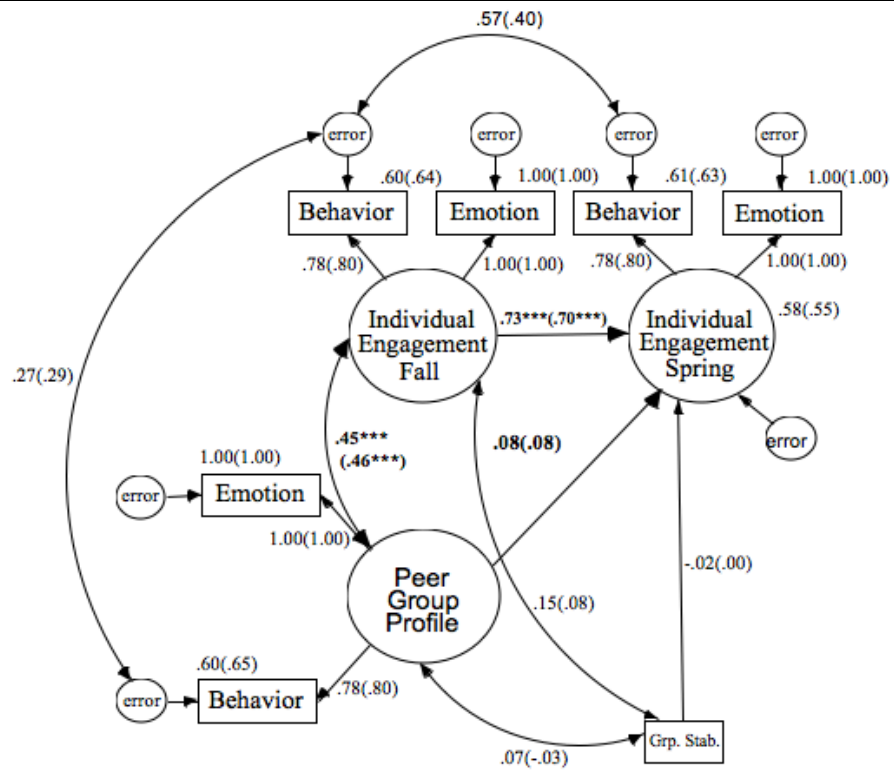

Note. $X^{2}(24)=38.20, p=.03 ; \mathrm{CMIN} / \mathrm{DF}=1.59 ; \mathrm{CFI}=.99 ; \mathrm{RMSEA}=.04 ; 90 \%$ C.I. $=.01-.06$. $\Delta X^{2}(1)=3.27, p>.07 . N=366 . * * * \mathrm{p}<.001 * * \mathrm{p}<.01 * \mathrm{p}<.05$. Values for male students appear in parentheses.

In the last step (figure 5.5), cross-group equality constraints placed on the path of the model representing peer influence (peer group engagement fall $\rightarrow$ student engagement spring) contributed to losses in model fit; however, these losses were not significant $\left(\Delta \chi^{2}(1)=3.24, p>.07\right)$. These results suggest that differences in peer influence between boys and girls may only be marginally significant, and that the possibility that girls' and boys' susceptibilities to peer influence is equivalent cannot be ruled out.

Moderated Path Analysis. Results from a moderated path analysis support the results from the SEM analysis (figure 5.6). As can be seen in the figure, student engagement in fall and sex both significantly predict student engagement in spring ( $b=.74, p<.001, b=.08, p<.05$, respectively). 
Figure 5.6

Moderated Path Model: Peer Group Engagement X Sex

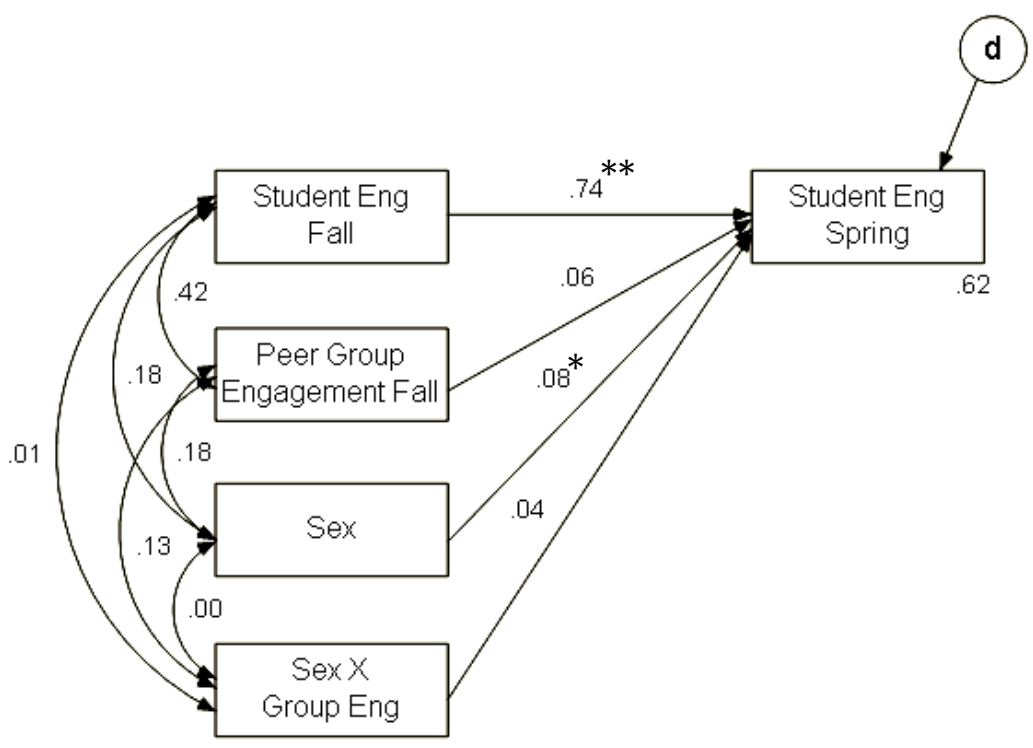

Note. $N=366 .{ }^{* *} p<.001 * \mathrm{p}<.05$.

Moreover, the path coefficient of the interaction variable was found to be nonsignificant $(b=.04, p>.05)$, suggesting no significant moderating effect of peer relatedness on peer group influence of student engagement (See table 5.3 for details).

Generally, results from the path analysis suggest that the extent to which peer group engagement predicts changes in student engagement from fall to spring does not depend upon the sex of the target student.

Table 5.3

Moderated Path Analysis: Group Engagement Spring X Sex

Student Engagement Spring

\begin{tabular}{llll} 
& Variable & \multicolumn{1}{c}{$\beta$} & \\
\hline Student Engagement Fall & $.74^{* *}$ & .81 \\
Peer Group Engagement Fall & .06 & .10 & \\
Sex & $.08^{*}$ & .10 & \\
Grp. Engagement X Sex & .04 & .14 & .62 \\
$\mathrm{R}^{2}$ & & &
\end{tabular}
$\mathrm{R}^{2}$

Note. $N=290 . \mathrm{CI}=$ Confidence Interval. $* * \mathrm{p}<.001 * \mathrm{p}<.05$ 
Research question 2: Are students who feel close to their peers and have a strong sense of belonging in their peer group more susceptible to peer influence than students who lack a sense of group belongingness or peer relatedness? A significant difference between highly peer-related students and less peer-related students in their susceptibility to peer influence was expected. Specifically, it was expected that students who feel a strong relational bond to peer affiliates (high peer-relatedness) should be more influenced by their peers than students who experience a weak relational bond to their peer affiliates (low peer-relatedness). Results from both sets of analyses failed to support this hypothesis. Contrary to what was expected, results from a multiple-groups SEM analysis suggest no difference between high peer-related students and low peer-related students in their susceptibility to peer influence. Similarly, results from the moderated path analysis suggest no significant moderating effect of peer relatedness.

Multiple-groups SEM. For the multiple-groups analysis, a high peer-relatedness group $(n=122)$ and a low peer-relatedness group $(n=121)$ were formed with individuals who reported the highest third and lowest third peer-relatedness, respectively. The two groups differed significantly in their reports of peer-relatedness $(F(1,241)=1170.26$, $p<.001)$. Students who made up the high peer-relatedness group were on average more highly related toward their peers $(M=3.92, S D=.11)$ than students who made up the low peer-relatedness group $(M=2.71, S D=.38)$. Furthermore, students who felt close to their age mates were more engagement in fall $(M=3.23, S D=.56)$ and spring $(M=3.18$, $S D=.62)$ than students who did not feel related to their peers $(M=2.91, S D=.58$, in fall; $M=2.92, S D=.64$, in spring). Significant differences were also found between the two 
groups in the school engagement of the peers with whom they choose to affiliate $(F(1,192)=5.96, p<.05)$. Students who felt close to their peers typically affiliated with peers who were more engaged $(M=3.21, S D=.39)$ compared to the peers with whom less peer-related students spent most of their time with $(M=3.08, S D=.39)$.

As illustrated by figure 5.7, the configural model of the multiple-groups SEM shows good fit to the data $\left(\chi^{2}(26)=36.39, p>.05, \mathrm{CFI}=.99, \mathrm{RMSEA}=.04\right.$, C.I. $\left.=.00-.06\right)$ and highlights interesting model differences between the high and low peer-relatedness groups. Controlling for sex, peer group stability, and prior engagement, peer group engagement in fall predicted student engagement in spring at only a marginally significant level for the low-relatedness group $(r=.11, p>.05)$. Fall peer group engagement did not significantly predict student engagement in spring for the high-

Figure 5.7

Multigroup SEM Configural Model. Group differences in peer influence. Low vs. High Peer Relatedness.

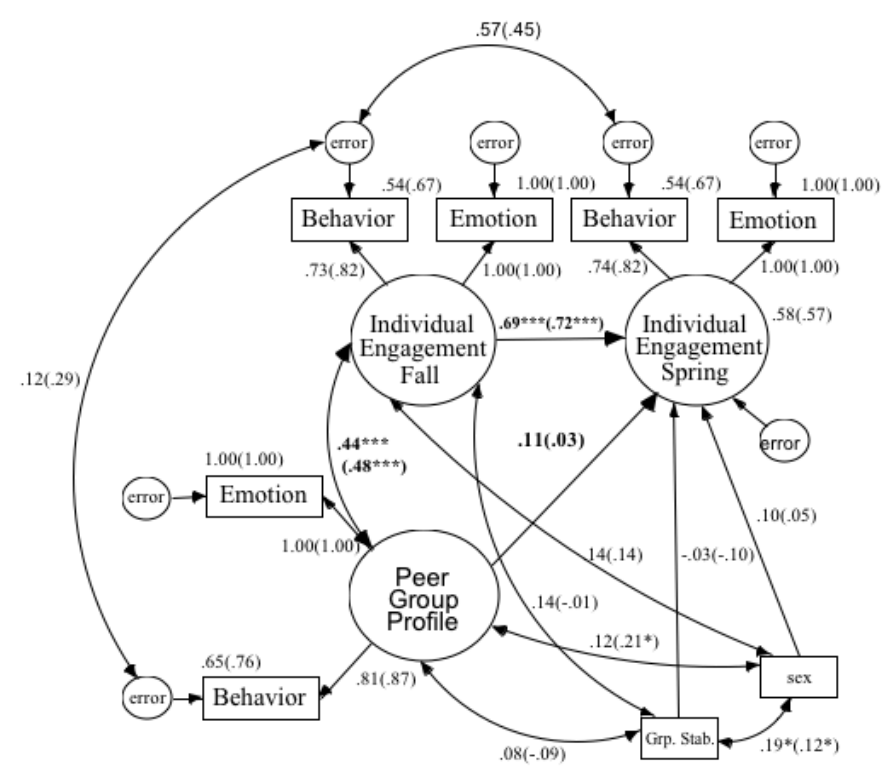

Note. $X^{2}(26)=36.39, p=.09 ; \mathrm{CMIN} / \mathrm{DF}=1.40 ; \mathrm{CFI}=.99 ; \mathrm{RMSEA}=.04 ; 90 \%$ C.I. $=.00-.06$. $N=366 . * * * \mathrm{p}<.001 * \mathrm{p}<.05$. Values for high peer-relatedness students appear in parentheses. 
relatedness group $(r=.03, p>.05)$. Although the predictive paths were found to be nonsignificant for both groups, there were differences between the two groups. Whether these differences were significant was explored in the following two steps.

In the second step (figure 5.8), invariance testing at the measurement-level of the model revealed no significant reductions in fit (compared to the configural model; $\left.\Delta \chi^{2}(3)=0.30, p>.05\right)$ when cross-group equality constraints were placed on the factor loadings, indicating that measurement items functioned similarly across the groups. In the last step (figure 5.9), cross-group equality constraints placed on the path of the model representing peer influence (peer group engagement fall $\rightarrow$ student engagement spring) did not contribute to a significant loss in model fit $\left(\Delta \chi^{2}(1)=.70, p<.004\right)$. This result fails to support the hypothesis that significant differences in susceptibility to peer

Figure 5.8

Multigroup SEM Measurement Model. Group differences in peer influence. Low vs. High Peer Relatedness.

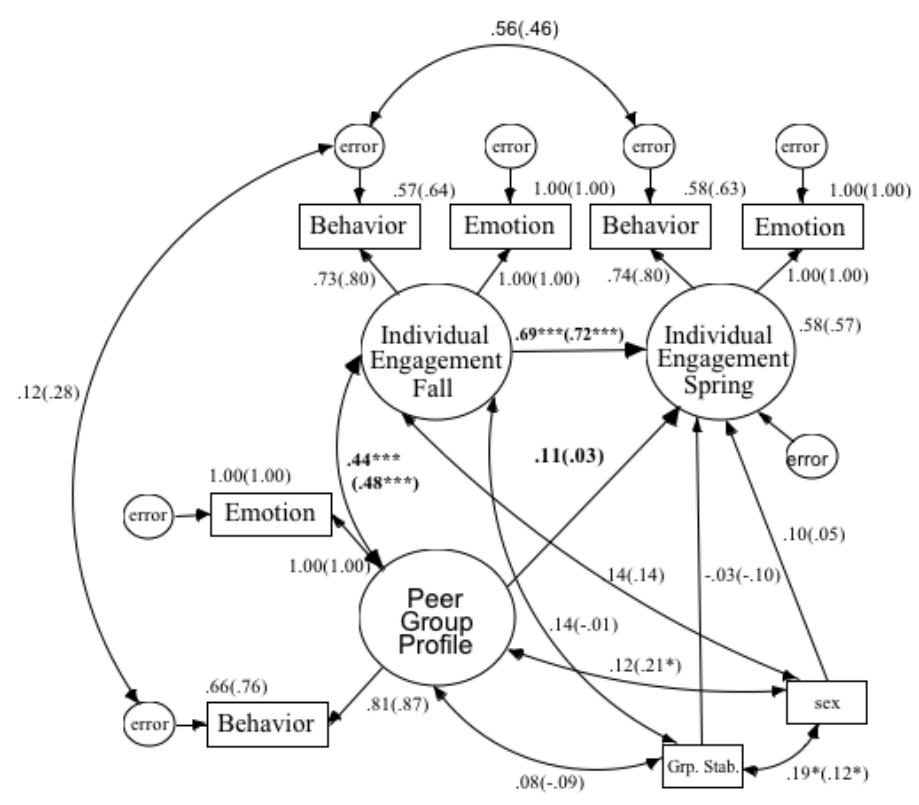

Note. $X^{2}(29)=40.02, p=.08 ; \mathrm{CMIN} / \mathrm{DF}=1.38 ; \mathrm{CFI}=.99 ; \mathrm{RMSEA}=.04 ; 90 \%$ C.I. $=.00-.06$. $\Delta X^{2}(3)=3.63, p>.05 . N=366 . * * * \mathrm{p}<.001 * * \mathrm{p}<.01 * \mathrm{p}<.05$. Values for high peer-relatedness students appear in parentheses. 
Figure 5.9

Multigroup SEM Path Invariance Model. Group differences in peer influence. Low vs. High Peer Relatedness.

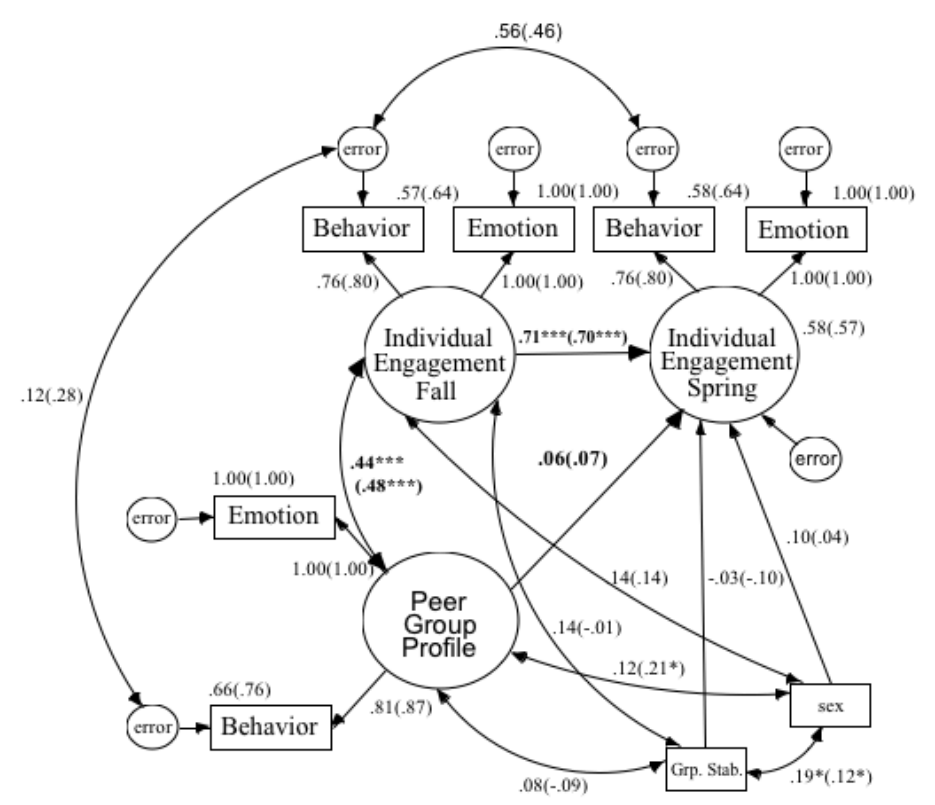

Note. $X^{2}(30)=40.72, p=.09 ; \mathrm{CMIN} / \mathrm{DF}=1.36 ; \mathrm{CFI}=.99 ; \mathrm{RMSEA}=.04 ; 90 \%$ C.I. $=.01-.06$. $\Delta X^{2}(1)=.70, p>.05 . N=366 . * * * \mathrm{p}<.001 * \mathrm{p}<.05$. Values for high peer-relatedness students appear in parentheses.

influence exist between highly peer-related students and less peer-related students. These results suggest that students who lack a feeling of closeness to their peers may be as susceptible to peer influence of their academic engagement students who feel very close to peers they spend time with.

Moderated Path Analysis. Results from a moderated path analysis support the results from the SEM analysis (figure 5.10). As can be seen in the figure, student engagement in fall, and group engagement in fall, both significantly predict student engagement in spring ( $b=.74, p<.001, b=.08, p<.05$, respectively). However peer relatedness did not significantly predict student engagement in spring $(b=.01, p>.05)$; moreover, the path coefficient of interaction variable is nonsignificant $(b=-.04, p>.05)$, 
indicating that there is not a significant moderating effect of peer relatedness on peer group influence on student engagement. Generally, results from the path analysis suggest that the extent to which peer group engagement predicts changes in student engagement from fall to spring does not depend upon how close to their peers a student feels (See table 5.4 for details).

Figure 5.10

Moderated Path Model: Peer Group Engagement X Peer Relatedness.

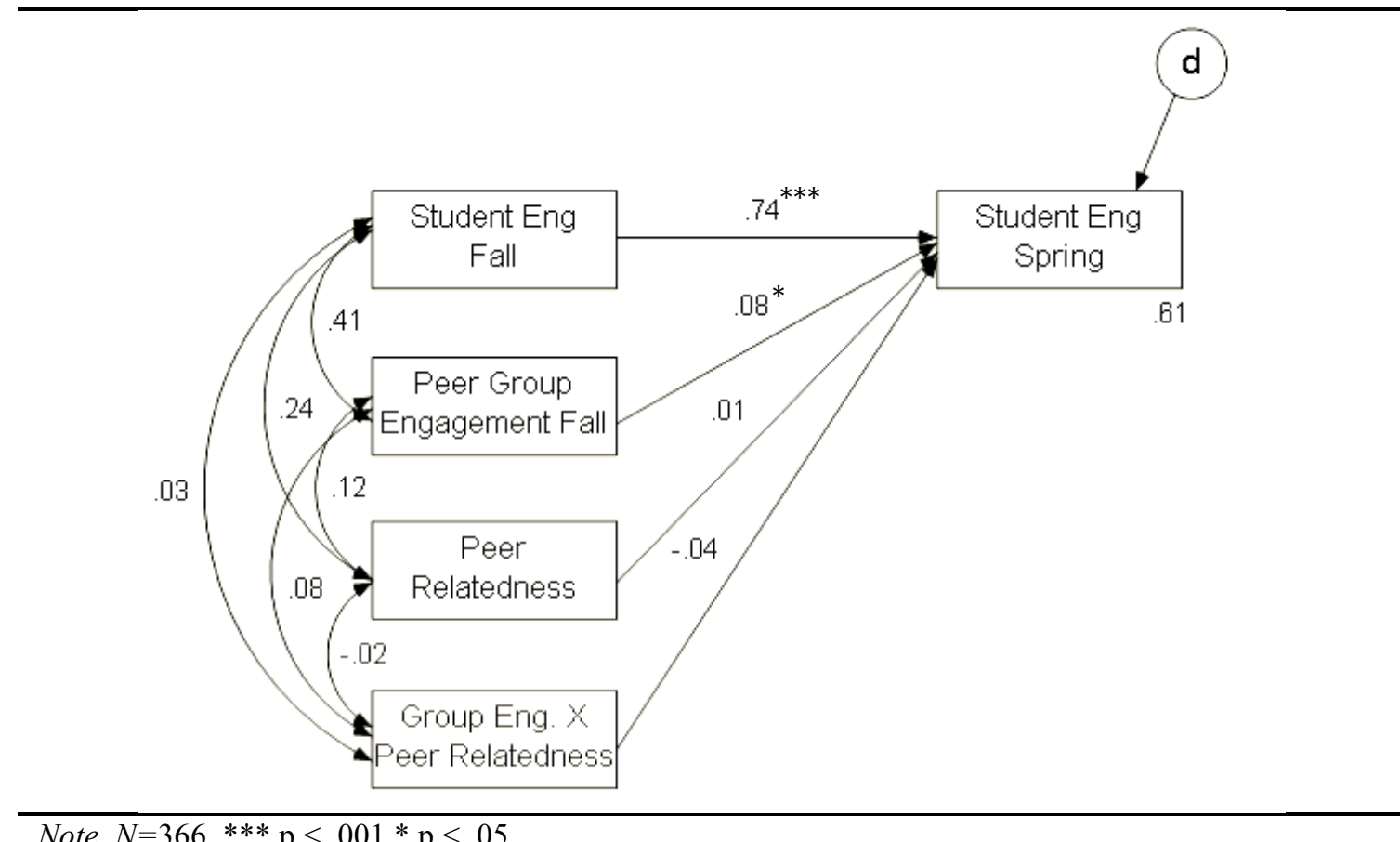

Note. $N=366 . * * * \mathrm{p}<.001 * \mathrm{p}<.05$.

Table 5.4

Moderated Path Analysis: Group Engagement Spring X Peer Relatedness

Student Engagement Spring

\begin{tabular}{|c|c|c|c|}
\hline Variable & $\beta$ & $\mathrm{B}$ & \\
\hline Student Engagement Fall & $.74 * *$ & .81 & \\
\hline Peer Group Engagement Fall & $.08 *$ & .13 & \\
\hline Peer Relatedness & .01 & .01 & \\
\hline Grp. Engagement X Peer Relatedness & -.04 & -.11 & \\
\hline $\mathrm{R}^{1^{1}}$ & & & .61 \\
\hline
\end{tabular}

Note. $N=290 . \mathrm{CI}=$ Confidence Interval. $* * \mathrm{p}<.001 * \mathrm{p}<.05 \dagger \mathrm{p}<.10$ 
Research question 3: Are students who hang out with many peer affiliates (high degree centrality) more susceptible to influence by their peers than students who hang out with few peer affiliates (low degree centrality)? A significant difference between high-centrality students and low-centrality students in their susceptibility to peer influence was expected. Specifically, it was expected that students who have a relatively large number of peer affiliates (high degree centrality) would be more influenced than students who have a relatively small number of peer affiliates (low degree centrality). The two sets of analysis offer contradicting results. No significant difference between highly central students and least central students in their susceptibility to peer influence was found using multiple-groups SEM analysis. However, contrary to these findings, results from a moderated path analysis suggest that students who are socially well connected to their peers are more susceptible to influence from their peers compared to students who are socially less well connected to their peers. Details of both sets of analyses are discussed below.

Multiple-groups SEM. For the multiple-groups SEM analysis, a high degree group $(n=124)$ and a low degree group $(n=118)$ were formed with individuals who received the highest third and lowest third degree scores, respectively. The two groups differed significantly in network degree centrality $(F(1,240)=961.50, p<.001)$. On average students in the high degree group affiliated with over three times as many peers $(M=9.51$, $S D=2.61)$ than students in the low degree group $(M=2.54, S D=1.19)$ and marginally in engagement in fall ( 3.20 vs. $3.07 ; F(1,240)=3.65, p<.06$; but not in spring; 3.12 vs. 3.10 ; $F(1,240)=.03, p>.05)$. Furthermore, marginally significant differences were found 
Figure 5.11

Multigroup SEM Configural Model. Group differences in peer influence. Low vs. High Centrality.



Note. $X^{2}(26)=34.12, p=.13 ; \mathrm{CMIN} / \mathrm{DF}=1.31 ; \mathrm{CFI}=.99 ; \mathrm{RMSEA}=.04 ; 90 \%$ C.I. $=.00-.07 .{ }^{* * *}$ $\mathrm{p}<.001 * * \mathrm{p}<.01 * \mathrm{p}<.05$. Values for highly central students appear in parentheses.

between the two groups in the school engagement of the peers with whom they choose to affiliate $(3.17$ vs. $3.08 ; F(1,237)=3.43, p<.07)$.

As illustrated by figure 5.11, the configural model of the multiple-groups SEM shows good fit to the data $\left(\chi^{2}(26)=34.12, p>.05, \mathrm{CFI}=.99, \mathrm{RMSEA}=.04\right.$, C.I. $\left.=.00-.07\right)$ but highlights only slight model differences between high-degree students and lowdegree students. Controlling for both prior engagement and peer group stability, peer group engagement in fall did not significantly predict student engagement in spring for low-degree students $(\mathrm{r}=.07, p>.05)$, and significantly predicted student engagement only marginally for high-degree students $(\mathrm{r}=.11, p<.12)$. Whether differences between the two groups were significant was explored in the following two steps.

In the second step (figure 5.12), invariance testing at the measurement-level of the model revealed differences between high- and low-degree students for some of the factor 
Figure 5.12

Multigroup SEM Measurement Model. Group differences in peer influence. Low vs. High Centrality.

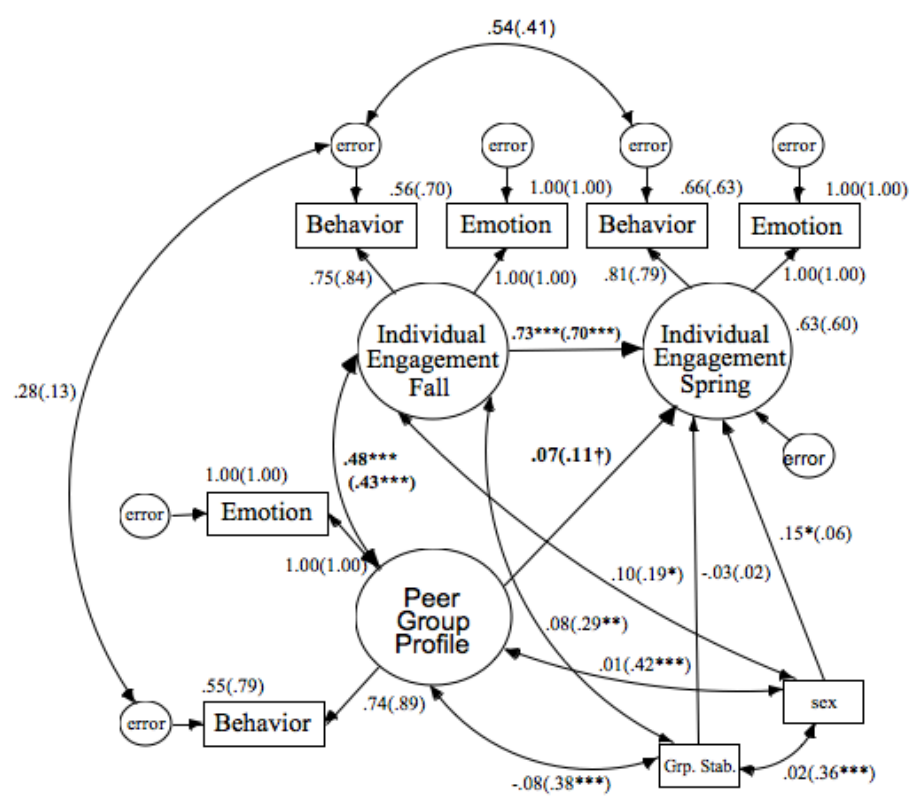

Note. $X^{2}(28)=41.19, p=.05 ; \mathrm{CMIN} / \mathrm{DF}=1.47 ; \mathrm{CFI}=.99 ; \mathrm{RMSEA}=.04 ; 90 \%$ C.I. $=.00-.07$. $\Delta X^{2}(2)=5.10, p>.05 . * * * \mathrm{p}<.001 * * \mathrm{p}<.01 * \mathrm{p}<.05$. Values for highly central students appear in parentheses.

loadings. Specifically, differences were found in how the emotional engagement item loaded onto the peer group engagement factor. In order to proceed with the analysis, this constraint was released and the factor loading was allowed to vary between the groups (see Tabachnick et. al, 2007) and the fit of the resulting model was not found to be significantly worse than the configural model $\left(\Delta \chi^{2}(2)=5.10, p>.05\right)$, suggesting partial measurement equivalence between boys and girls for the constrained items.

In the last step (figure 5.13), cross-group equality constraints placed on the path of the model representing peer influence (peer group engagement fall $\rightarrow$ student engagement spring) contributed to losses in model fit; however, these losses were not significant $\left(\Delta \chi^{2}(1)=.64, p>.05\right)$. These results suggest that differences in susceptibility to 
Figure 5.13

Multigroup SEM Path Invariance Model. Group differences in peer influence. Low vs. High Centrality.

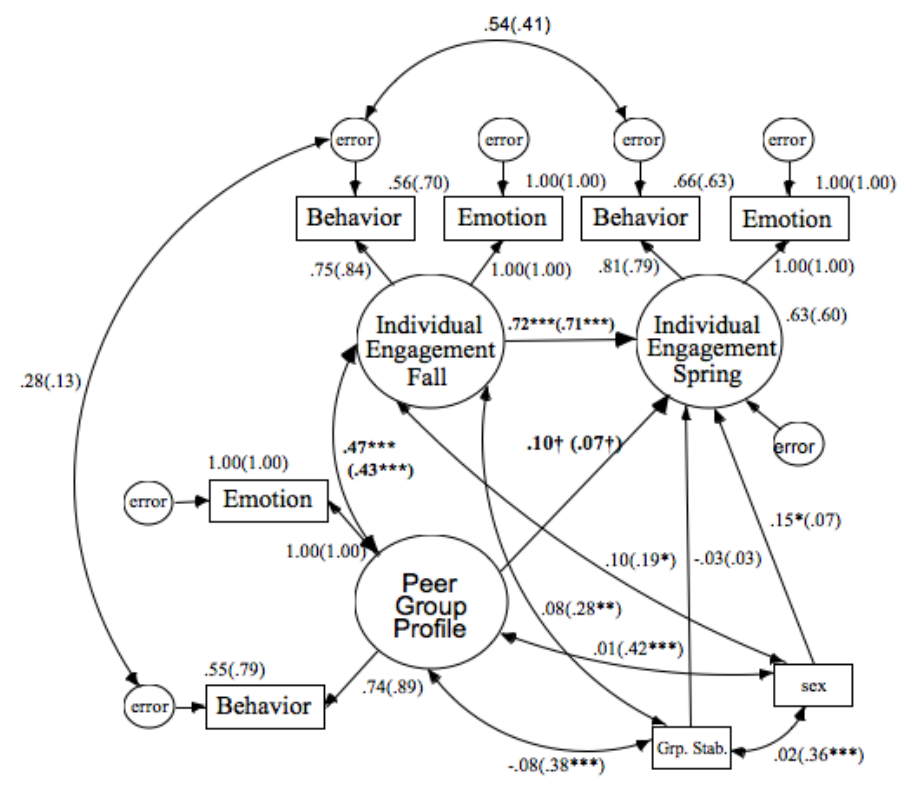

Note. $X^{2}(29)=41.62, p=.06 ; \mathrm{CMIN} / \mathrm{DF}=1.44 ; \mathrm{CFI}=.99 ; \mathrm{RMSEA}=.04 ; 90 \%$ C.I. $=.00-.07$. $\Delta X^{2}(1)=0.43, p>.05 . * * * \mathrm{p}<.001 * * \mathrm{p}<.01 * \mathrm{p}<.05$. Values for highly central students appear in parentheses.

peer influence between highly central students and less central students (by degree) are not significant, and that students who tend to hang out with many peers are not more susceptible to peer influence than students who hang out with fewer peers.

Moderated Path Analysis. Results from a moderated path analysis paint a different picture (figure 5.14). As can be seen in the figure, student engagement in fall, group engagement in fall, and degree centrality all significantly predict student engagement in spring $(b=.75, p<.001, b=.12, p<.01$, and $b=.07, p<.05$, respectively). Interestingly, the path coefficient of the interaction variable was significant $(b=.09$, $p<.05)$, indicating a significant moderating effect of centrality on peer group influence of student engagement. Contrary to results of the multiple groups SEM, results from the path analysis suggest that the extent to which peer group engagement predicts changes in 
student engagement from fall to spring depends upon how many peers an individual frequently interacts with (see table 5.5 for details). Specifically, as illustrated by the interaction plot seen in figure 5.15, the relationship between peer group engagement in fall and students' engagement in spring is stronger for students who tend to affiliate with a larger group of peers.

Figure 5.14

Moderated Path Model: Peer Group Engagement X Degree Centrality

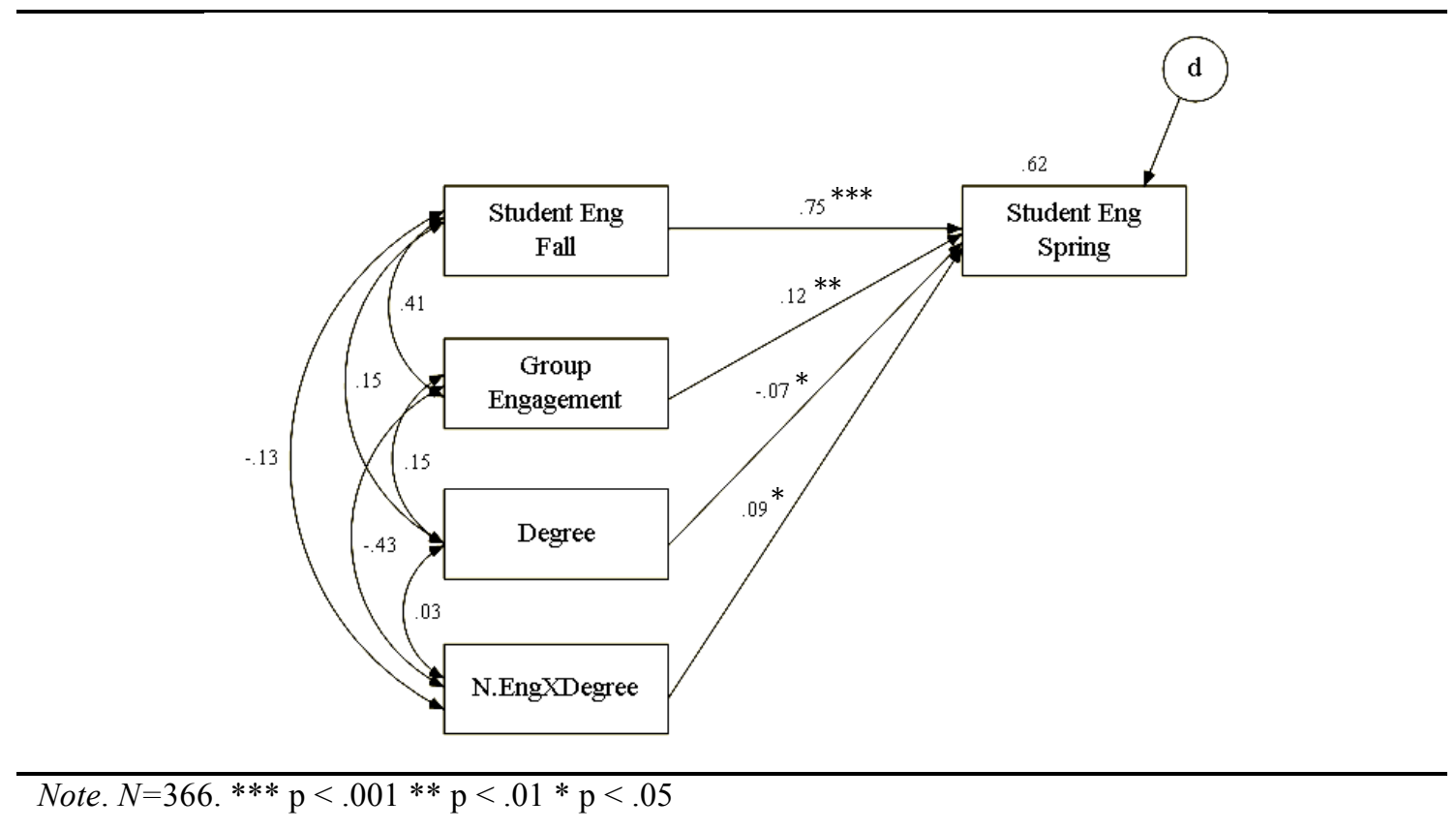

Table 5.5

Moderated Path Analysis: Group Engagement Spring X Degree

\begin{tabular}{lccc}
\hline & \multicolumn{3}{c}{ Student Engagement Spring } \\
\cline { 2 - 4 } & Variable & $\beta$ & $\mathrm{B}$ \\
\hline Student Engagement Fall & $.75^{* * *}$ & .82 \\
Peer Group Engagement Fall & $.12^{* *}$ & .20 & \\
Degree & $-.07^{*}$ & -.01 & \\
Grp. Engagement X Degree & $.09^{*}$ & .04 & \\
$\mathrm{R}^{2}$ & & & .62 \\
\hline Note. $N=290 . \mathrm{CI}=$ Confidence Interval. $* * * \mathrm{p}<.001 * * \mathrm{p}<.01 * \mathrm{p}<.05 \dagger \mathrm{p}<.10$ &
\end{tabular}


Figure 5.15

Group engagement X Degree interaction plot

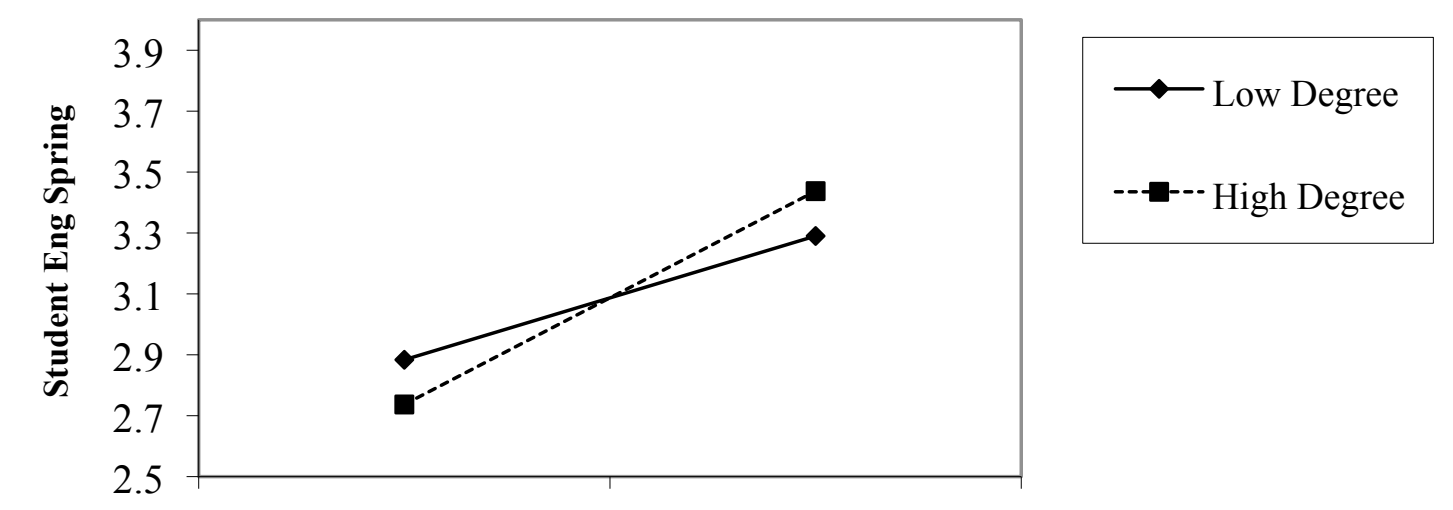

Low Group Engagement High Group Engagement

Research question 4: Are students whose parents are highly involved in their academic lives less susceptible to peer influence than students whose parents are less involved? A significant difference in susceptibility to peer influence between students whose parents are highly involved in their school lives and students whose parents are less involved in their school lives was expected. Specifically, it was expected that students whose parents are highly involved (high parental involvement) would be less susceptible to peer influence than students whose parents are less involved (low parental involvement). As expected, results from both sets of analysis suggest a significant difference between high parental involvement students and low parental involvement students in their susceptibility to peer influence. More specifically, results from these analyses suggest that peer influence may be stronger for individuals whose parents are uninvolved. 
Multiple-groups SEM. For the multiple-groups analysis, a high parental involvement group $(n=126)$ and a low parental involvement group $(n=128)$ were formed with individuals who reported the highest third and lowest third parental involvement scores. The two groups differed significantly in their experiences of parental involvement (3.73 vs. $2.66 ; F(1,252)=1062.83, p<.001)$, and engagement in fall and spring (3.28 vs. $2.95 ; F(1,252)=20.59, p<.001$; and 3.27 vs. $2.92 ; F(1,252)=20.28, p<.001$, respectively). Furthermore, significant differences were found between the two groups in the school engagement of the peers with whom they choose to affiliate (3.25 vs. 3.06;

$F(1,206)=12.95, p<.001)$.

Figure 5.16

Multigroup SEM Configural Model. Group differences in peer influence. Low vs. High Parental Involvement.

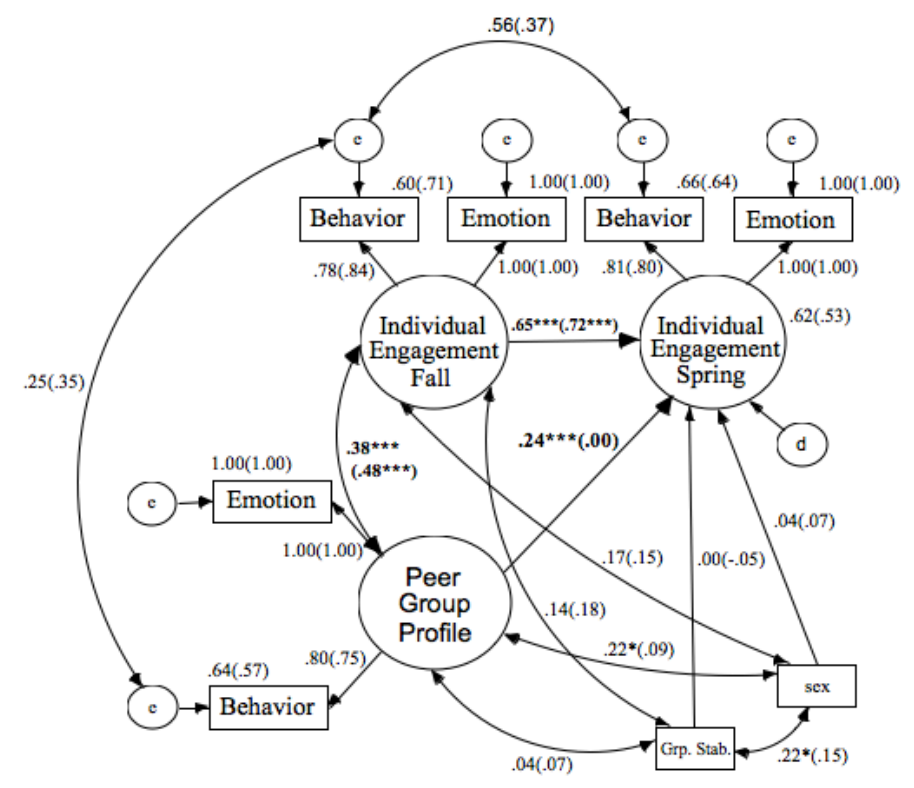

Note. $X^{2}(26)=19.65, p=.81 ; \mathrm{CMIN} / \mathrm{DF}=.76 ; \mathrm{CFI}=1.00 ; \mathrm{RMSEA}=.00 ; 90 \%$ C.I. $=.00-.03$. $N=366 . * * * \mathrm{p}<.001 * \mathrm{p}<.05$. Values for students who have highly involved parents appear in parentheses. 
As illustrated by figure 5.16, the configural model of the multiple-groups SEM shows good fit to the data $\left(\chi^{2}(26)=19.65, p>.05, \mathrm{CFI}=1.00, \mathrm{RMSEA}=.00, \mathrm{C} . \mathrm{I} .=.00-.03\right)$ and highlights interesting model differences between the high and low parental involvement groups. Controlling for sex, peer group stability, and prior engagement, peer group engagement in fall significantly predicted student engagement in spring for the low parental involvement group $(\mathrm{r}=.24, p<.001)$ but not for the high parental involvement group $(\mathrm{r}=.00, p>.05)$. Whether differences between the two groups were significant was explored in the following two steps.

In the second step (figure 5.17), invariance testing at the measurement-level of the model revealed no significant reductions in fit (compared to the configural model; $\left.\Delta \chi^{2}(3)=0.17, p>.05\right)$ when cross-group equality constraints were placed on the

\section{Figure 5.17}

Multigroup SEM Measurement Model. Group differences in peer influence. Low vs. High Parental Involvement.

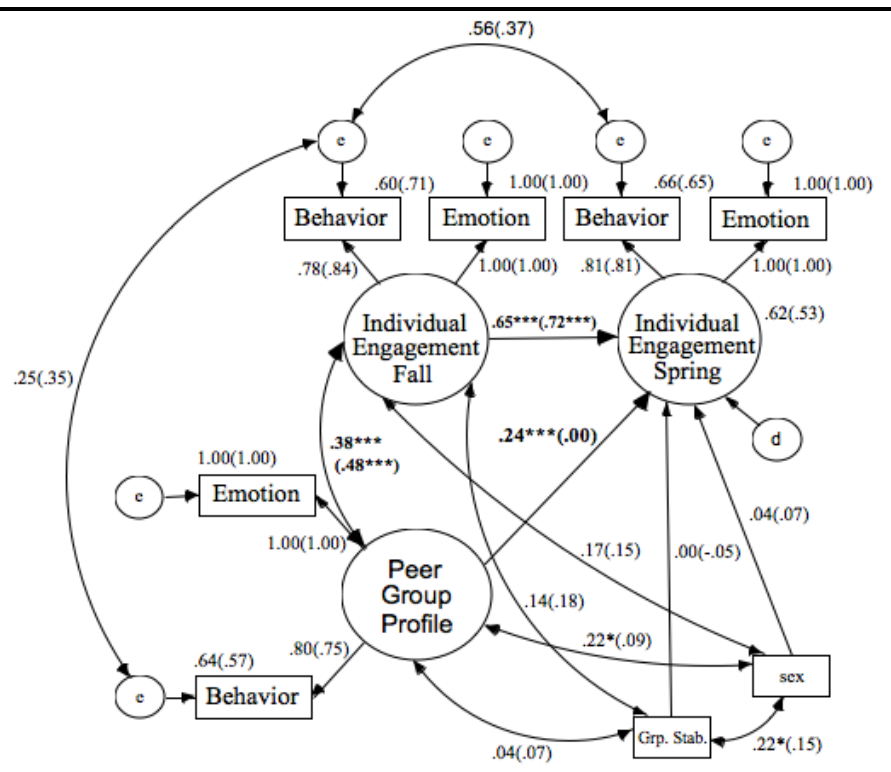

Note. $X^{2}(29)=19.82, p=.90 ; \mathrm{CMIN} / \mathrm{DF}=.68 ; \mathrm{CFI}=1.00 ; \mathrm{RMSEA}=.00 ; 90 \%$ C.I. $=.00-.02 ;$ $\Delta X^{2}(3)=.17, \mathrm{p}>.05 . N=366 . * * * \mathrm{p}<.001 * \mathrm{p}<.05$. Values for students who have highly involved parents appear in parentheses. 
Figure 5.18

Multigroup SEM Path Invariance Model. Group differences in peer influence. Low vs. High Parental Involvement.

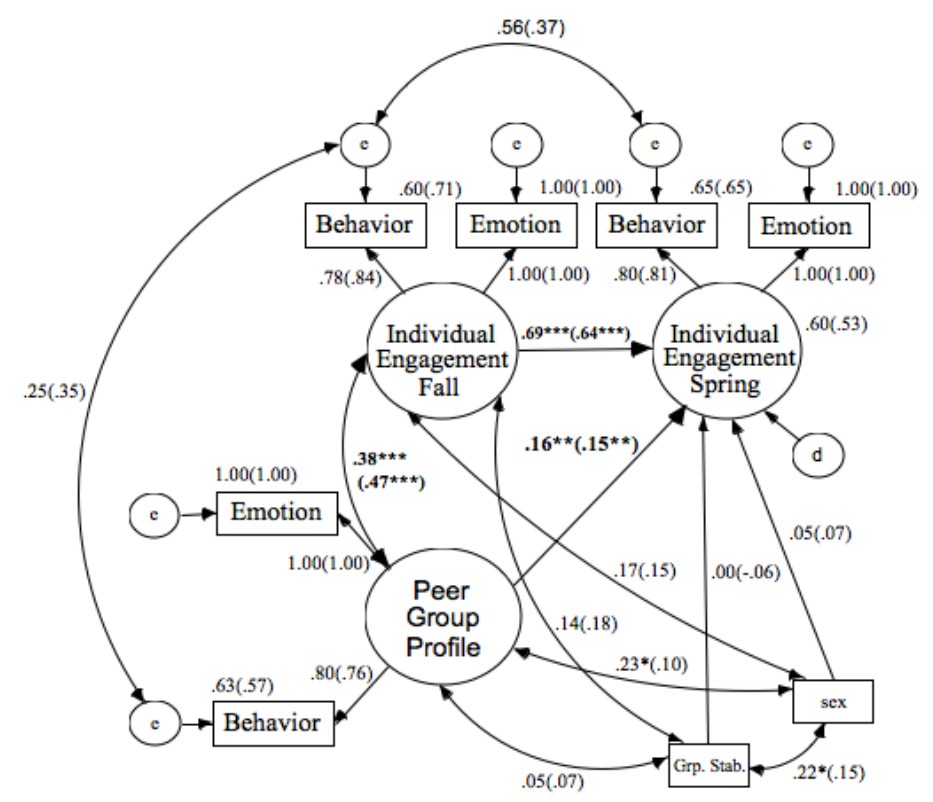

Note. $X^{2}(30)=24.12, p=.77 ; \mathrm{CMIN} / \mathrm{DF}=.80 ; \mathrm{CFI}=1.00 ; \mathrm{RMSEA}=.00 ; 90 \%$ C.I. $=.00-.03$; $\Delta X^{2}(1)=4.30, p=.038 . N=366 . * * * \mathrm{p}<.001 * \mathrm{p}<.05$. Values for students who have highly involved parents appear in parentheses.

factor loadings, indicating that measurement items functioned similarly across the groups.

In the last step (figure 5.18), cross-group equality constraints placed on the path of the model representing peer influence (peer group engagement fall $\rightarrow$ student engagement spring) contributed to significant losses in model fit $\left(\Delta \chi^{2}(1)=4.30, p<.05\right)$. These results suggest that significant differences in susceptibility to peer influence exist between students who experience their parents as highly involved and students who experience their parents as uninvolved; specifically, results suggest that students whose parents are uninvolved may be more susceptible to peer influence of their academic engagement than students who experience their parents as being involved. 
Figure 5.19

Moderated Path Model: Peer Group Engagement X Parental Involvement

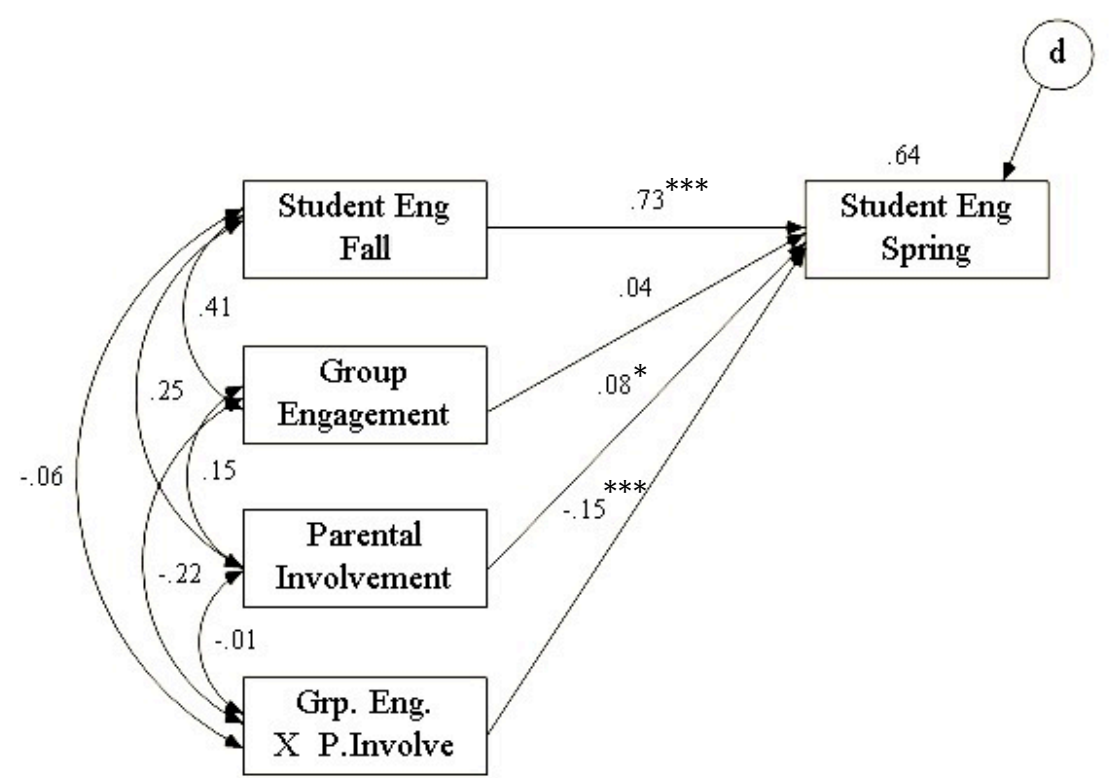

Note. $N=366 .{ }^{* * *} \mathrm{p}<.001 * * \mathrm{p}<.01 * \mathrm{p}<.05$

Moderated Path Analysis. Results from a moderated path analysis support findings from the multiple-groups SEM analysis (figure 5.19). As can be seen in the figure, student engagement in fall and parental involvement both significantly predicted student engagement in spring $(\mathrm{b}=.73, p<.001 ; \mathrm{b}=.08, p<.05)$. Moreover, the path coefficient of interaction variable is significant $(b=-.15, p>.01)$, indicating a moderating effect of parental involvement on peer group influence of student engagement. Generally, results from the path analysis suggest that the extent to which peer group engagement predicts changes in student engagement from fall to spring depends upon how involved a student's parents are (see table 5.6 for details). The interaction plot in figure 5.20 reveals that the relationship between peer group engagement in fall and students' engagement in spring is strongest for students who experience their parents as uninvolved. These results represent supportive evidence that students who experience 
Table 5.6

Moderated Path Analysis: Peer Group Engagement X Parental Involvement

\begin{tabular}{llcl}
\hline & \multicolumn{3}{c}{ Student Engagement Spring } \\
\cline { 2 - 4 } \multicolumn{1}{c}{ Variable } & \multicolumn{2}{c}{$\beta$} & $\mathrm{B}$ \\
\hline Student Engagement Fall & $.73^{* * *}$ & .80 & \\
Peer Group Engagement Fall & .04 & .06 & \\
Parental Involvement & $.08^{*}$ & .10 & \\
Grp. Engagement X Parental Involvement & $-.15^{* *}$ & -.42 & .63 \\
$\mathrm{R}^{2}$ & & & \\
\hline Note. $N=290 . \mathrm{CI}=$ Confidence Interval. ${ }^{* * *} \mathrm{p}<.001^{* *} \mathrm{p}<.01$ & & &
\end{tabular}

Figure 5.20 Group engagement $X$ parental involvement interaction plot

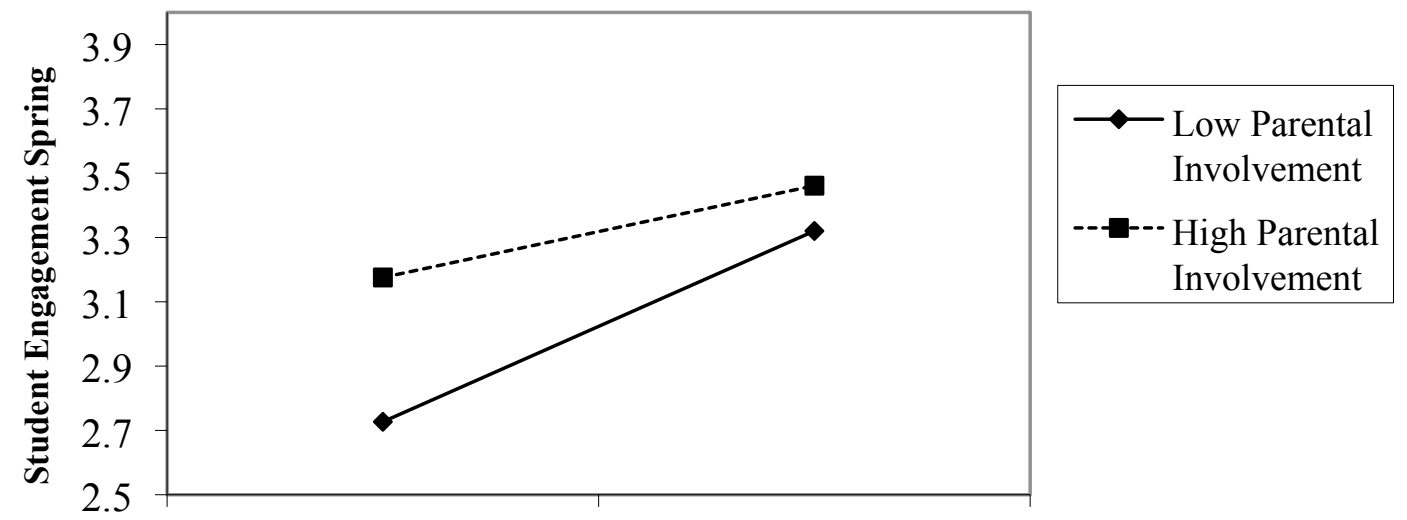

Low Group Engagement High Group Engagement

their parents as being uninvolved may be more susceptible to peer influence on the development of their own engagement.

Research question 5: Are students whose engagement in school is different than their peers more susceptible to peer influence than students whose school engagement is similar to their peers' engagement? A significant difference in peer group susceptibility was expected between students whose own engagement differed highly from that of their peers and students whose own engagement differed little. Specifically, it was expected that students who differed greatly from their peers (high person-to-group difference) 
would be more susceptible to peer influence than students who differed little (low personto-group difference). Results from both sets of analysis support this hypothesis, and suggest a significant difference between these two types of students. More specifically, results from these analyses suggest that peer influence may be stronger for individuals who spend much of their time with peers who, compared to them, are not similarly engaged in academics.

Multiple-groups SEM. For the multiple-groups analysis, a high person-to-group difference group $(n=123)$ and a low person-to-group difference group $(n=122)$ were formed with individuals who had the highest and lowest third person-to-group difference

Figure 5.21

Multigroup SEM Configural Model. Group differences in peer influence. Low vs. High Person-togroup difference in engagement.

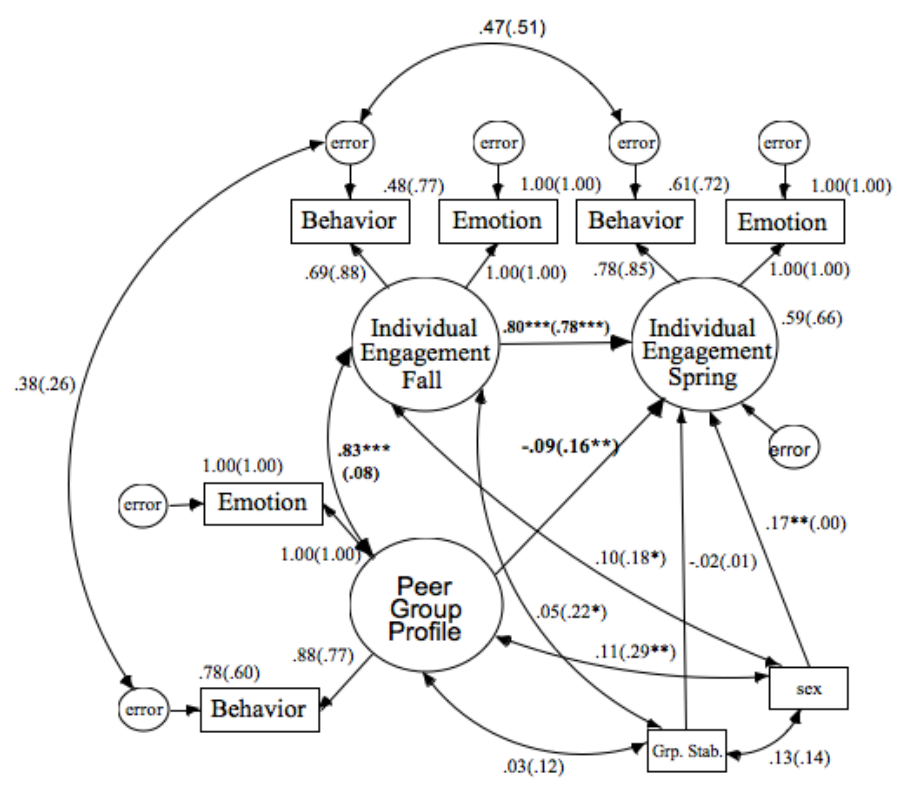

Note. $X^{2}(26)=92.97, \mathrm{p}<.001 ; \mathrm{CMIN} / \mathrm{DF}=3.59 ; \mathrm{CFI}=.95 ; \mathrm{RMSEA}=.10 ; 90 \%$ C.I. $=.08-.13$. $N=366 . * * * \mathrm{p}<.001 * * \mathrm{p}<.01 * \mathrm{p}<.05$. Values for students whose own engagement differed highly from that of their peer group's appear in parentheses. 
in engagement scores. The two groups differed significantly in their person-to-group difference scores $(M=.73$ vs. $M=.18 ; F(1,243)=482.80, p<.001)$. However, the two groups did not differ significantly in engagement in both fall and spring ( $M=3.08$ vs. $M=3.19 ; F(1,243)=2.25, p>.05$; and $M=3.04$ vs. $M=3.14 ; F(1,243)=1.51, p>.05$, respectively). Furthermore, no significant differences were found between the two groups in the school engagement of the peers with whom they choose to affiliate ( $M=3.10 \mathrm{vs.}$ $M=3.16 ; F(1,243)=1.14, p>.05)$.

As illustrated by figure 5.21, the configural model of the multiple-groups SEM shows adequate fit to the data $\left(\chi^{2}(26)=92.97, \mathrm{CFI}=.95, \mathrm{RMSEA}=.10\right)$ and highlights interesting model differences between the high and low person-to-group difference

Figure 5.22

Multigroup SEM Measurement Model. Group differences in peer influence. Low vs. High Person-togroup difference in engagement.

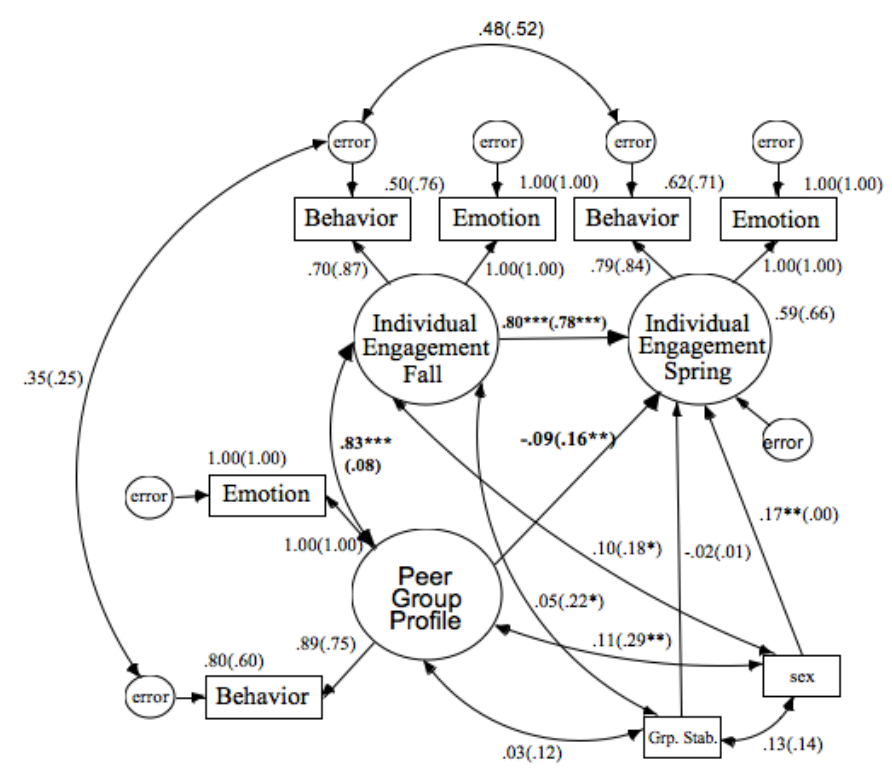

Note. $X^{2}(28)=95.28, \mathrm{p}<.001 ; \mathrm{CMIN} / \mathrm{DF}=3.40 ; \mathrm{CFI}=.95 ; \mathrm{RMSEA}=.10 ; 90 \%$ C.I. $=.08-.12$; $\Delta X^{2}(2)=2.31, p>.05 . N=366 . * * * \mathrm{p}<.001 * * \mathrm{p}<.01 * \mathrm{p}<.05$. Values for students whose own engagement differed highly from that of their peer group's appear in parentheses. 
groups. Controlling for sex, peer group stability, and prior engagement, peer group engagement in fall significantly predicted student engagement in spring for the high person-to-group difference group $(\mathrm{r}=.16, p<.01)$ but not for the low person-to-group difference group $(\mathrm{r}=-.09, p>.05)$. Whether differences between the two groups were significant was explored in the following two steps.

In the second step (figure 5.22), invariance testing at the measurement-level of the model revealed differences between high and low person-to-group difference groups for some of the factor loadings. Specifically, differences were found in how the behavioral engagement item in fall loaded onto the fall engagement factor. In order to proceed with the analysis, this constraint was released and the factor loading was allowed to vary

Figure 5.23

Multigroup SEM Path Invariance Model. Group differences in peer influence. Low vs. High Person-togroup difference in engagement.

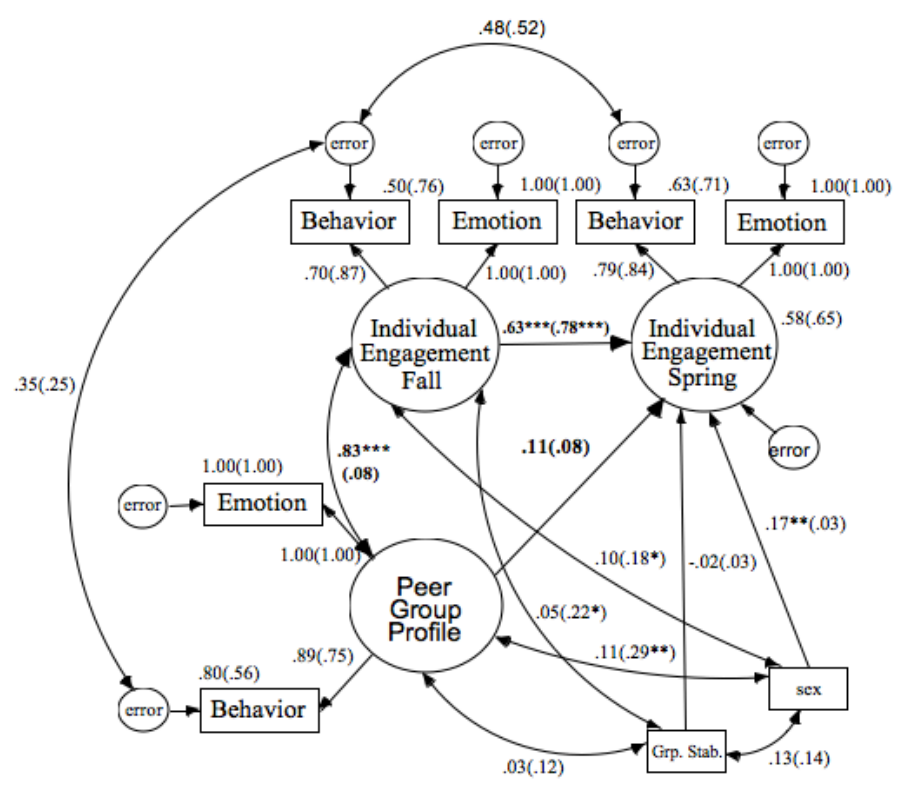

Note. $X^{2}(29)=100.99, \mathrm{p}<.001 ; \mathrm{CMIN} / \mathrm{DF}=3.48 ; \mathrm{CFI}=.95 ; \mathrm{RMSEA}=.10 ; 90 \%$ C.I. $=.08-.12$; $\Delta X^{2}(1)=5.71, p=.016 . N=366 . * * * \mathrm{p}<.001 * * \mathrm{p}<.01 * \mathrm{p}<.05$. Values for students whose own engagement differed highly from that of their peer group's appear in parentheses. 
between the groups (again, see Tabachnick et. al, 2007) and the fit of the resulting model was not found to be significantly worse than the configural model $\left(\Delta \chi^{2}(2)=2.31, p>.05\right)$, suggesting partial measurement equivalence between the two groups for the constrained items.

In the last step (figure 5.23), cross-group equality constraints placed on the path of the model representing peer influence (peer group engagement fall $\rightarrow$ student engagement spring) contributed to significant losses in model fit as assessed by a chisquare difference test $\left(\Delta \chi^{2}(1)=5.71, p<.016\right)$. These results suggest that significant differences in susceptibility to peer influence exist between students who are or are not different from their group in terms of school engagement; specifically, results suggest that students for whom this difference is great may be more susceptible to peer influence of their academic engagement than students for whom this difference is small.

Figure 5.24

Moderated Path Model: Peer Group Engagement X Person-to-group Difference in Engagement

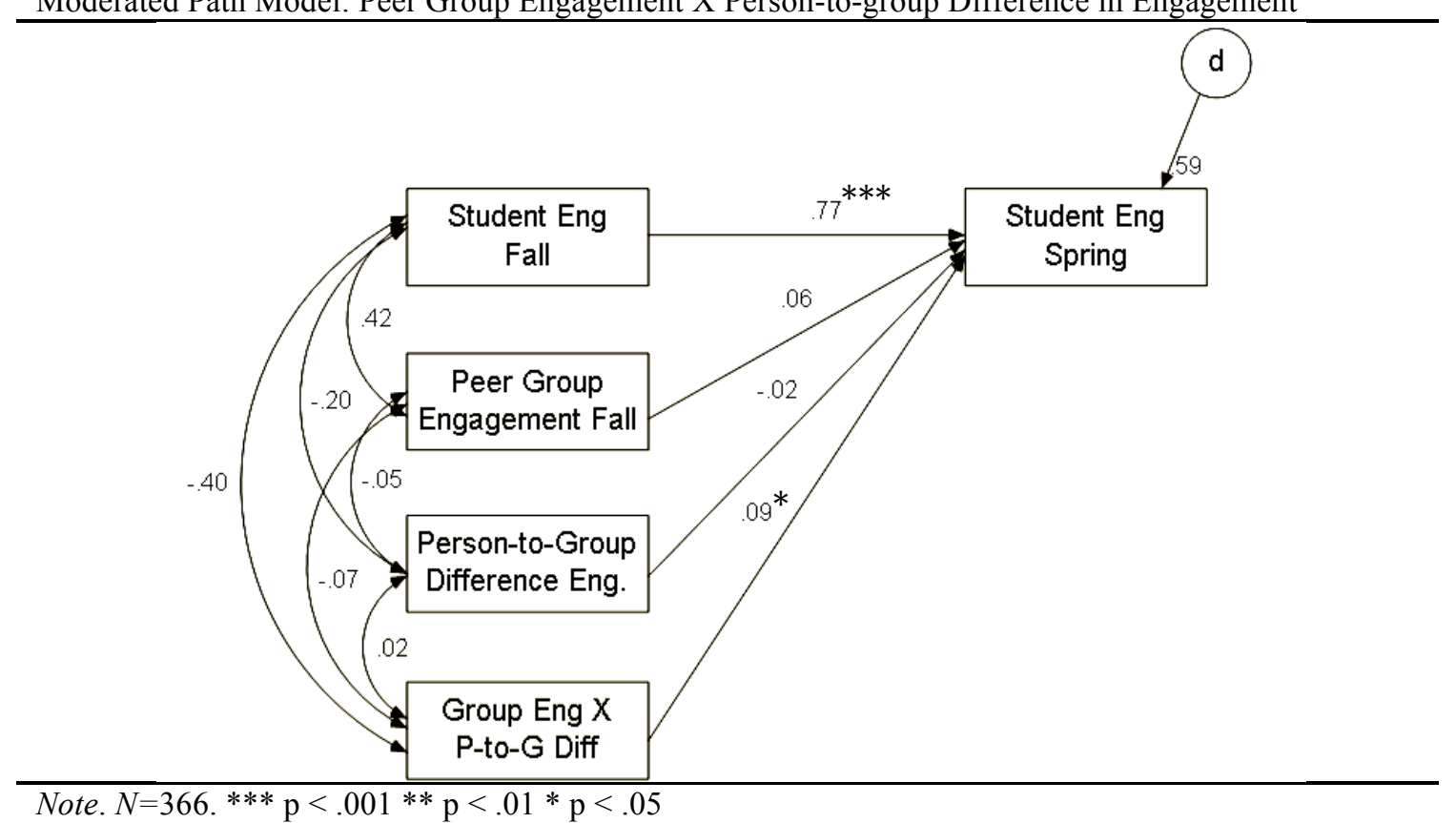

Note. $N=366 . * * * \mathrm{p}<.001 * * \mathrm{p}<.01 * \mathrm{p}<.05$ 
Moderated Path Analysis. Results from a moderated path analysis support the findings from the multiple-groups SEM analysis (See figure 5.24). As can be seen in the figure, student engagement in fall significantly predicted student engagement in spring $(b=.77, p<.001)$. Moreover, the path coefficient of the interaction variable is significant $(b=.09, p<.05)$, indicating a significant moderating effect of person-to-group difference on peer group influence of student engagement (See table 5.7 for details). Generally, results from the path analysis suggest that the extent to which peer group engagement predicts changes in student engagement from fall to spring depends upon how similar a student's academic engagement is to that of his or her peers. Specifically, as illustrated in the interaction plot in figure 5.25, the relationship between peer group engagement in fall and students' engagement in spring is stronger for students whose person/group difference in engagement in fall is great. In other words, these results support the contention that students who differ greatly from their peer group in terms of their own engagement may be more susceptible to peer group influence on the development of their own engagement.

Table 5.7

Moderated Path Analysis: Group Engagement Spring X Person-to-Group Difference

Student Engagement Spring

\begin{tabular}{llll}
\multicolumn{1}{c}{ Variable } & \multicolumn{1}{c}{$\beta$} & $\mathrm{B}$ \\
\hline Student Engagement Fall & $.77^{* *}$ & .84 \\
Peer Group Engagement Fall & .06 & .10 & \\
Person-to-group Difference in Engagement & -.02 & -.04 & \\
Grp. Engagement X Person-to-group Difference in Eng. & $.09^{*}$ & .38 & .64 \\
$\mathrm{R}^{2}$ & & &
\end{tabular}


Results: Differential Susceptibility 88

Figure 5.25

Group engagement $\mathrm{X}$ person-to-group difference interaction plot

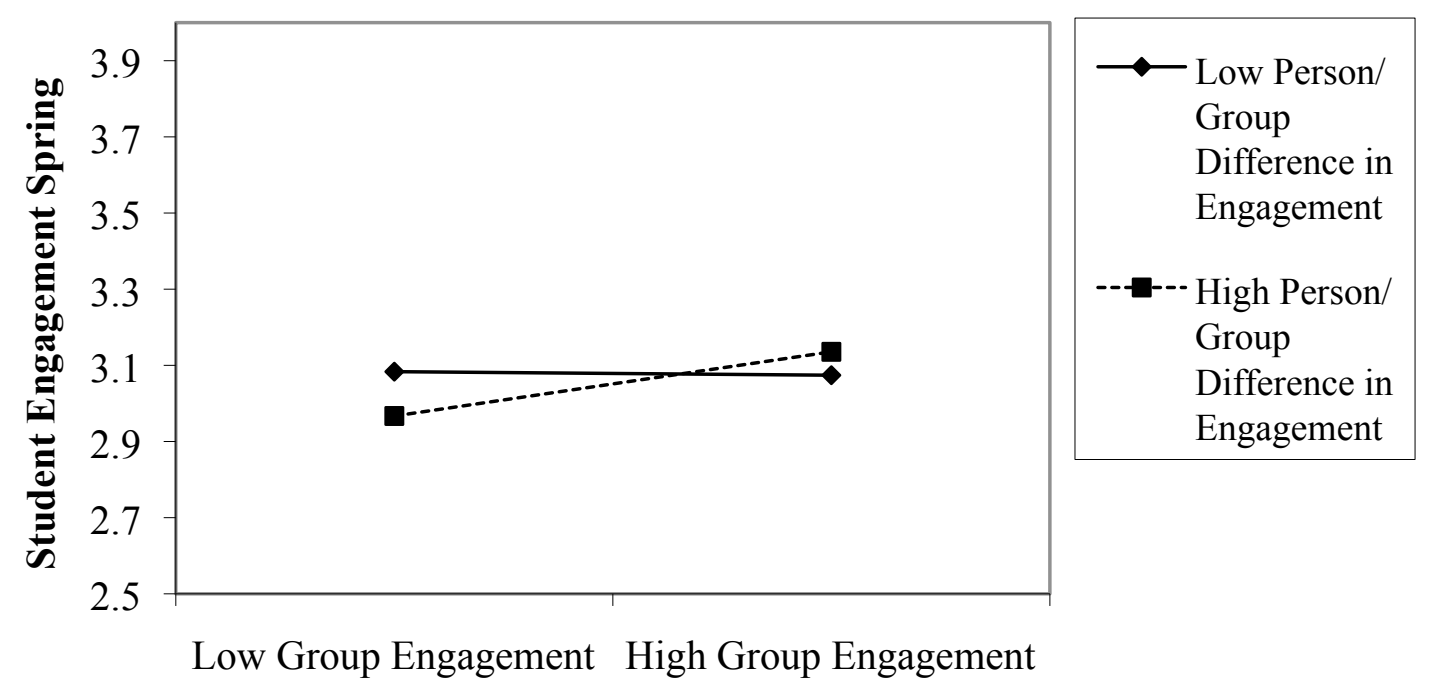


Chapter 6: Discussion

\section{Summary of Findings}

Building on previous research (Kindermann, 2007), this study examined whether the hypothesized associations between the academic engagement of a child's peer group members and the change in a child's own academic engagement over time is stronger for some individuals than others. Previous research suggests that peer group academic engagement explains about $2 \%$ of the variance in students' own academic engagement, controlling for parent and teacher effects and students' own previous engagement (Kindermann, 2007). Based upon previous research, a model of susceptibility was proposed and tested. By considering a students' gender, the number of peers they typically affiliate with (degree centrality), their sense of relatedness to their peers, their perception of parental involvement, and person-to-group differences in academic engagement, the current study found that for some individuals peers are a more significant source of influence than has previously been documented. An amended version of the model of susceptibility, with changes made based upon the empirical findings of the present research, can be found in figure 6.1 .

First, the current study found that while girls may be somewhat more susceptible to peer influence than boys, differences were only marginally significant. These results integrate well with findings from prior research, which suggest non-significant gender differences in resistance to peer pressure at this stage in development (Sumpter, Bokhorst, Steinberg, Westenberg, 2009). Results from the current study are also supported by prior research which suggests that while girls tend to be more socially 
integrated into the school social network (i.e., higher degree centrality) than boys, boys often associate with a more diverse set of peers compared to girls (Urberg, 1995).

Although the present study did not look specifically into these differences, it is possible that these qualities, unique to boy's and girl's peer environments (girls having many peers vs. boys having diverse peers), may contribute in a more or less equivalent ways to produce similarity, between boys and girls, in susceptibility to peer influence. It is possible, as supported by subsequent analyses, that both the number of peers a student Figure 6.1

Theory of differential susceptibility to peer influence on student engagement.

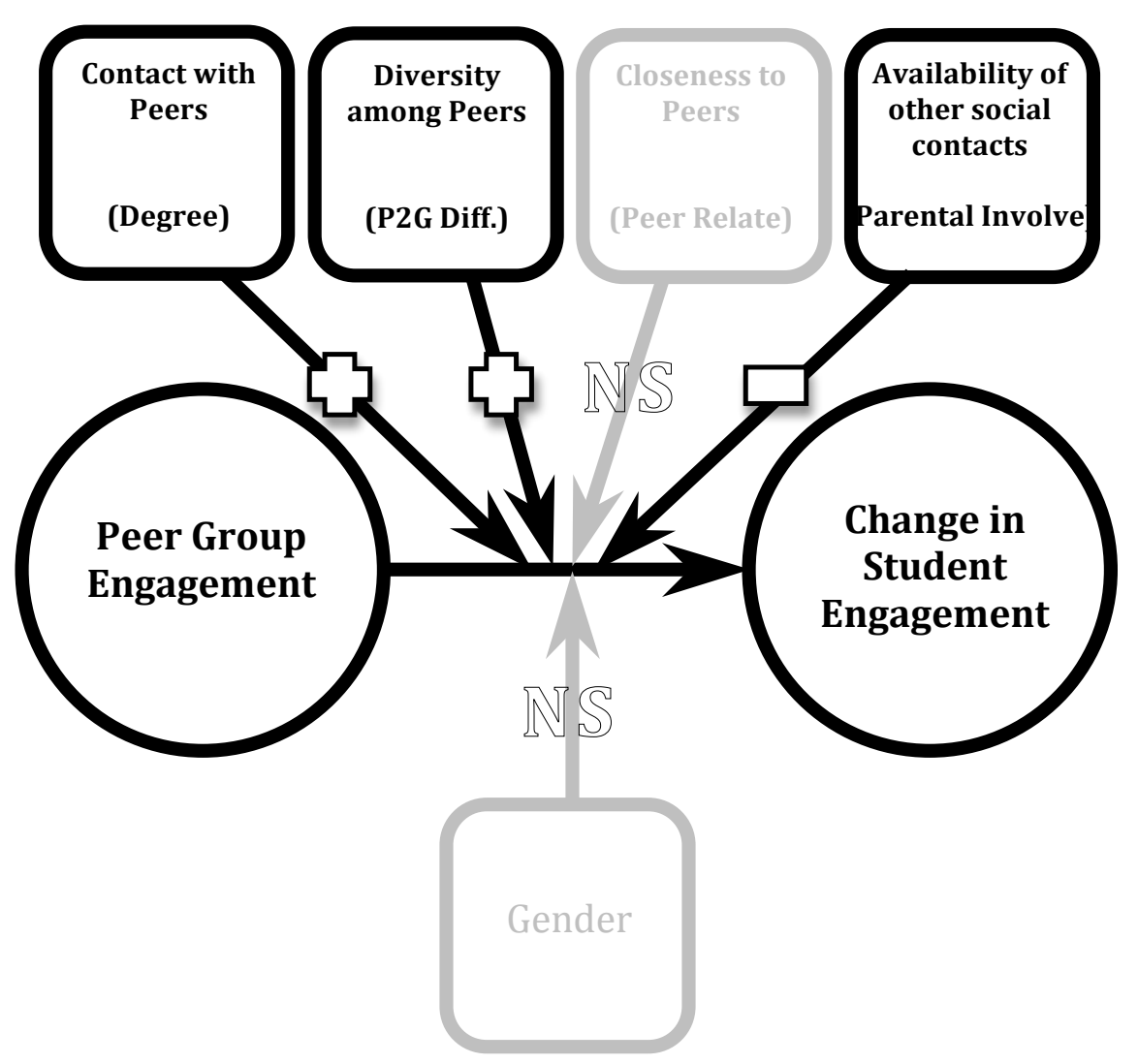


has and the diversity of students' peer group members may have some relation to the degree to which an individual is susceptible to peer influence on their academic engagement.

Second, while it was expected that students who feel relationally close to and accepted by the peers they affiliate with would be more susceptible to peer influence than students who do not feel close to and accepted by their peer affiliates, results of the current study failed to support this hypothesis. The current study found that students who feel close to and accepted by their peers are not significantly more (or less) susceptible to peer influence than students who feel less related to their peers. One possible explanation for these findings may be that the two groups of students are equally susceptible for different reasons. On the one hand, students who feel relationally distant from members of their peer group may be motivated to adhere to the norms and behaviors of the group in order to win the acceptance of their peers. On the other hand, students who feel accepted by their peers may be susceptible to peer influence because of the more intimate nature of their relationships.

Third, the current study provides mixed evidence concerning the moderating effect students' degree centrality has on their susceptibility to peer influence on their academic engagement. On the one hand, a contrast between extreme groups revealed no significant differences in susceptibility to peer influence. However, results from a moderated path analysis suggest that susceptibility to peer influence does depend upon how many peers a student frequently "hangs out with." Specifically, results suggest that 
students who tend to affiliate with a large number of peers may be more susceptible to their influence compared to students who tend to affiliate with fewer peers.

Fourth, the current study provides clear evidence which suggests that students who perceive their parents as uninvolved may be more susceptible to peer influence than students who perceive their parents as involved. For students who spend much of their time with peers who are disengaged in school, and participate in risky behaviors, having involved parents could make a life course-altering difference. Parents, if involved in the lives of their children, may serve to temper, or perhaps redirect the processes of peer socialization. For students who do not receive instrumental or emotional support at home, having a group of peers whom they can turn to when things get rough may be beneficial. Peers, who are highly engaged in school and related activities, may provide support and a sense of relatedness for students for whom these needs are not met at home.

Finally, the current study found that students who were most different from their peer group in school engagement were more susceptible to peer influence on the development of their school motivation than were students who were least different from their peer group. These results support the idea that susceptibility to influence may not solely be based upon qualities of the individual; rather, susceptibility to influence likely depends upon qualities of the individual in conjunction with qualities of the group. These results are supported by the Person Group Similarity Model (Wright, Giammarino, \& Parad, 1986; Stormshak \& Bierman, 1999), which postulates that members of groups acquire status and acceptance within the group based in part by their adherence to the group's norms for behavior. When a student's engagement in school is consistent with 
that of the group, the individual is more likely to be accepted by members of the group. When a student's engagement in school is inconsistent with that of the group, he or she is less likely to be accepted by members of the group. In order to gain the acceptance from his or her peers, a student may adjust his or her behavior to be in alignment with the behavior norms of the group.

\section{Strengths and Limitations}

This study had several strengths. First, the sample from which the data were obtained came from the only middle school in a rural town in the northeastern United States. Practically, this means that aside from children who were home-schooled or were bused to schools in other towns, the entire network of sixth-grade-aged children in the town was captured. This is an important strength of this research, as findings from most existing peer studies are based upon samples drawn from selected classrooms within selected schools. This feature protects against the possibility that a student may have other sources of peer influences outside of the sample (e.g., from a non-participating town, school, or classroom).

Another strength of this research is that it uses data obtained from multiple reporters. Students reported on their own and others' peer group memberships as well as their own sense of peer relatedness and parental involvement. Children are likely the best informants for obtaining social network information because they are constantly immersed in their own social environments and are more keenly aware of the groups of individuals who tend to congregate in the hallways of their school. The social network maps created by utilizing students as "expert" observers are likely more complete and 
accurate than they would be using teacher reports. Children are also the only reporters available to report on their own sense of peer group belongingness and perception of parental involvement. Naturally, no one is able to report on the experience of another individual. Therefore, obtaining this information via self-report was necessary.

Teachers provided reports of student engagement, which were also used to form the peer profiles of engagement. Using teacher-reports of student engagement reduces the self-enhancement bias that might occur when using student-reports of academic engagement. By using data collected by different methods (objective and subjective), and from different sources (student-report and teacher-report), problems of common method variance were avoided.

Finally, the focus on change over time as an outcome variable was a strength of the proposed study. First, developmental changes of any kind cannot be examined without looking at change over time. Second, the design looks at peer group influences on intraindividual change; thus, individuals serve as their own controls. Third, in order to demonstrate processes of influence, time must be part of the research design. As discussed previously, research that does not include change over time as a part of its design (e.g., cross-sectional research) cannot separate processes of assortiveness, or selection, from processes of influence. By focusing on change over time, control for preexisting similarities between individuals and the members of their peer groups was possible.

As is the case with any research, there were also some potential limitations to this study. Threats to internal validity include the possible presence of extraneous variables. 
This study examined peer groups in their natural contexts; therefore, a causal relationship can't be implied due to the possible effect unmeasured variables may have on the relationship under study. Unmeasured variables that covary with both changes in students' school motivation and the school motivation of their peers may represent an actual causal link. It is possible, for example, that the material being taught in the classroom explains, in a causal sense, both the developmental course of students' engagement as well as the engagement of their peers at the beginning of the school year. Because this information was not measured, we cannot confidently rule out the possibility that it is confounding the relationship being studied.

The process of maturation is another possible confound that was not measured or controlled for. Children at this age are entering into a period of rapid physiological development, and it is possible that the immature development of attention and emotional regulation at this developmental stage could explain decreases in engagement over the time period examined. Teachers also go through a process of maturation. Teachers may be less engaging as instructors at the second time point because they are physically and emotionally fatigued and, like the students, are looking forward to summer break. Again, since these possible explanations were not measured and controlled for, they cannot be ruled out as alternative explanations. However, this may only be problematic if people with high or low engaged peer groups were affected differently.

The validity of the results of this study may be limited by the age of the data. Since these data were collected, there has been an explosion of technological advancements that may have altered the relationships being studied. For example, since 
the data were collected the use of technologies such as the Internet and cell phones has become more common, particularly among youth. It is possible that the young people's use of social networking sites such as Myspace and Facebook, and the popularity of cell phone texting and instant messaging may have had an impact on the nature and frequency of how peers interact with each other.

Because of these emerging technologies, it is possible that effect sizes may differ if more recently sampled data were used. On the one hand, peer influence may be stronger because there are more channels across which peer effects could accumulate. On the other hand, it is also possible that due to these technologies effect sizes may be smaller if more recently sampled data were used. These developing technologies will make it increasingly more difficult for researchers to estimate the strength of peer influence because it will become more difficult to identify the peers with whom an individual spends a lot of time. Estimated effect sizes may be smaller with more current samples because the research design does not allow for the capture of online groups. It is also possible that being able to be connected to a wider network of peers, the influence one particular peer has on an individual may become weaker, and peer influence may become diluted. Although these technologies have undoubtedly had a significant effect on how people, particularly youth, interact with each other, it is also possible that the processes explored here have remained unchanged since these data were collected. Results from recent research provide some evidence that the power of peer influence may not be significantly different now than it was two decades ago (Kiuru, Aunola, Nurmi, Leskinen, \& Salmela-Aro, 2008). However, more work in this area is needed. 
The generalizability of the results of this study is also limited. The sample consists of predominately white, middle class sixth-grade students from a limited geographic region. Because of the relatively high degree of demographic homogeneity of the sample, results may not generalize well to populations of minority, or differently aged students living in other parts of the world. For example, would results from this study have looked different had participants been recruited from an ethnically diverse urban school? Future research should explore the possibility that in different cultures and contexts sources of susceptibility to peer influences may differ.

Another potential limitation of this research is that it only focused on one component of the peer context, the peer group. One benefit of focusing on peer groups as a social context is that they are observable; specifically, peer groups are groups of individuals who spend a lot of time together. Friendships or antipathies may be harder to capture using this method because they are not always observable. Despite the methodological benefit of focusing on peer groups, however, by neglecting to capture the other components of the peer context, the observed effects may underestimate the effect that peers have on children's own academic engagement. Indeed, prior research suggests that by considering both the peer group and friends simultaneously, the observed effects of peer influence may double (Kindermann, in press). Future research should explore the possible synergistic effect the multiple facets of the peer context have on students' development.

The use of teacher-reports as the only indicator of student's classroom motivation may represent another limitation of this research. Teacher reports are biased in that they 
rely on the teacher's ability to accurately infer and report on a student's motivation through observable behavior in an unbiased way. There are two other commonly used ways to measure engagement in the classroom, student reports and observations.

Although they may be prone to subjective biases, student reports are most able to clearly capture a student's motivational experience (assuming the student is honest about their classroom experience). However, student-reports rely on a student's understanding of and willingness to share his or her own classroom motivational state. Observations, on the other hand, are less biased than student- or teacher-reports. However, observational data can only be gathered on psychological phenomenon that may be observed. Although some aspects of classroom engagement are easily observable (i.e., behavioral engagement), other aspects are more difficult to observe (i.e., emotional engagement).

By relying solely on teacher-reports of student's classroom engagement, the proposed study's estimation of the effect peer groups have on change in student's own engagement may be biased. Future work should make use of all three sources of information on students' engagement, counter-balancing the strengths and weakness of each.

Other limitations should also be mentioned. First, the current study only examines the effects of peer group influence on children's own school engagement across a single year. It is possible that the effects of peer influence accumulate across years or even get stronger for students who move through grades with the same group of peers. Unfortunately the design of this research cannot address this question. Future studies should be designed with these limitations in mind. Second, while the proposed research 
does take into account the role of parents in relation to the peer influence process it does not consider how teachers may play a crucial role in the peer influence process. Kindermann (in press) discusses how teachers are able to directly affect the peer influence process through conscious consideration and manipulation of who sits next to or works with whom. On the one hand, if this type of social organization and management is common practice for teachers, the extent to which peers select those with whom they affiliate with on their own may be rightfully called into question. On the other hand, it is plausible that a significant amount of peer selection and influence processes occur outside of the teacher's jurisdiction, either outside of school, between classes, or at recess or lunch breaks. If this is the case, then teachers impact on the influence peers have on children's own development may be minimal. Unfortunately, the current research does not address this fascinating question.

Finally, a major limitation of the proposed research is that it does not explore the mechanisms through which peer influence occurs. Previous research suggests that children may influence each other through processes of reinforcement (Sage \& Kindermann, 1999), role-modeling (Kandel, 1985), and adherence to group norms (Schofield, Pattinson, Hill, \& Borland, 2001); however, this study is not able to explore these mechanisms directly.

\section{Implications and Future Research}

Despite the limitations of this study, I believe that this research contributes to the existing literature by providing a clearer understanding of the power peers have as influencers of academic motivation. Previous research has explored the power of peer 
Discussion: Differential Susceptibility 100

influence on the average individual, ignoring the subtle differences between individuals that likely determine the extent to which one may be influenced. The current study represents an attempt at exploring some of the qualities of individuals that may make them more or less susceptible. Findings from prior research indicate that the power of peer influence on students' academic motivation over the course of an academic year is relatively weak. However, by identifying features that explain why students are differentially susceptible to peer influence, this study adds to the literature by showing that for some young individuals the power of peer influence is stronger than has previously been shown.

Results from the current study highlight the importance of considering the size of students' peer groups, parental involvement, and person-to-group differences in school engagement when exploring peer influence and processes through which it occurs. Results support a model of susceptibility to peer influence which suggests that the extent to which a student is shaped by the influence of his or her peers depends on the amount of peers doing the influencing, the level of parental involvement, and how different from their peers students are initially. The role parental involvement plays as a condition that may foster differences in susceptibility to peer influence is particularly interesting. For individuals who affiliate with academically disaffected peers, an involved parent may diminish the extent to which members of their peer group influence them. On the other hand, for students whose parents are uninvolved, having peers who are academically engaged may act as a buffer against academic disaffection. 
Discussion: Differential Susceptibility 101

While the proposed study advances the field by exploring what makes some individuals' academic engagement more or less susceptible to peer influence, future research should investigate features of students that make them more or less influential of the peers whom they affiliate with. It is hoped that this study will contribute toward this future line of research by identifying pathways of how this may be done. 
References: Differential Susceptibility 102

\section{References}

Altermatt, E.R., Pomerantz, E.M. (2005). The implications of having highachieving versus low-achieving friends: A longitudinal analysis. Social Development, 14,1, 61-81.

Anderman, E. A., \& Maehr, M. L. (1994). Motivation and schooling in the middle grades. Review of Educational Research, 64, 287-310.

Arbuckle, J. L. (2003). Amos 5. Chicago: SmallWaters.

Aud S., Hussar W., Planty M., Snyder, T., Bianco, K., Fox, M.A., Frohlich, L., Kemp, J., \& Drake, L. (2010). The Condition of Education 2010 (NCES 2010-028).

Washington, DC: National Center of Education Statistics, Institute of Education Sciences, US Department of Education; 2010.

Barker, R.G., \& Wright, H.F. (1955). Midwest and its children. New York: Harper \& Row.

Bauman, K.E., Ennet, S.T. (1994) Peer influence on adolescent drug use. American Psychologist, 49(9), 820-822.

Bavelas, A. (1948). A mathematical model for group structures. Human Organization, 7 , 2, 16-30.

Bavelas, A. (1950). Communication patterns in task-oriented groups. Journal of the Acoustical Society of America, 22, 6, 725-730.

Borgatti, S.P., Mehra, A., Brass, D.J., Labiancha, G. (2009). Network analysis in the social sciences. Science, 323, 892-895. 
Berndt, T.J. (1979). Developmental changes in conformity to peers and parents. Developmental Psychology, 15, 6, 608-616.

Berndt, T.J., Hawkins, J.A., Jiao, Z. (1999). Influences of friends and friendships on adjustment to junior high school. Merrill-Palmer Quarterly, 45, 1, 13-41.

Berndt, T.J., Laychak, A.E., \& Park, K. (1990). Friends' influence on adolescents' academic achievement motivation: An experimental study. Journal of Educational Psychology, 82(4), 664-670.

Bronson, W.C. (1975). Developments in behavior with age mates during the second year of life. In M. Lewis \& L.A. Rosenblum (Eds.), Friendship and peer relations. New York: Wiley.

Bronfenbrenner, U., \& Morris, P. A. (1998). The ecology of developmental processes. In W. Damon \& R. M. Lerner (Eds.), Handbook of child psychology:Vol. 1 Theoretical models of human development $\left(5^{\text {th }}\right.$ ed., pp. 993-1028). New York: Wiley.

Brown, B. B. (1993). The meaning and measurement of adolescent crowd affiliation. Society for Research on Adolescence, 7, 7-9.

Brown, B.B., \& Dietz, E.L. (2009). Informal peer groups in middle childhood and adolescence. In K.H. Rubin, W. Bukowski, \& B. Laursen, Handbook of peer interactions, relationships, and groups (pp. 361-376). New York: Guilford. Buhler, C. (1930). The first year of life. Rahway, N.F.: John Day. 
References: Differential Susceptibility 104

Bukowski, W.M., Metzow, C., \& Meyer, F. (2009). Friendship as process, function, and outcome. In K.H. Rubin, W. Bukowski, \& B. Laursen, Handbook of peer interactions, relationships, and groups (pp. 217-231). New York: Guilford.

Cairns, R. B., Perrin, J. E., \& Cairns, B. D. (1985). Social structure and social cognition in early adolescence: Affiliative patterns. Journal of Early Adolescence, $5,339-355$.

Cairns, R.B., Cairns, B.D., Neckerman H.J. (1989). Early school dropout: Configurations and determinants. Child Development, 60, 1437-1452.

Cairns, R. B., Gariépy, J.-L., \& Kindermann, T. A. (1990). Identifying social clusters in natural settings. Unpublished manuscript, University of North Carolina at Chapel Hill.

Cairns, R. B., \& Cairns, B. D. (1994). Lifelines and risks: Pathways of youth in our time. New York: Cambridge University Press.

Caims, R. B., Leung, M.-C, Buchanan, L., \& Cairns, B. D. (1995). Friendships and social networks in childhood and adolescence: Fluidity, reliability, and interrelations. Child Development, 66, 1330-1345.

Christakis, N.A., Fowler, J.H. (2007). The spread of obesity in a large social network over 32 years. New England Journal of Medicine, 357(4), 370-379.

Christakis, N.A., Fowler, J.H. (2008). The collective dynamics of smoking in a large social network. New England Journal of Medicine, 358(21), 2249-2258. 
Reference: Differential Susceptibility 105

Connell, J. P., Spencer, M. B., \& Aber, J. L. (1994). Educational risk and resilience in African-American youth: Context, self, action, and out- comes in school. Child Development, 65, 493-506.

Deci, E. L., \& Ryan, R. M. (1985). Intrinsic motivation and self-determination in human behavior. New York: Plenum.

Downs, A. (2001). It's all in the family: Middle schools share the secrets of parent engagement. Middle Ground, 4(3), 10-15.

Eccles, J. S., Midgley, C., \& Adler, T. F. (1984). Grade-related changes in school environment: Effects on achievement motivation. In J. G. Nicholls (Ed.), Advances in motivation and achievement (pp. 283-331). Greenwich, CT: JAI Press.

Eccles, J. S., Wigfield, A., \& Schiefele, U. (1998). Motivation to succeed. In W. Damon (SeriesEd.) \& N. Eisenberg (Vol. Ed.), Handbook of child psychology: Vol. 3. Social, emotional, and personality development ( $5^{\text {th }}$ ed., pp. 1017-1095). New York: Wiley.

Eckert, P. (1989). Jocks and burnouts: Social categories and identity in the high school. New York: Teachers College Press.

Ellis, W.E., \& Zarbatany, L. (2007). Peer group status as a moderator of group influence on children's deviant, aggressive, and prosocial behavior. Child Development, $78(4), 1240-1254$. 
References: Differential Susceptibility 106

Englund, M.M., Luckner, A.E., Whaley, G.J.L., \& Egeland, B. (2004). Children's achievement in early elementary school: Longitudinal effects of parental involvement, expectations, and quality of assistance. Journal of Educational Psychology, 96, 723-730.

Ennett, S.T., Bauman, K.E. (1993). Peer group structure and adolescent cigarette smoking: a social network analysis. Journal of Health and Social Behavior, 34(3), 226-236.

Espelage, D.L., Holt, M.K., Henkel, R.R. (2003) Examination of peer-group contextual effects on aggression during early adolescence. Child Development, 74, 1, 205220.

Espelage, D.L., Swearer, S.M. (2003). Research on school bullying and victimization: What have we learned and where do we go from here? School Psychology Review, 32, 365-383.

Farmer, T.W., Rodkin, P.C. (1996). Antisocial and prosocial correlates of classroom social positions: The social network centrality perspective. Social Development, 5(2), 174-188.

Festinger, L. (1954). A theory of social comparison processes. Human Relations, 7, 117140.

Fuligni, A.J., Eccles, J.S. (1993). Perceived parent-child relationships and early adolescents' orientation toward peers. Developmental Psychology, 29, 4, $622-$ 632. 
Reference: Differential Susceptibility 107

Fuligni, A.J., Ecles, J.S., Barber, B.L., Clements, P. (2001). Early adolescent peer orientation and adjustment during high school. Developmental Psychology, 37, 1, 28-36.

Furrer, C., Skinner, E.A. (2003). Sense of relatedness as a factor in children's academic engagement and performance. Journal of Educational Psychology. Vol.95(1), pp. 148-162.

Freeman, L.C. (1978). Centrality in social networks: Conceptual clarification. Social Networks, 1, 215-239.

Fredricks, J.A., Blumenfeld, P.C., Paris, A.H. (2004). School engagement: Potential of the concept, state of the evidence. Review of Educational Research, 74, 1, 59-109.

Fredricks, J. A., \& Eccles, J. S. (2002). Children's competence and value beliefs from childhood to adolescence: Growth trajectories in two "male-typed" domains. Journal of Developmental Psychology, 38, 519-533.

Gest, S.D., Graham-Bermann, S.A., Hartup, W.W. (2001). Peer experience: Common and unique features of number of friendships, social network centrality and sociometric status. Social Development, 10(1), 23-40.

Grolnick, W.S., \& Slowiaczek, J.L. (1994). Parental involvment in children's schooling: A multidimentional conceptualization and motivational model. Child Development, 65, 237-252.

Harris, J.R. (1995). Where is the child's environment? A group socialization theory of development. Psychological Review, 102, 3, 458-409. 
References: Differential Susceptibility 108

Harris, J.R. (1998). The nurture assumption: Why children turn out the way they do. New York: Free Press.

Hartup, W.W. (1983). Peer Relations. In P.H. Mussen (Gen. Ed.), Handbook of Child Psychology (Vol. 4), E.M. Hetherington (Ed.), Socialization, personality, and social development (pp.103-196). New York: Wiley.

Hymel, S., Comfort, C., Schonert-Reichl, K., \& McDougall, P. (1996). Academic failure and school dropout: The influence of peers. In J. Juvonen \& K. R. Wentzel (Eds.), Social motivation: Understanding children's school adjustment (pp. 313-345). New York: Cambridge University Press.

Jimerson, S. J., Campos, E., \& Greif, J. L. (2003). Towards an understanding of definitions and measures of school engagement and related terms. The California School Psychologist, 8, 7-27.

Johnston, J. H. (1998). Family involvement models in middle schools. In M. L. Fuller \& G. Olsen (Eds.), Home-school relations: Working successfully with parents and families (191-207). Needham Heights, MA: Allyn \& Bacon.

Kandel, D.B. (1978). Homophily, selection, and socialization in adolescent friendships. The American Journal of Sociology, 84, 2, 427-436.

Kandel, D.B. (1985). On processes of peer influences of adolescent drug use: A developmental perspective. Advances in Alcohol and Substance Use, 4, 139-163. 
Reference: Differential Susceptibility 109

Kindermann, T. A. (1993). Natural peer groups as contexts for individual development: The case of children's motivation in school. Developmental Psychology, 29, 970 -977 .

Kindermann, T.A. (1995). Distinguishing buddies from bystanders: The study of children's development within natural peer contexts. In. T.A. Kindermann \& J. Valsiner (Ed.), Development of person-context relations (pp.205-226). Hillsdale: Lawrence Erlbaum Associates, Inc.

Kindermann, T.A. (1996). Strategies for the study of individual development within naturally-existing peer groups. Social Development, 5,2, 158-173.

Kindermann, T.A. (2007). Effects of naturally existing peer groups on changes in academic engagement in a cohort of sixth graders. Child Development, 78,4, 1186-1203.

Kindermann, T.A. (2008). Can we make causal inferences about the influence of children's naturally-existing social networks on their school motivation? In N.A. Card, T.D. Little, \& J.P. Selig (Eds.), Modeling dyadic Interdependent data in developmental research, (pp. 343-376). Mahwah, NJ: Erlbaum.

Kindermann, T., \& Gest, S. D. (2009). Assessment of the peer group: Identifying naturally occurring social networks and capturing their effects (pp. 100-117). In K. Rubin, W. Bukowski \& B. Laursen (Eds.), Handbook of Peer Interactions, Relationshiops and Groups. New York: Guilford Press. 
References: Differential Susceptibility 110

Kindermann, T.A., Skinner, E.A. (2010). Will the real peer group please stand up? A "tensegrity" approach to examining the synergistic influences of peer groups and friendship networks on academic development. Unpublished manuscript, Portland State University, Portland, OR.

Kiuru, N., Aunola, K., Nurmi, J., Leskinen, E., \& Salmela-Aro, K. (2008). Peer group influence and selection in adolescent's school burnout, Merrill-Palmer Quarterly, 54(1), 23-55.

Kline, R.B. (2011). Principles and practice of structural equation modeling. New York: Guilford Press.

Kurdek L.A., Sinclair R.J. (2000). Psychological, family, and peer predictors of academic outcomes in first through fifth grade children. Journal of Educational Psychology, $92,3,449-457$.

Laursen, B., Bukowski, W.M., Nurmi, J.-E., Marion, D., Salmela-Aro, K., Kiuru, N. (2010). Opposites detract: Middle school peer group antipathies. Journal of Experimental Child Psychology, 106(4), 240-256.

Leung, MC. (1996). Social networks and self-enhancement in chinese children: A comparison of self-reports and peer reports of group membership. Social Development, 6,2, 146-157.

Leung, M-C. (1998). SCM 4.0 [Computer software and manual]. Chapel Hill, NC: University of North Carolina.

Marsden, P.V., Friedkin, N.E. (1993). Network Studies of Social Influence. Sociological Methods \& Research, 22, 1, 127-151. 
Reference: Differential Susceptibility 111

Marsh, H.W., Martin, A.J., Cheng, J.H.S. (2008). A multilevel perspective on gender in classroom motivation and climate: Potential benefits of male teachers for boys? Journal of Educational Psychology. Vol.100(1), pp. 78-95.

Mo, Y., \& Singh, K. (2008). Parents' relationships and involvement: Effects on students' school engagement and performance. RMLE Online: Research in Middle Level Education, 31(10), 1-11.

Moreno, J.L. (1953). Who shall survive? Beacon, N.Y.: Beacon. (Original work published 1934)

Piaget, J. (1959). The language and thought of the child. London: Routledge \& Kegan. (Original work published 1923)

Prinstein, M.J., Brechwald, W.A., \& Cohen, G.L. (2011). Susceptibility to peer influence: Using a performance-based measure to identify adolescent males at heightened risk for deviant peer socialiation. Developmental Psychology. Advance online publication. Doi:10.1037/a0023274.

Qin, Z., Johnson, D. W., \& Johnson, R. T. (1995). Cooperative versus competitive efforts and problem solving. Review of Educational Research, 65, 129-144.

Rodkin, P.C., Farmer, T.W., Pearl, R., Van Acker, R. (2000). Heterogeniety of popular boys: Antisocial and prosocial configurations. Developmental Psychology, 36, 1, $14-24$.

Roeser, R.W., Eccles, J.S., Sameroff, A.J. (2000). School as a context of early adolescents' academic and social-emotional development: A summary of research findings. The elementary School Journal, 100(5), 443-471. 
References: Differential Susceptibility 112

Roeser, R.W., Midgley, C., \& Urdan, T.C. (1996). Perceptions of the school psychological environment and early adolescents psychological and behavioral functioning in school: The mediating role of goals and belonging. Journal of Educational Psychology, 88, 408-422.

Rosenquist, J.N., Fowler, J.H., Christakis, N.A. (2010). Social network determinants of depression. Molecular Psychiatry.

Rozin, P., Riklis, J., Margolis, L. (2002). Mutual exposure of close peer relationships do not seem to foster increased similarity in food, music or television program preferences. Appetite, 42, 41-48.

Ryan, A.M. (2001). The peer group as a context for the development of young adolescent motivation and achievement. Child Development, 72, 4, 1135-1150.

Sage, N. A., \& Kindermann, T. A. (1999). Peer networks, behavior contingencies, and children's engagement in the classroom. Merrill-Palmer Quarterly, 45, 143-171.

Schofield, P.E., Pattinson, P.E., Hill, D.J., \& Borland, R. (2001). The influence of group identification on the adoption of peer group smoking norms. Psychology and Health, 16, 1-16.

Skinner, E.A., Kindermann, T.A., Connell, J.P., \& Wellborn, J.G. (2009). Engagement and disaffection as the organizational constructs in the dynamics of motivational development. In K. Wentzel \& A. Wigfield (Eds.), Handbook of motivation in school (pp. 223-245). Malwah, NJ: Erlbaum. 
Reference: Differential Susceptibility 113

Skinner, E. A., Kindermann, T. A., \& Furrer, C. (2008). A motivational perspective on engagement and disaffection: Conceptualization and assessment of children's behavioral and emotional participation in academic activities in the classroom. Educational and Psychological Measurement, 69, 493-525.

Skinner, E.A., Wellborn, J.G., \& Connell, J.P. (1990) What it takes to do well in school and whether I've got it: A process model of perceived control and children's engagement in the classroom. Journal of Educational Psychology, 82, 22-32.

Skinner, E.A., \& Belmont, M.J. (1993). Motivation in the classroom: Reciprocal effects of teacher behavior and student engagement across the school year. Journal of Educational Psychology, 85, 571-581.

Skinner, E. A., \& Pitzer, J. (in press). Developmental dynamics of engagement, coping, and everyday resilience. In S. Christenson, A. Reschly, \& C. Wylie (Eds.), The Handbook of Research on Student Engagement. New York: Springer Science.

Skinner, E. A., Zimmer-Gembeck, M. J., \& Connell, J. P. (1998). Individual differences and the development of perceived control. Monographs of the Society for Research in Child Development, 254 (vol. 63, no.2-3).

Stormshak, E.A., Bierman, K.L. (1999). The relation between behavior problems and peer preference in different classroom contexts. Child Development, 70, 1, 169183.

Sumter, S.R., Bokhorst, C.L., Steinburg, L., Westenberg, P.M. (2009). The developmental pattern of resistance to peer influence in adolescence: Will the teenager ever be able to resist? Journal of Adolescence, 32, 1009-1021. 
References: Differential Susceptibility 114

Teven, J. J., \& McCroskey, J. C. (1997). The relationship of perceived teacher caring with student learning and teacher evaluation. Communication Education, 46, 1-9.

Urberg, K.A., Değirmencioğlu, S.M., Tolson, J.M., Halliday-Scher, K. (1995). The structure of adolescent peer groups. Developmental Psychology, 31, 4, 540-547.

Urberg, K.A., Değirmencioğlu, S.M., Pilgrim, C. (1997). Close friend and peer group influence on adolescent cigarette smoking and alcohol use. Developmental Psychology, 33, 5, 834-844.

Urberg, K.A., Değirmencioğlu, S.M., Tolson, J.M., Halliday-Scher, K. (2000). Adolescent social crowds: Measurement and relationship to friendships. Journal of Adolescent Research, 15,4. 427-445.

Urberg, K.A., Luo, Q., Pilgrim, C., Değirmencioğlu, S.M. (2003). A two-stage model of peer influence in adolescent substance use: Individual and relationship-specific differences in susceptibility to influence. Adictive Behaviors, 28, 1243-1257.

Vincze, M. (1971). The social contacts of infants and young children reared together. Early Child Development and Care, 1, 99-109.

Von Eye, A. (1990). Introduction to configural frequency analysis: The search for types and antitypes in cross-classifications. New York: Cambridge University Press.

Vygotsky, L.S. (1962). Thought and language. Chicago: MIT Press.

Wellborn, J.G. (1991). Engaged vs. disaffected action: Conceptualization and measurement of motivation in the academic domain. Unpublished doctoral dissertation, University of Rochester. 
Wentzel, K.R., Caldwell, K. (1997). Friendships, peer acceptance, and group membership: Relations to academic achievement in middle school. Child Development, 68, 6, 1198-1209.

Wentzel, K. R. (1999). Social-motivational processes and interpersonal relationships: Implications for understanding motivation at school. Journal of Educational Psychology, 91, 76-97.

White, H.C., Boorman, S.A., Breiger, R.L. (1976). Social structure from multiple networks: I. blockmodels of roles and positions. American Journal of Sociology, $81,4,730-780$.

Wright, J. C., Giammarino, M., \& Parad, H. W. (1986). Social status in small groups: Individual-group similarity and the social "misfit". Journal of Personality and Social Psychology,50, 523-536. 


\section{Appendix A. Teacher-reported School Engagement Items}

\section{Engagement-Behavior}

When we start something new in class, this student participates in discussions.

In my class, this student works as hard as he/she can.

When I explain new material, this students listens carefully.

In my class, this student does more than required.

\section{Disaffection Behavior}

When we start something new in class, this student doesn't pay attention.

When we start something new in class, this student thinks about other things.

In my class, this student does just enough to get by.

In my class, this student comes unprepared.

\section{Engagement Emotion}

When we start something new in class, this student is enthusiastic.

When working on classwork in my class, this student appears involved.

When working on classwork in my class, this student seems to feel good.

In my class, this student seems interested.

\section{Disaffection- Emotion}

When working on classwork in my class, this student appears worried.

In my class, this student is anxious.

In my class, this student seems unhappy.

When I explain new material, this student doesn't seem to care.

In my class, this student is angry.

When working on classwork in my class, this student appears frustrated.

When we start something new in class, this student seems restless.

When working on classwork in my class, this student seems uninterested. 
Appendix B. Self-reported Peer Relatedness Items

Emotional security with classmates

\begin{tabular}{ll}
$\begin{array}{ll}\text { When I'm with } \\
\text { my classmates }\end{array}$ & I feel accepted \\
& I feel like I belong. \\
& I feel left out. \\
& I feel unimportant. \\
\hline & Emotional security with friends \\
\hline $\begin{array}{l}\text { When I'm with } \\
\text { my friends }\end{array}$ & I feel accepted. \\
& I feel like I belong. \\
& I feel left out. \\
& I feel unimportant.
\end{tabular}




\section{Appendix C. Parental Involvement Items}

\begin{tabular}{|c|c|}
\hline \multirow[t]{3}{*}{ Knowledge } & $\begin{array}{l}\text { My parents know when it is time for my report card to be out. } \\
\text { My parents know a lot about what is important to me in } \\
\text { school. }\end{array}$ \\
\hline & $\begin{array}{l}\text { My parents don't know a lot about what happens to me in } \\
\text { school. }\end{array}$ \\
\hline & My parents don't seem to know how I feel about school. \\
\hline \multirow[t]{2}{*}{ Time Spent } & My parents spend time with me on schoolwork. \\
\hline & My parents talk with me about schoolwork \\
\hline \multirow[t]{4}{*}{ Affection } & My parents enjoy hearing about my school day. \\
\hline & $\begin{array}{l}\text { My parents think that what I have to say about school is } \\
\text { important. }\end{array}$ \\
\hline & My parents aren't interested in what happens to me in school. \\
\hline & $\begin{array}{l}\text { Sometimes I think my parents don't care about what goes on } \\
\text { for me in school. }\end{array}$ \\
\hline \multirow[t]{4}{*}{ Availability } & My parents have plenty of time to talk to me about school. \\
\hline & When I want to talk about school my parents take the time \\
\hline & My parents are too busy to hear about my school day. \\
\hline & My parents don't seem to have enough time for me. \\
\hline \multirow[t]{4}{*}{ Dependability } & I can count on my parents when I have problems in school \\
\hline & When things go wrong in school, I can depend on my parents \\
\hline & $\begin{array}{l}\text { I can't always depend on my parents when things get hard in } \\
\text { school }\end{array}$ \\
\hline & I can't count on my parents for help with my schoolwork. \\
\hline
\end{tabular}

